\title{
Oxidation and Volatilization from Tungsten Brush High Heat Flux Armor During High Temperature Steam Exposure
}

\author{
G. R. Smolik \\ R. J. Pawelko \\ R. A. Anderl \\ D. A. Petti
}


INEEL/EXT-2000-00390

\title{
Oxidation and Volatilization from Tungsten Brush High Heat Flux Armor During High Temperature Steam Exposure
}

\author{
Galen R. Smolik \\ Robert J. Pawelko \\ Robert A. Anderl \\ David A. Petti
}

Published May 2000

Idaho National Engineering and Environmental Laboratory Idaho Falls, Idaho 83415

Prepared for the

U.S. Department of Energy

Office of Energy Research

Under the DOE Idaho Operations

Contract DE-AC07-99ID13727 


\section{ABSTRACT}

Tungsten brush accommodates thermal stresses and high heat flux in fusion reactor components such as plasma facing surfaces or armor. However, inherently higher surface areas are introduced with the brush design. We have tested a specific design of tungsten brush in steam between 500 and $1100^{\circ} \mathrm{C}$. Hydrogen generation and tungsten volatilization rates were determined to address fusion safety issues. The brush prepared from 3.2-mm diameter welding rods had a packing density of 85 percent. We found that both hydrogen generation and tungsten volatilization from brush, fixtured to represent a unit within a larger component, were less than projections based upon the total integrated surface area (TSA). Steam access and the escape of hydrogen and volatile oxide from void spaces within the brush are restricted compared to specimens with more direct diffusion pathways to the test environment. Hydrogen generation rates from restrained specimens based on normal surface area (NSA) remain about five times higher than rates based on total surface areas from specimens with direct steam access. Volatilization rates from restrained specimens based upon normal surface area (NSA) were only 50 percent higher than our historic cumulative maximum flux plot (CMFP) for tungsten. This study has shown that hydrogen generation and tungsten volatilization from brush do not scale according to predictions with previously determined rates, but in fact, with higher packing density could approach those from flat surfaces. 


\section{SUMMARY}

In this report we present the results of experimental measurements of the oxidation and oxidation-driven volatilization from tungsten brush specimens exposed in steam. The specimens are representative of a product developed for high heat flux armor for fusion devices. Specimens were tested in steam between 500 and $1100^{\circ} \mathrm{C}$. Hydrogen generation rates and the extent of oxidation incurred by the specimens were determined from measurements with a quadrupole mass spectrometer (QMS). The volatilized and residual amounts of tungsten trioxide on the specimens were calculated from QMS results and changes in specimen mass. We compared the oxidation rates of the tungsten brush product with those that we have measured from a pressed and sintered tungsten alloy. Specimens were tested in both an open and restrained condition at the highest temperatures of 1000 and $1100^{\circ} \mathrm{C}$. We did this to determine the influence of direct access and steam flow on the oxidation and volatilization from the specimen. The restrained condition would be more representative of a unit of tungsten brush within a larger heat flux component.

We present the experimental procedures in Section 2. This section includes descriptions of the test specimens and test plan. A detailed description of the test system used to expose specimens at various temperatures in the steam and to measure hydrogen generation is given. Experimental results are presented in Section 3. Hydrogen generation measurements obtained from the QMS are presented. These include instantaneous rates and total cumulative hydrogen production as a function of elapsed steam exposure time. Although non-linear oxidation kinetics, e.g. parabolic behavior, are sometimes observed, we calculate overall average rates for the various tests. These rates are based upon the cumulative hydrogen measurements, total accessible surface area (TSA) of the tungsten rods, and steam exposure time. These rates are used to compare the oxidation behavior of the tungsten brush product with the previously tested pressed and sintered product. We also calculate rates more applicable for engineering applications based upon normal or projected surface areas (NSA). Photographs of specimens are presented in Section 3 showing the physical appearances and extent of oxidation incurred by the various specimens.

We discuss the experimental results in Section 4. We present the results of measured hydrogen generation rates and calculated amounts of $\mathrm{WO}_{3}$ formed during oxidation and amounts tungsten volatilized. We find a fairly good agreement between oxidation rates from the powder metallurgy tungsten product from the 1996 studies and nonrestrained tungsten brush and individual rods when rates are based upon the total surface area (TSA) of accessible tungsten. This provides credibility to the experimental procedures used in the various experiments and shows the similarity in oxidation behavior of the various products when steam access is not restricted. Significantly less of the $\mathrm{WO}_{3}$ that formed on the tungsten brush volatilized compared to the tungsten rods directly exposed to the steam. This shows that the mobilization of radioactive species from the tungsten brush would not be as severe as predicted by previous mass flux measurements scaled to total surface area. Restrained specimens of the tungsten brush exposed at the highest temperatures showed even lower oxidation and volatilization rates compared to nonrestrained specimens. Volatilization of $\mathrm{WO}_{3}$ from within the interstices of the tungsten brush is restricted compared to surfaces with direct access to the steam. Oxidation products accumulate within these spaces at high temperatures hindering the access of steam. Oxidation rates are reduced by a factor of 2 to 3 compared to specimens without restraint. Volatilization rates from the restrained specimens based upon normal surface area (NSA) are also reduced to levels only slightly higher than our previously determined cumulative maximum flux plot (CMFP) for tungsten. The oxidation and volatilization rates of the restrained specimens based on the normal surface area (NSA) are those that we recommend for predicting hydrogen generation and tungsten mobilization for steam ingress accidents involving tungsten brush. These rates could vary somewhat for a brush with a different geometry. 


\section{ACKNOWLEDGMENTS}

This work is supported by the U.S. Department of Energy, Office of Energy Research, under the DOE Idaho Operations Contract DE-AC07-99ID13727. The authors wish to thank Scott O'Dell with Plasma Processes, Inc. from Huntsville, Alabama for providing the specimens of tungsten brush for testing. Photographic and metallographic characterization of the tungsten brush specimens were provided by Todd Morris, Jim O’Brien, and Mike Hankins. 


\section{CONTENTS}

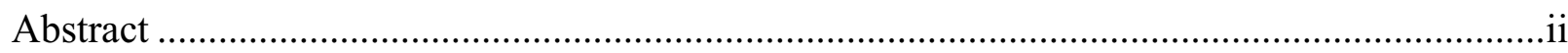

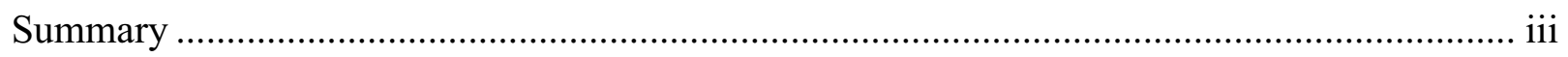

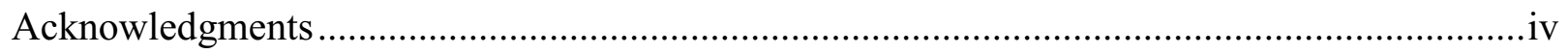

Definitions and Acronyms ……………............................................................................

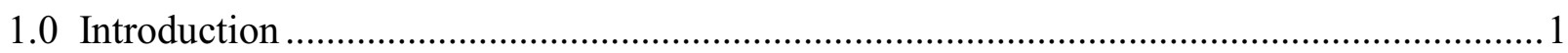

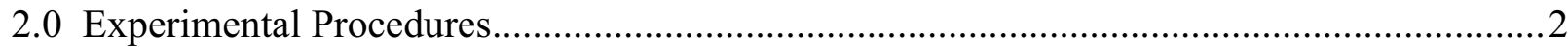

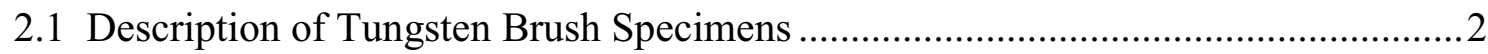

2.2 Characterization of Tungsten Brush Specimens ..................................................

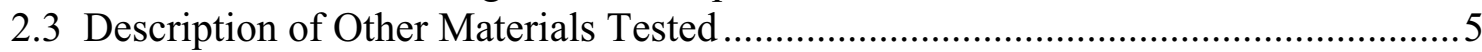

2.4 Steam Chemical Reactivity Experimental System...................................................5

2.5 Calculation of Extent of Oxidation and Volatilization ............................................

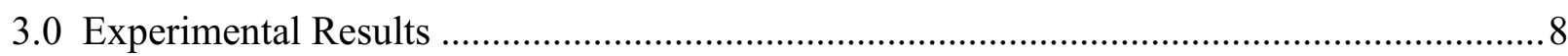

3.1 Hydrogen Generation Results from Various Products ............................................. 8

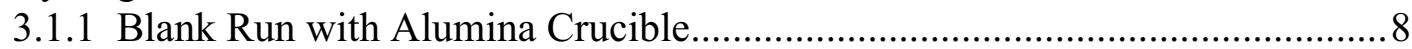

3.1.2 Hydrogen Generation by Inconel Components............................................

3.1.3 Hydrogen Generation from Tungsten Rods .................................................. 10

3.1.4 Hydrogen Generation from Tungsten Brush.................................................13

3.1.5 Tungsten Brush with and without Restraint.................................................13

3.1.6 Specimen Appearances and Oxide Formation ...............................................15

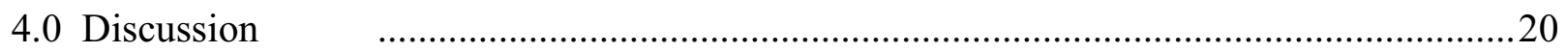

4.1 Oxidation Kinetics of Tungsten Brush Specimens ................................................20

4.2 Comparison of Oxidation Rates with PM Product..................................................21

4.3 Hydrogen Generation Rates for Engineering Applications..................................22

4.4 Extent of Oxidation Incurred by Specimens ............................................................23

4.5 Volatilization from Various Products and Configurations........................................24

4.6 Comparison of Volatilization with Previous CMFPs...............................................25

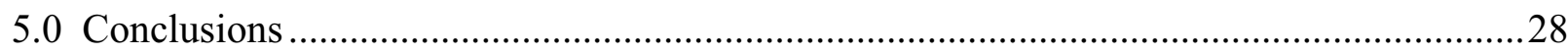

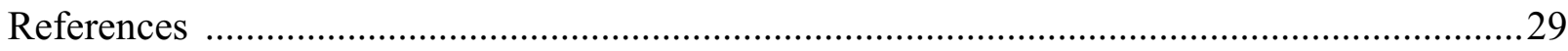

Appendix A: Plots of Hydrogen Generation Rates and Cumulative Hydrogen

Determined from Quadrupole Mass Spectrometer Measurements A-1 


\section{DEFINITIONS and ACRONYMS}

Surface areas used for rate determinations:

Hydrogen generation rates $\left(1 / \mathrm{m}^{2}-\mathrm{s}\right)$ and volatilization rates $\left(\mathrm{g} / \mathrm{m}^{2}-\mathrm{s}\right)$ are dependent upon the surface area selected to express the rates. We express surface areas by two different methods in this report. Surface area represented by a projected or normal view from the top of the specimen is called the normal surface area (NSA). The total or integrated surface area on the top and circumferential surfaces of the tungsten rods in the brush specimen exposed to the steam is referred to as the total surface area (TSA). Specific geometric features of the brush such as rod diameters and lengths, and packing density, will affect the shape factor or ratio between the TSA and NSA. The shape factors for the surfaces of the specific brush design tested in this study were between 13 to 14 . Brush with other geometric features would have a different shape factor.

CMFP Cumulative Maximum Flux Plot

EBTS Electron Beam Test System

HIPped Hot Isotopic Pressed

NSA Normal Surface Area

QMS Quadrupole Mass Spectrometer

PM Powder Metallurgy

SEM Scanning Electron Microscopy

TSA Total Surface Area 


\section{INTRODUCTION}

Tungsten brush is a new innovative design developed to accommodate high thermal stresses induced in high heat flux components. Such components are candidates as armor to protect walls in future fusion reactors. The design and performance details of these components tested under high heat flux cycles produced by electron beams are reported elsewhere.[1,2,3] Basically the brush consists of a closely packed array of round tungsten rods typically 1.5 or $3.2 \mathrm{~mm}$ in diameter. The rods are initially held vertically in place with Inconel 600 honeycomb. High purity copper is then vacuum plasma sprayed into the honeycomb from the backside to provide permanent embedment. The brush is then bonded to a water-cooled substrate by various means to provide efficient heat removal. The effectiveness of these components is evident by tests showing endurances of up to 500 cycles at heat loads of $30 \mathrm{MW} / \mathrm{m}^{2}$. Although such a rod-type design reduces stresses associated with thermal cycling, the rods increase the surface area of tungsten per unit area of the heat flux component. This could have safety implications in the event of an accident involving steam ingress in a fusion reactor system. Steam will react with the heated surfaces producing hydrogen and forming potentially volatile radioactive oxide products. We have previously investigated and modeled the quantities of hydrogen and volatilized oxides produced from other tungsten product forms.[4,5,6,7] In the current investigation we have tested specimens of tungsten brush in high temperature steam to determine hydrogen generation rates, and we have calculated the amounts of tungsten volatilized. The objectives were to determine whether the rates from the tungsten brush scaled with those from previous investigations, or whether the more intricate surfaces due to the void spaces between the rods influenced the oxidation and volatilization processes. 


\section{EXPERIMENTAL PROCEDURES}

We tested tungsten brush specimens in the chemical reactivity experimental system described below in Section 2.3. The system uses a quadruple mass spectrometer (QMS) to measure the hydrogen generated during steam exposure. The mass of the specimen of approximately 16- $\mathrm{mm} \times 16-\mathrm{mm}$ was also measured before and after the test. A weight gain occurs due to oxygen pick-up during the oxidation process. However, at higher temperatures some concurrent weight loss occurs due to the volatilization of hydroxide or hydrated tungsten oxides. We use differences between the amount of oxidation indicated from the cumulative hydrogen from QMS and mass change to calculate amounts of oxide volatilized and remaining on the specimens. The details for these calculations are given in Section 2.3. Specimens of the tungsten brush were tested for various times between 500 and $1000^{\circ} \mathrm{C}$. Some initial tests at higher temperatures showed that the expansion of oxide between the rods forced the rods to spread apart. We therefore performed some tests with a restraining fixture placed around the perimeter of the specimen. This would be more typical of a unit section contained within a larger array of an armor component. Specimens were examined and photographed prior to and after the tests. Image analyses was used to determine total exposed surface areas on the top surfaces and the perimeters of the rods. Scanning electron microscopy with energy dispersive x-ray analyses was used to characterize surface features and chemical composition of the rods resulting from the fabrication processes.

\subsection{Description of Tungsten Brush Specimens}

Plasma Processes Inc. located in Huntsville, Alabama prepared the tungsten brush specimens used for this study. They used the same materials and processes as those used to make armor brush components tested at Sandia National Laboratories' Electron Beam Test System (EBTS). A drawing and photograph in Figure 1 show the specimen configuration. Tungsten welding rods with $1.5 \mathrm{wt} \%$ lanthana $\left(\mathrm{La}_{2} \mathrm{O}_{3}\right)$ were cut to $12-\mathrm{mm}$ lengths. These rods were held in place with a 3-mm high Inconel 600 honeycomb base. High purity OFHC copper was vacuum plasma sprayed onto the back of the sample. The copper embedded about $2 \mathrm{~mm}$ of the tungsten rods and provided a 1-mm thick copper backing layer. The tungsten rods extended about $10 \mathrm{~mm}$ above the copper base and about $7 \mathrm{~mm}$ above the Inconel honeycomb. The brush was prepared in approximately the same size as that used for the high heat flux tests, i. e., about $16 \mathrm{~mm}$ wide and $64 \mathrm{~mm}$ long. The brush sample was then HIPped to consolidate the plasma sprayed copper. The temperatures of the tungsten rods during plasma spraying and HIPping were maintained below the melting point of copper. Electrical discharge machining was then used to cut 16-mm x 16-mm specimens from the brush. These specimens were ultrasonically cleaned in acetone and then baked out for one hour at $350^{\circ} \mathrm{C}$ in a vacuum near $10^{-4}$ torr. We used scanning electron microscopy (SEM) to examine an as-received tungsten brush specimen. The SEM micrograph in Figure 2 shows some non-uniform deposit on the circumference of a rod located on the second row from the edge of the specimen. Energy dispersive x-ray spectroscopy (EDS) showed a high copper concentration at a location about $2.5 \mathrm{~mm}$ above the Inconel base (Spot 2). Concentrations of various elements measured at this location were $\mathrm{Cu}-46.2$ at $\%, \mathrm{~W}-26.6$ at $\%, \mathrm{O}-11.6$ at $\%, \mathrm{Zn}-7.7$ at $\%, \mathrm{Ni}-6.0$ at $\%$, and $\mathrm{La}-1.9$ at $\%$. The analyses from Spot 1 by comparison showed only 96.6 at $\%$ tungsten and 3.4 at $\%$ copper. The copper deposition apparently occurred during the plasma spraying operation. Since copper does not oxidize in steam, this copper deposit may actually provide some protection during steam exposure. 


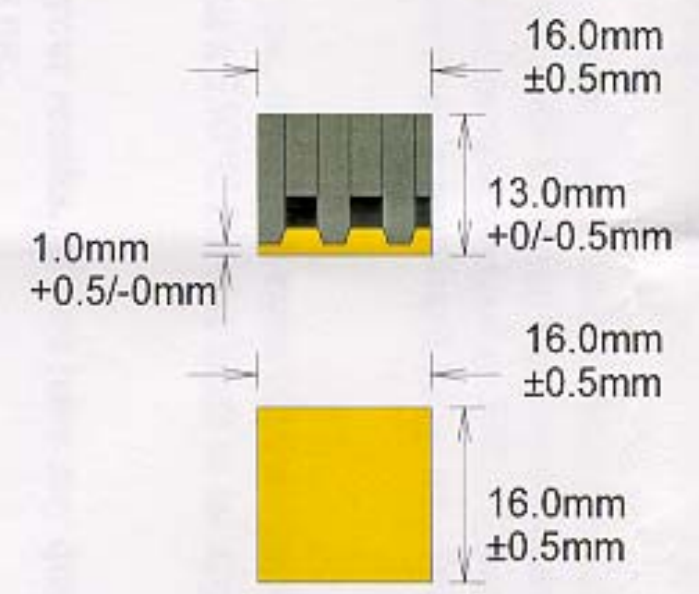

(a)

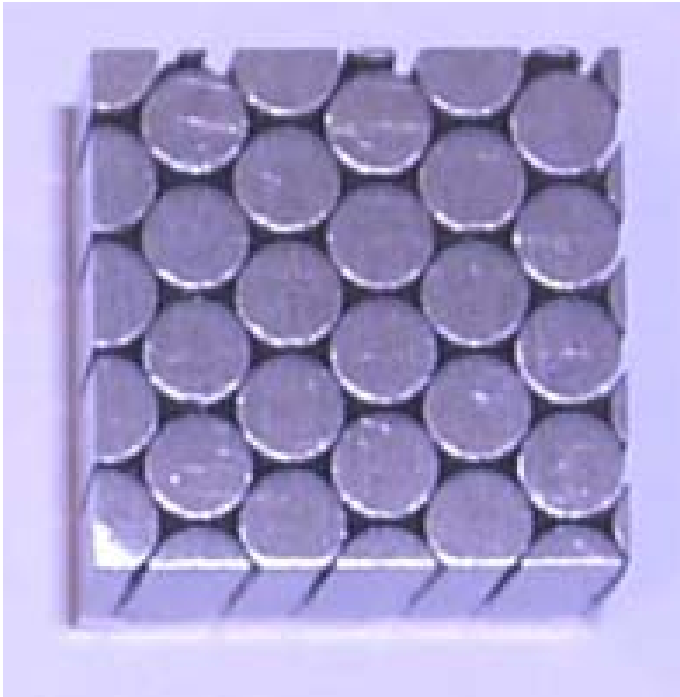

(b)

Figure 1. Configuration of tungsten brush specimens prepared for steam oxidation tests.

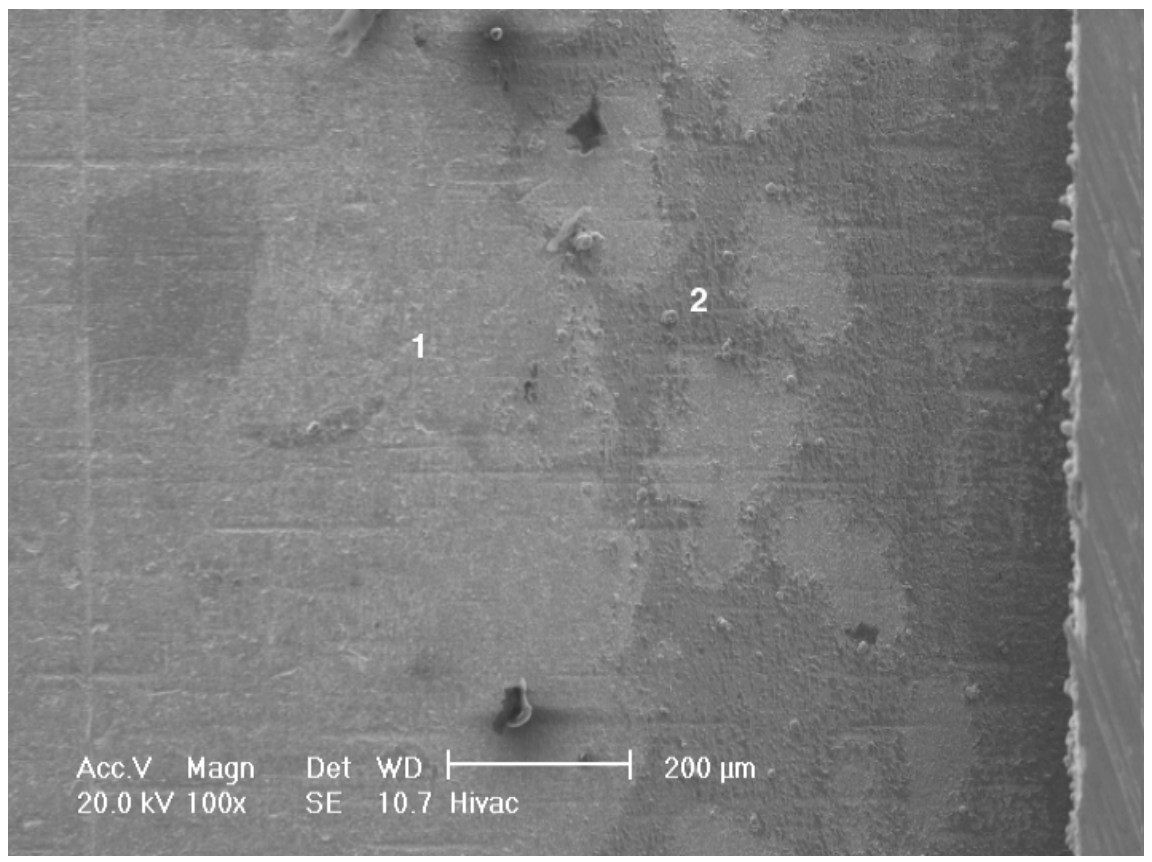

Figure 2. SEM image of a rod in a tungsten brush specimen showing copper deposited from overspray. 


\subsection{Characterization of Tungsten Brush Specimens}

We used image analyses from photographs such as that shown in Figure 1(b) to quantify the surfaces of each specimen. Top surface areas and perimeters of each rod, or rod segment, were measured. We then calculated circumferential surface areas assuming that each rod extended $10 \mathrm{~mm}$ above the copper base. We considered the "total" surface area of tungsten exposed to steam at the start of a test to be the surfaces on the top and perimeter of the rods. We also measured the overall $\mathrm{x}$ - and $\mathrm{y}$-dimensions to provide normal or projected areas for the tungsten brush specimens. Measurements, surface areas, initial weights, and test parameters for the specimens are given in Table 1. The mass of the tungsten rods in the brush is calculated using the volume in the 10-mm height extending above the copper base and a density of 19.3 $\mathrm{g} / \mathrm{cm}^{3}$. Image analyses also showed that the brush had about an 85 percent packing density which is the same as that mentioned for brush with $3.2 \mathrm{~mm}$ diameter rods and honeycomb supporting structure.[1]

Table 1. Test parameters for tungsten brush and other products.

\begin{tabular}{|c|c|c|c|c|c|c|c|}
\hline $\begin{array}{l}\text { Test } \\
\text { I.D. }\end{array}$ & $\begin{array}{l}\text { Type of } \\
\text { product }\end{array}$ & $\begin{array}{l}\text { Temp. } \\
{ }^{\circ} \mathrm{C}\end{array}$ & $\begin{array}{l}\text { Time } \\
\text { (min.) }\end{array}$ & $\begin{array}{c}\text { Total } \\
\text { area }\left(\mathrm{cm}^{2}\right)\end{array}$ & $\begin{array}{c}\text { Normal } \\
\text { area }\left(\mathrm{cm}^{2}\right)\end{array}$ & $\begin{array}{c}\text { Initial } \\
\text { weight }(\mathrm{g})\end{array}$ & $\begin{array}{c}\text { Mass of W rods } \\
\text { exposed }(\mathrm{g})\end{array}$ \\
\hline WB-7 & brush & 500 & 640 & 32.936 & 2.391 & & 38.976 \\
\hline WB-4 & brush & 600 & 640 & 32.294 & 2.457 & & 40.028 \\
\hline WB-6 & brush & 700 & 340 & 33.329 & 2.450 & & 39.449 \\
\hline WB-1 & brush & 800 & 340 & 32.460 & 2.419 & & 38.318 \\
\hline WB-2 & brush & 900 & 340 & 31.559 & 2.427 & & 37.728 \\
\hline WB-3 & brush & 1000 & 340 & 32.325 & 2.426 & & 38.783 \\
\hline WB-5 & $\begin{array}{c}\text { brush } \\
\text { (restrained) }\end{array}$ & 1000 & 580 & 32.735 & 2.492 & & 39.814 \\
\hline WB-8 & brush & 1100 & 340 & 32.832 & 2.425 & & 39.160 \\
\hline WB-7b & $\begin{array}{c}\text { brush } \\
\text { (restrained) }\end{array}$ & 1100 & 340 & 32.936 & 2.391 & & 38.976 \\
\hline WR-1 & (4) rods & 500 & 700 & 10.8572 & ---- & 15.2964 & \\
\hline WR-2 & (4) rods & 600 & 340 & 11.0911 & ---- & 15.3222 & \\
\hline WR-3 & (4) rods & 600 & 703 & 10.6981 & ---- & 15.1012 & \\
\hline WR-4 & (4) rods & 600(a) & 701 & 11.6994 & ---- & 15.4221 & \\
\hline WR-5 & (3) rods & 600(b) & 575 & 8.0533 & ---- & 11.3871 & \\
\hline WR-6 & (4) rods & 700 & 312 & 10.9759 & ---- & 15.5071 & \\
\hline WR-7 & (4) rods & 800 & 340 & 10.3106 & ---- & 14.4910 & \\
\hline WR-8 & (2) rods & 900 & 337 & 5.3455 & ---- & 7.5590 & \\
\hline WR-9 & (1) rods & 1000 & 340 & 2.6734 & ---- & 3.7956 & \\
\hline $\mathrm{IN}-1$ & Inconel 600 & 800 & 163 & 44 & & 1.7272 & \\
\hline & honeycomb & \multicolumn{3}{|c|}{$(2.5 \mathrm{~cm} \times 3.5 \mathrm{~cm} \times 0.3 \mathrm{~cm}$ thick $)$} & & & \\
\hline $\mathrm{IN}-2$ & Inconel 718 & 1100 & 324 & 20.0 & & 34.7165 & \\
\hline & collar & \multicolumn{5}{|c|}{ (1.6-cm square $\times 0.6 \mathrm{~cm}$ thick walls $\times 1.6$ height) } & \\
\hline $\mathrm{Al}_{2} \mathrm{O}_{3}$ & crucible & 800 & 163 & & & & \\
\hline & & \multicolumn{3}{|c|}{$(4.0 \mathrm{~cm} \times 3.0 \mathrm{~cm} \times 0.6 \mathrm{~cm}$ high } & & & \\
\hline
\end{tabular}

(a) annealed at $900^{\circ} \mathrm{C}$ for one hour prior to testing. (b) annealed at $1200^{\circ} \mathrm{C}$ for one hour prior to testing. 


\subsection{Description of Other Materials Tested}

Other materials were tested to provide a baseline for comparison with results from the tungsten brush specimens. These included sections of $1.5 \mathrm{wt} \%$ lanthana welding rod of the same origin as that used for the tungsten brush specimens. Some of the rods were tested with the as-received surface ground condition and others were annealed at $900^{\circ} \mathrm{C}$ and $1200^{\circ} \mathrm{C}$ to represent thermal effects from plasma spraying and HIPping. Sections of the Inconel 600 honeycomb and the Inconel 718, the material used for restraining collars, were also tested to determine if these materials might provided any significant quantities of hydrogen. A blank run of the rectangular alumina crucible $(6 \mathrm{~mm} \times 30 \mathrm{~mm}$ x $40 \mathrm{~mm})$ used to hold the specimens were also made at $800^{\circ} \mathrm{C}$. The test parameters for these comparative tests are included in Table 1. We have previously tested a pressed and sintered tungsten powder metallurgy product [4-6] in steam. Results from this sintered product are compared with that from the tungsten brush. The pressed powders of tungsten and other elements were heated in hydrogen at $1500^{\circ} \mathrm{C}$. The liquid phase sintering process formed large grains consisting primarily of tungsten. The tungsten grains were surrounded by a lower melting point $\mathrm{W}-\mathrm{Ni}$-Fe phase. This microstructure would be quite different from that in the tungsten welding rods. These rods as-received, annealed, and in the brush most likely all contain significant residual deformed material and are not fully recrystallized.

\subsection{Steam Chemical Reactivity Experimental System}

Steam chemical reactivity measurements for the tungsten brush specimens were conducted in an experimental system developed for measuring hydrogen generation rates from various types of beryllium specimens. The test setup illustrated in Figure 3 is comprised of a flow-through system in an inert-gas glovebox and in a Class-A laboratory hood. An argon carrier gas sweeps preheated steam into the reaction chamber. This gas mixture along with hydrogen produced from the steam reaction with the tungsten brush specimen is then passed through a process line equipped with condensers, a cryotrap, and instrumentation for gas analyses. Steam condensation downstream from the sample furnace is achieved in two Friedrich condensers and the cyrotrap maintained near zero degrees centigrade. The argon carrier gas then transports the hydrogen gas through the remaining system process line. Hydrogen concentrations are obtained from this gas mixture by using a precision controlled sampling leak through a valve leading to an on-line quadrupole mass spectrometer (QMS). Typical system operating parameters include the following: line pressure (675-685 torr), argon carrier-gas flow rate $(100 \mathrm{std} \mathrm{cc} / \mathrm{min})$, steam flow rate $(2500 \mathrm{std} \mathrm{cc} / \mathrm{min}$ generated from a water input of $2 \mathrm{cc} / \mathrm{min})$, steam-generator temperature $\left(350^{\circ} \mathrm{C}\right)$. The tube furnace containing the reaction chamber can be controlled between $25^{\circ} \mathrm{C}$ to $1200^{\circ} \mathrm{C}$. The ion chamber and ethylene glycol trap were by-passed for the current tests. These components were used when testing irradiated specimens containing tritium. The system response time for these conditions is about six minutes and the detection sensitivity for the $\mathrm{H}_{2}$ gas in argon carrier gas is about 3 ppm. Specimens were placed at the center of the reaction-chamber hot zone in a rectangular shaped alumina crucible. The crucible had low sides to avoid any interference of the impingement of the steam flow onto the specimen. Temperatures in the reaction chamber were based on prior measurements with a Type-K thermocouple (TC) located at the sample position that was in turn referenced to the controlling TC for the furnace. Additional details concerning the performance of this experimental system are found in a previously published report $[8,9]$ that serves as a Quality Assurance document for the chemical-reactivity measurements. 
Accurate determination of the quantities of hydrogen gas generated or released in the system hinged on two factors: (1) accurate measurement of the pressure and flow rates in the process line and (2) calibration of the QMS and sampling valve setting for each experiment. Pressure measurements in the process line were made with a capacitance manometer and the atmospheric pressure was checked daily via consultation with the local calibration laboratory. Carrier gas flow rates were controlled with a calibrated mass flowmeter. They were also checked regularly throughout an experiment with the bubble-tube flow meter. Absolute calibration of the QMS/sampling valve arrangement was done using $\mathrm{Ar}-\mathrm{H}_{2}$ gas mixture standards in place of the high-purity argon carrier gas. The standard gas-mixtures had $\mathrm{H}_{2}$ contents that varied from $50 \mathrm{ppm}$ to $50,000 \mathrm{ppm}$, to ensure a wide calibration range for the system. Measured QMS mass peaks included mass- 2 for $\mathrm{H}_{2}$ and mass- 40 for ${ }^{40} \mathrm{Ar}$. These measurements provided calibration curves relating mass-2/mass-40 QMS peak-height ratios as a function of the $\mathrm{H}_{2}$ concentrations in the $\mathrm{Ar}$ gas-mixture standard. The wide range of calibration gas standards provided an accurate calibration of the QMS for $\mathrm{H}_{2}$ in argon. The uncertainties could be about 15 to 20 percent at the ppm $\mathrm{H}_{2}$ level and a few percent at the 10,000-ppm $\mathrm{H}_{2}$ level.

A computer-based, automated data acquisition system was used to acquire data measured with the QMS. The QMS sequentially measured mass spectra from 1 to $50 \mathrm{AMU}$ in a histogram mode. The time to cycle for a single mass spectrum was about $74 \mathrm{sec}$. Data were acquired as a function of elapsed time. Other parameters, such as sample masses before and after a test, furnace temperatures, line pressures, carrier-gas flow rates, and selected QMS peak-heights were recorded in experiment log books. The QMS data provide kinetic information on hydrogen generation rates while the integration of this data yields the total quantity of hydrogen generated.

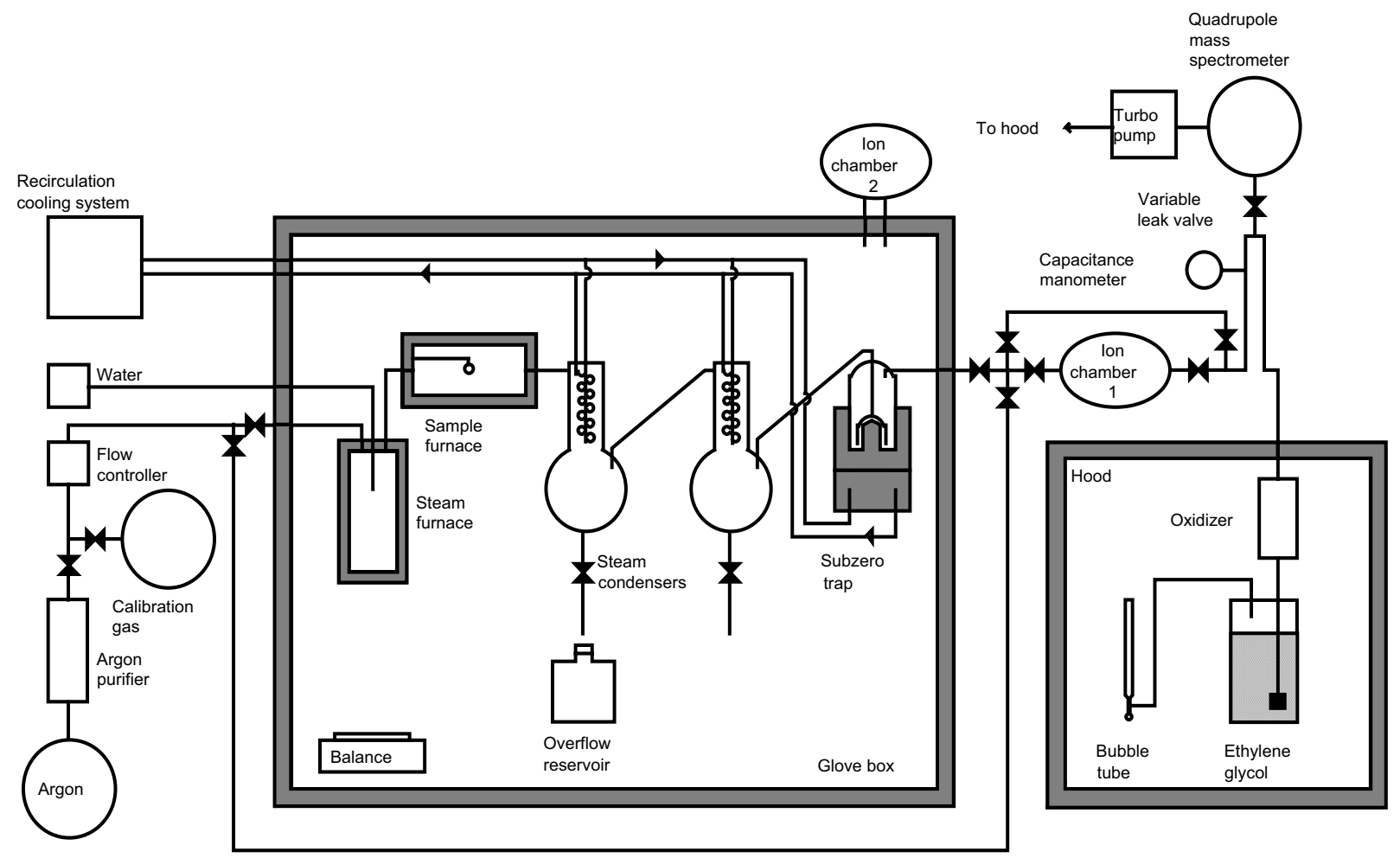

Figure 3. Schematic illustration of the experimental system used to test the tungsten brush specimens in high temperature steam. 


\subsection{Calculation of Extent of Oxidation and Volatilization}

We can calculate the amount of tungsten oxidized and the amount of oxide volatilized by using the quantity of hydrogen measured with the QMS and the mass change during oxidation. The mass change of the specimen involves the concurrent processes of oxygen pick-up and tungsten loss due to volatilization. We assume hydrogen is primarily produced by the reaction of steam with tungsten to form tungsten trioxide, $\mathrm{WO}_{3}$, as shown by Equation (1). The amounts of other oxides of higher oxidation states, e.g., $\mathrm{WO}_{2}$, are small and can be neglected. The process of volatilization shown by Equation (2) resulting from the formation of a volatile hydrated oxide or hydroxide species does not contribute to the production of any additional hydrogen.

$$
\begin{aligned}
& \mathrm{W}+3 \mathrm{H}_{2} \mathrm{O} \rightarrow \mathrm{WO}_{3}+3 \mathrm{H}_{2} \\
& \mathrm{WO}_{3}+\mathrm{H}_{2} \mathrm{O} \rightarrow \mathrm{WO}_{3} \bullet \mathrm{H}_{2} \mathrm{O} \text { or } \mathrm{WO}_{2} \bullet(\mathrm{OH})_{2}
\end{aligned}
$$

In the past we have used transpiration tests and inductive coupled plasma-atomic emission, or -mass, spectroscopy to measure the amount of tungsten volatilized. This measurement along with the mass change allow us to determine the amount of oxide remaining on the specimens according to Equation (3).

$$
\Delta m(\text { mass change })=M_{\text {specimen }}^{\text {oxygen }}-M_{\text {Volatilized }}^{\text {Tungsen }}(I C P \text { meas. }),
$$

Rearranging Equation (3) provides Equation (3-a) that expresses the amount of oxygen remaining on the specimen after volatilization.

$$
M_{S}^{0}=\Delta m+M_{V}^{W}
$$

The total amount of tungsten reacted can be expressed by Equation (4) which shows the amount of tungsten volatilized and the amount of tungsten associated with the oxide remaining on the specimen. The mass of tungsten associated with the oxide can be obtained from the amount of oxygen on the specimen using the molecular weights for tungsten and oxygen in the trioxide according to Equation (5).

$$
\begin{aligned}
& M_{T}^{W}=M_{V}^{W}+M_{S}^{W}, \\
& M_{T}^{W}=M_{V}^{W}+(184 / 48) M_{S}^{O},
\end{aligned}
$$

By substituting Equation (3-a) into Equation (5), we obtain Equation (6).

$$
M_{T}^{W}=M_{V}^{W}+(184 / 48)\left\lfloor\Delta m+M_{V}^{W}\right\rfloor .
$$

We can use the QMS measurement for hydrogen to calculate the total amount of tungsten reacted ( $M_{T}^{W}$ ) and rearrange to solve for the amount of tungsten volatilized $\left(M_{V}^{W}\right)$ as shown in Equation (7). A final expression for tungsten volatilized is provided by Equation (8).

$$
\begin{aligned}
& (232 / 48) M_{V}^{W}=M_{T}^{W}-(184 / 48) \Delta m, \\
& M_{V}^{W}=(48 / 232) M_{T}^{W}-(184 / 232) \Delta m
\end{aligned}
$$




\section{EXPERIMENTAL RESULTS}

\subsection{Hydrogen Generation Results from Various Products}

The QMS and mass changes recorded for tests of the various product forms are listed in Table 2. Detailed QMS plots for each test showing mass-2/mass-40 ratio, hydrogen concentration (ppm), hydrogen generation rate (std ccm) and cumulative hydrogen ( $\mathrm{std} \mathrm{cc}$ ) are given in Appendix A. In this section we provide test data showing that negligible or only limited contributions resulted from the alumina ceramic crucibles and Inconel components. The hydrogen generation plots of the tungsten brush specimens are compared with plots from sections of welding rods having more direct exposure to the steam environment. The amounts of tungsten oxidized and volatilized from the various specimens obtained by the method of calculation described in Section 2.3 are included in Table 2.

\subsubsection{Blank run with Alumina Crucible}

Hydrogen generation rates and the cumulative plot for the blank run on the alumna crucible are shown in Figure 4. The alumina crucible had been baked out for one hour at $1000^{\circ} \mathrm{C}$ prior to the test. Signals of hydrogen generation rates are very low relative to background. The cumulative amount of hydrogen of about $0.07 \mathrm{std} \mathrm{cc}$ after three hours is small compared to more than $3.4 \mathrm{std} \mathrm{cc}$ generated during our lowest temperature test of tungsten brush at $500^{\circ} \mathrm{C}$.

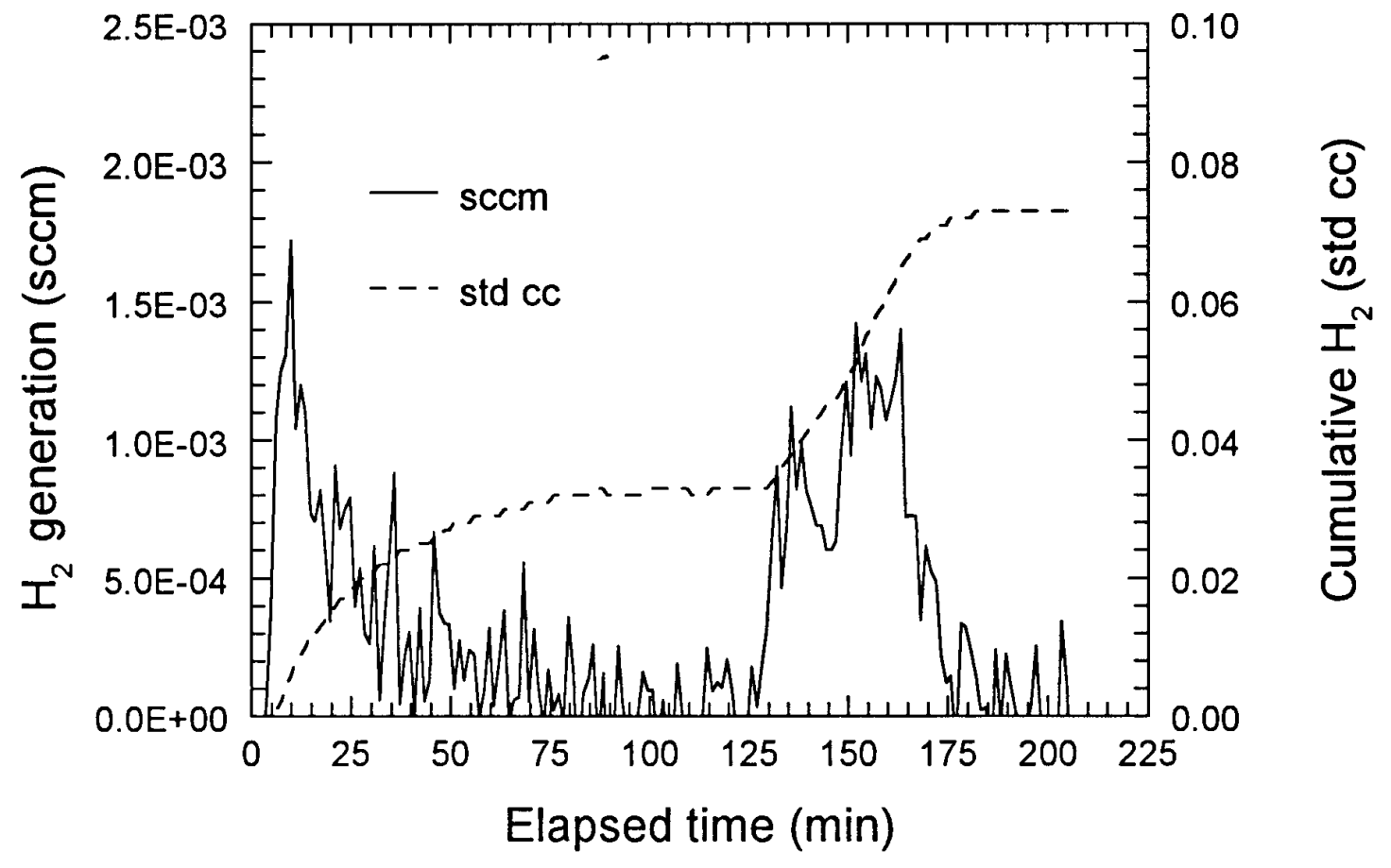

Figure 4. QMS data showing only limited hydrogen release from a blank run on the alumina ceramic boat exposed in steam at $1000^{\circ} \mathrm{C}$. 


\subsubsection{Hydrogen Generated by Inconel Components.}

Plots for hydrogen generation from a section of Inconel 600 honeycomb tested at $800^{\circ} \mathrm{C}$ is shown in Figure 5. Hydrogen generation shows a strong parabolic behavior. The peak rate of $0.18 \mathrm{std} \mathrm{ccm}$ decreases by a factor of ten within one hour. We would expect such behavior from an alloy that forms a dense, protective oxide scale. The cumulative hydrogen generation was about 5.3 std cc during the 163 minutes of exposure. Most was produced during the first hour. The section of 3-mm high honeycomb was $25 \mathrm{~mm}$ wide x $35 \mathrm{~mm}$ long. Only 30 percent as much honeycomb was used in the $16 \mathrm{~mm} \times 16 \mathrm{~mm}$ brush specimens. In addition, the plasma sprayed copper covers most of this honeycomb. Less than one std cc of hydrogen would be produced from the Inconel honeycomb during a 340-minute exposure at $800^{\circ} \mathrm{C}$ assuming 25 percent of the Inconel is exposed, the brush specimens contain only 30 percent as much honeycomb as our blank test, and the rate is linear. Parabolic behavior rather than an assumed linear rate would make the quantity of hydrogen produced even lower. This is quite low compared to the 124 std cc measured for the tungsten brush test WB- 1 at $800^{\circ} \mathrm{C}$. We can conclude that the hydrogen production from the steam reaction with the Inconel honeycomb is not significant.

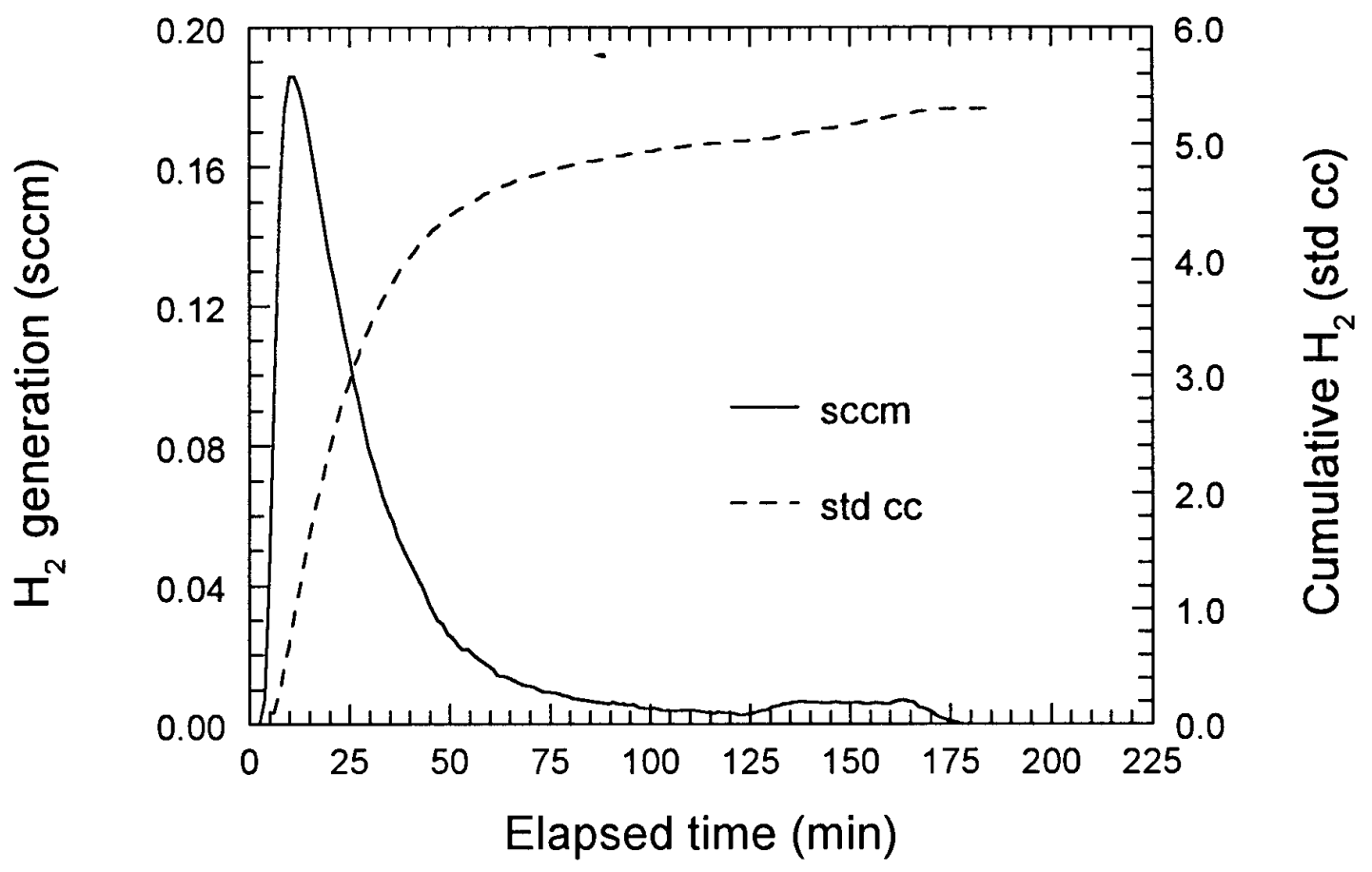

Figure 5. Hydrogen generation from Inconel 600 honeycomb tested for 163 minutes at $800^{\circ} \mathrm{C}$.

A blank specimen of Inconel 718 was tested at $1100^{\circ} \mathrm{C}$ to establish the contribution of this material in the fixture used during the restraining tests. The rectangular shaped specimen had $20 \mathrm{~cm}^{2}$ of surface area. Oxidation behavior was again parabolic similar to that shown in Figure 5. The hydrogen generation decreased to one-fourth of the peak rate during the first hours. Hydrogen production during this exposure as indicated both by the QMS and mass gain was about 35 std cc. The restraining collars on the brush specimens tested at 1000 and $1100^{\circ} \mathrm{C}$ had a total surface area of $30 \mathrm{~cm}^{2}$. About $21 \mathrm{~cm}^{2}$ were on the outward facing surfaces directly exposed to the steam. Since the exposed Inconel areas and the exposure times for the blank test and the $1100^{\circ} \mathrm{C}$ restrained test are about the same we might expect about $35 \mathrm{std} \mathrm{cc}$ of hydrogen from the Inconel collar in WB-8. This compares to a total quantity of $1510 \mathrm{std} \mathrm{cc}$ of 
hydrogen produced from the restrained specimen at $1100^{\circ} \mathrm{C}$. This is only slightly more than 2 percent. Again, we can conclude that the Inconel 718 component did not contribute significantly to the hydrogen produced during the test.

\subsubsection{Hydrogen Generation from Tungsten Rods}

The tungsten rods were secured together with platinum wire and placed in the shallow ceramic crucibles. This configuration shown by the photographs in Section 3.1.6 should allow unrestricted steam access to the rods. Plots for the hydrogen generation rate and cumulative hydrogen for the tungsten rods tested at $500^{\circ} \mathrm{C}$ are shown in Figure 6. The kinetics show a slightly parabolic behavior. The rate decreases by about 50 percent after ten hours. This parabolic trend is much weaker than that observed for the Inconel tests suggesting that the oxide layer may not be nearly as protective. There is, however, a time lag associated with signals from the chemical reactivity measurement system described in Section 2.3. Initially high concentrations of hydrogen releases, such as those produced by parabolic kinetics, are diffused throughout the volume of the system. Peak rates and the apparent parabolic behavior are therefore somewhat affected by the magnitude of the reactive surface areas. The total quantity of hydrogen produced from the four rods during the 700 minute exposure was about $1.35 \mathrm{std} \mathrm{cc}$. The quantity of hydrogen generated based upon the mass gain of 0.0012 gram was 1.68 std cc.

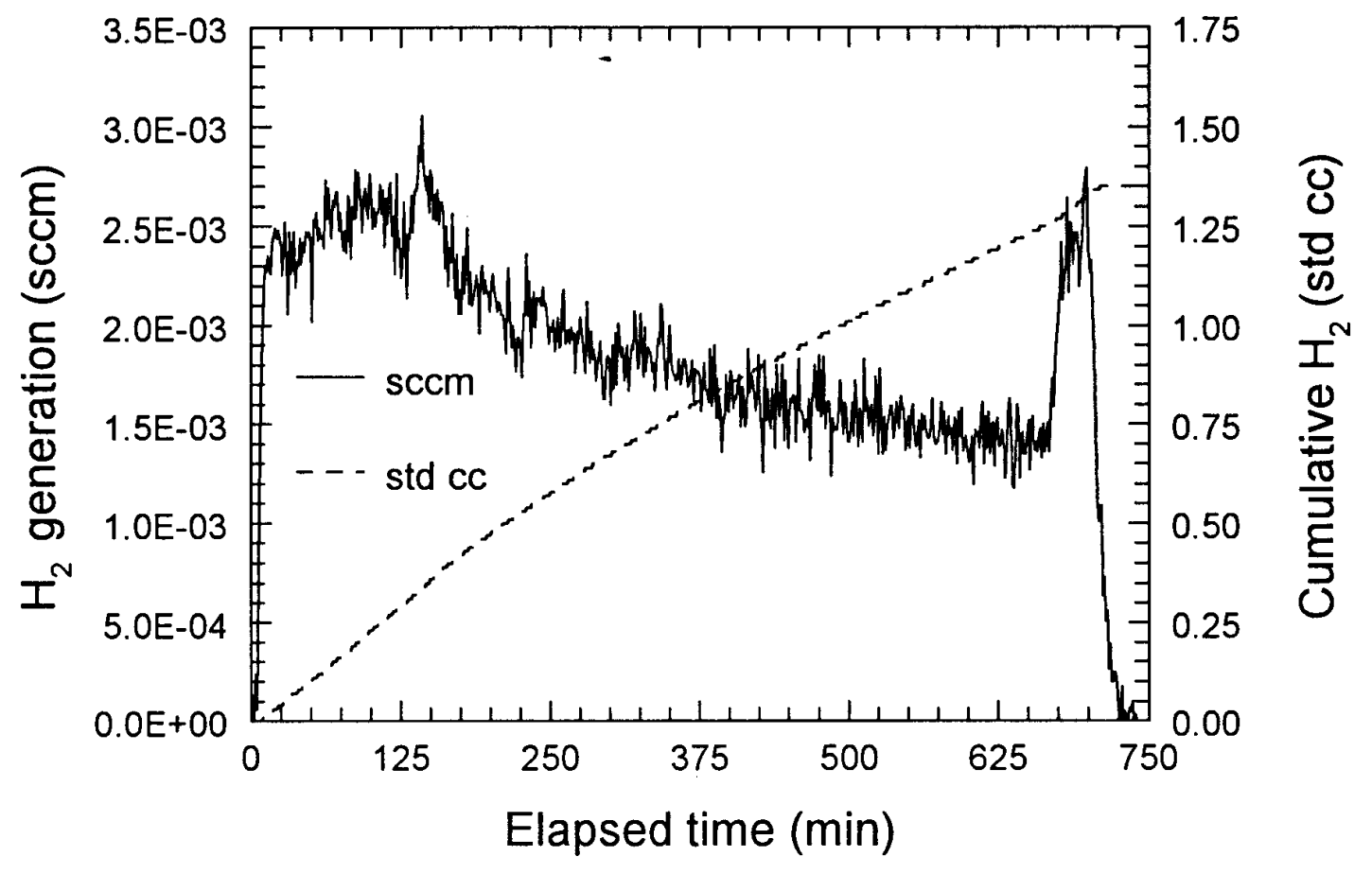

Figure 6. Hydrogen generation rate and cumulative hydrogen from tungsten rods tested at $500^{\circ} \mathrm{C}$ in steam for 700 minutes. 


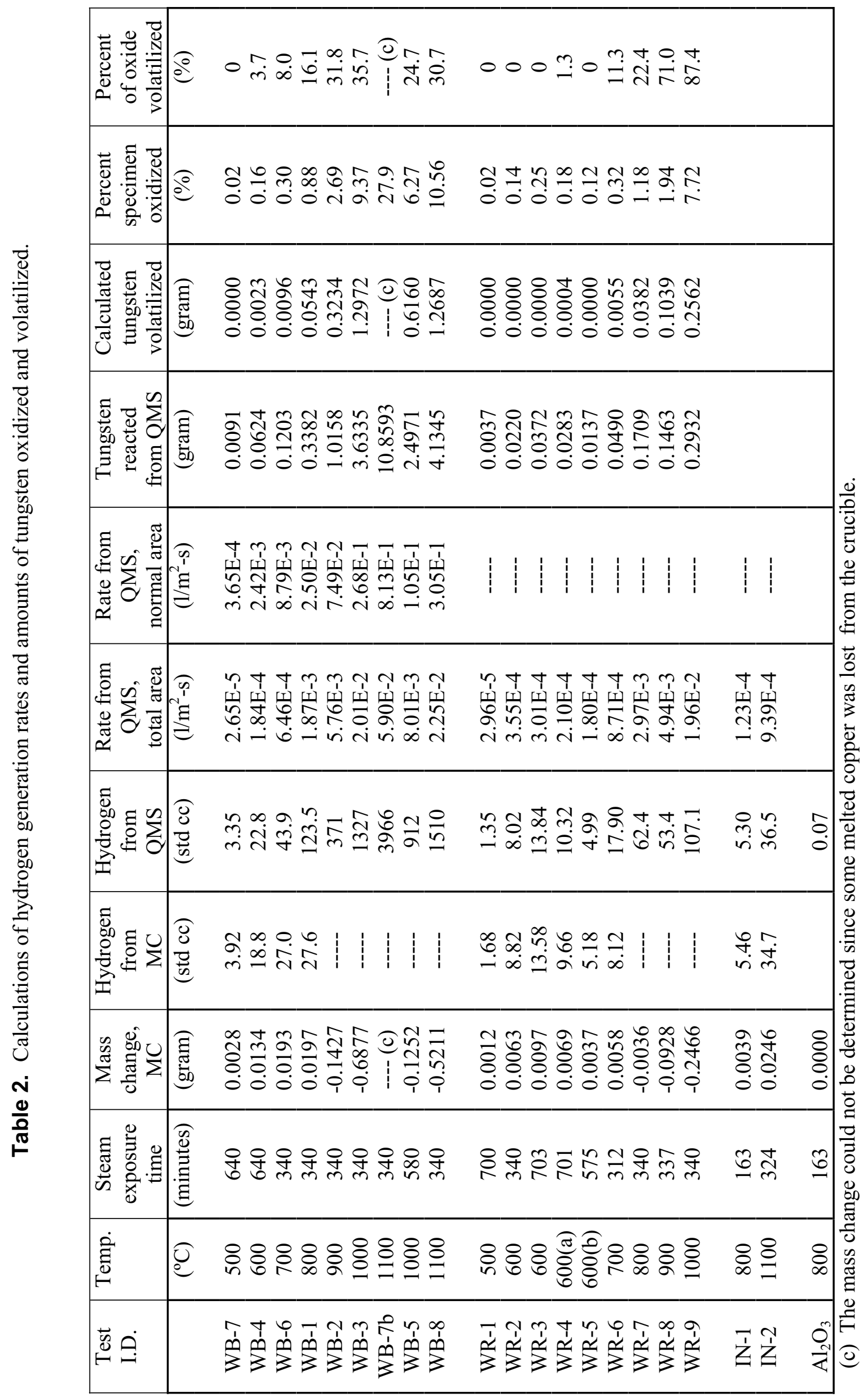


Four different sets of tungsten rods were tested at $600^{\circ} \mathrm{C}$. The rods for two of the tests, WR-2 and WR-3, were tested in the as-received condition. The surfaces of these specimens were very shinny showing the surface-ground finish resulting from the final preparation of the welding rods. The rods for the other tests were annealed at 900 and $1200^{\circ} \mathrm{C}$, respectively, for one hour prior to testing. There was no visual evidence of an oxide layer after the anneals. We also did not observe weight gain on a balance readable to four decimal places. It may be possible, however, that more than 0.0001 gram of oxygen is necessary to form a visually apparent oxide film. Plots of hydrogen generation rates for the four steam tests at $600^{\circ} \mathrm{C}$ are shown in Figure 7. The trends for the two tests with the as-received rods agree quite well. They do not show a high peak typical of what we have observed for Inconel tests with strong parabolic behavior. The rates gradually decrease imparting a slight parabolic character to the cumulative plots. Reaction rates from the two tests with annealed rods are also remarkably similar. They display a linear behavior throughout the tests and are about 40 percent lower than the specimens that were not annealed. Differences between the reaction rates of the as-received and annealed rods shows some influence from the thermal cycle. The lower rates may be due to some oxygen pick-up during vacuum annealing. Information given in Section 2.3 indicates that recrystallization and grain growth would not be expected at such low annealing temperatures. Some recovery may have occurred, however, particularly in a severely cold-worked surface layer produced by the final machining operation. It is not clear how recovery would change the oxidation kinetics from parabolic to linear while reducing the overall rate. Perhaps surface roughness or deformation features provide higher effective surface areas on the as-received rods.

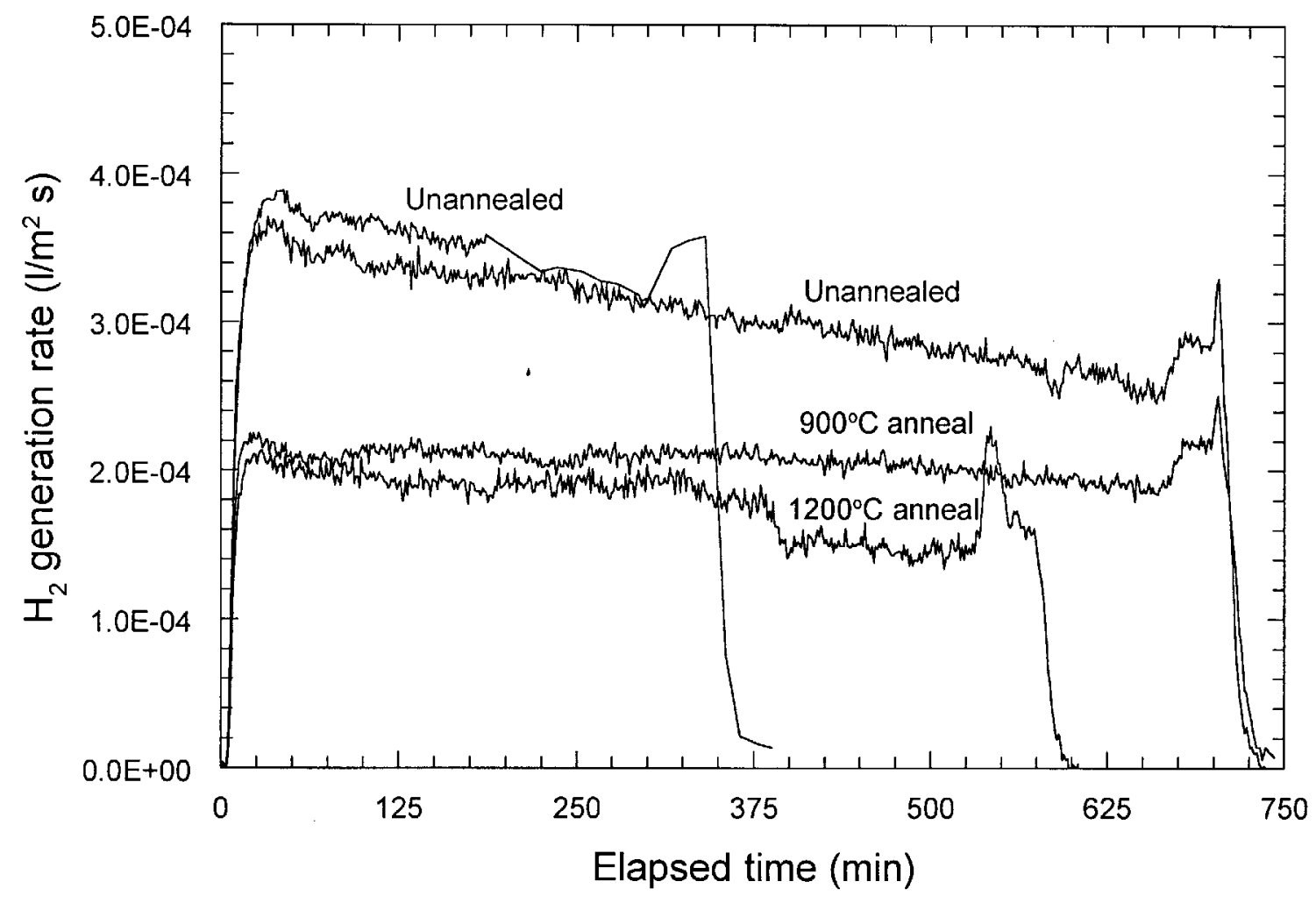

Figure 7. Hydrogen generation rates for the as-received and annealed tungsten rods tested at $600^{\circ} \mathrm{C}$ in steam. 
Cumulative hydrogen plots for the tungsten rods tested at 700,800 , and $900^{\circ} \mathrm{C}$ shown both in Appendix A and in the following Section 3.1.4 where they are compared with those for brush specimens. These tests all display parabolic oxidation kinetics. The cumulative plots in Appendix A have not been adjusted to compensate for the different number of rods tested at the various temperatures. The cumulative plots in Section 3.1.4 have been calculated to show hydrogen generation based upon the per unit area of tungsten. This makes the cumulative hydrogen plots in Section 3.1.4 more directly comparable for the different type of specimens at a given temperature. The oxidation kinetics at $1000^{\circ} \mathrm{C}$, shown in Appendix A and Section 3.1.4, display only a slight initial parabolic trend but then became more linear after about two hours.

\subsubsection{Hydrogen Generation from Tungsten Brush}

We initially tested tungsten brush specimens with direct exposure to the steam. Diffusion paths of steam ingress and hydrogen egress were through the void spaces in the 16- $\mathrm{mm} \times 16-\mathrm{mm}$ specimens with 3.2- $\mathrm{mm}$ diameter by $10-\mathrm{mm}$ long rods. Hydrogen generation rates were determined based upon the total areas on the tops and perimeters of the tungsten rods. Detailed records of the QMS measurements are given in Appendix A. Comparisons of the cumulative hydrogen plots from the tungsten brush with those obtained from the tungsten rods from Section 3.1.3 are shown in Figure 8. These plots have been adjusted to compare the per unit surface area of tungsten from both types of specimens. There is generally good agreement between results from the tungsten brush and the tungsten rods in Figure 8 . This is particularly true at the lowest temperature of $500^{\circ} \mathrm{C}$ and the higher temperatures of 900 and $1000^{\circ} \mathrm{C}$. The quantities of hydrogen produced from as-received rods are somewhat higher than brush specimens at 600,700 , and $800^{\circ} \mathrm{C}$. The annealed rods with the exception of showing linear kinetics rather than parabolic behavior compare very well with the tungsten brush at $600^{\circ} \mathrm{C}$. This suggests that the higher reactivity of the as-received rods at these intermediate temperatures may be due to the absence of some thin oxide or presence of a heavily deformed surface layer from machining. In addition, possible oxidation or recovery incurred by the rods on the brush during fabrication appears to have been similar to that for the annealed rods. Any influence of a preexisting oxide or surface recovery appears to become negated at higher temperatures. The higher temperature tests in Figure 8 show however that diffusion of steam into and hydrogen from the open brush are essentially equivalent to that occurring at the rod specimens.

\subsubsection{Tungsten Brush with and without Restraint}

We observed that the tungsten rods in the brush tested at $1000^{\circ} \mathrm{C}$ were forced apart by the oxide formed within the interstices. We prepared a restraining collar that fit snugly around the brush specimen. This would more closely represent a small unit of brush within a larger array. The cumulative plots for brush specimen tested at 1000 and $1100^{\circ} \mathrm{C}$ with and without the restraining collar are shown in Figure 9. Hydrogen generation is reduced by a factor of 2 to 3 for the restrained specimens. The trends of the cumulative plots are also somewhat different. The plots for the specimens without restraint become more linear with time whereas those for the restrained specimens are more parabolic. We subsequently show evidence that this behavior may be due to an accumulation of oxide that apparently reduces steam access or pressure within the locations between the rods. 


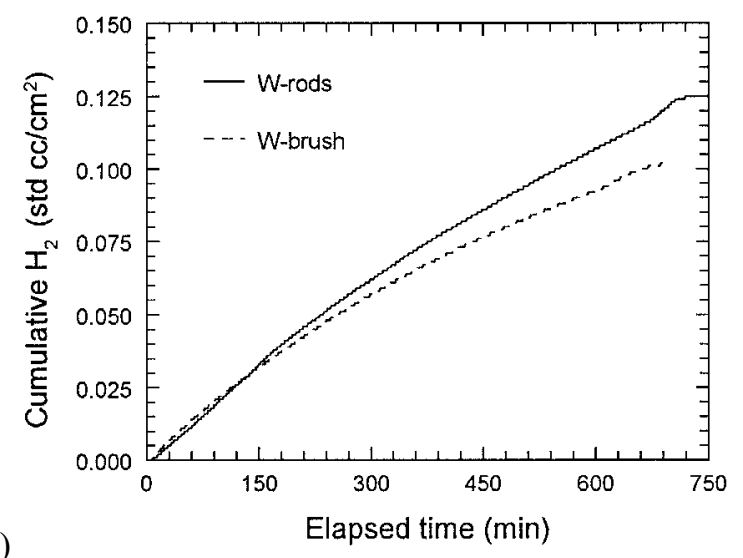

(a)

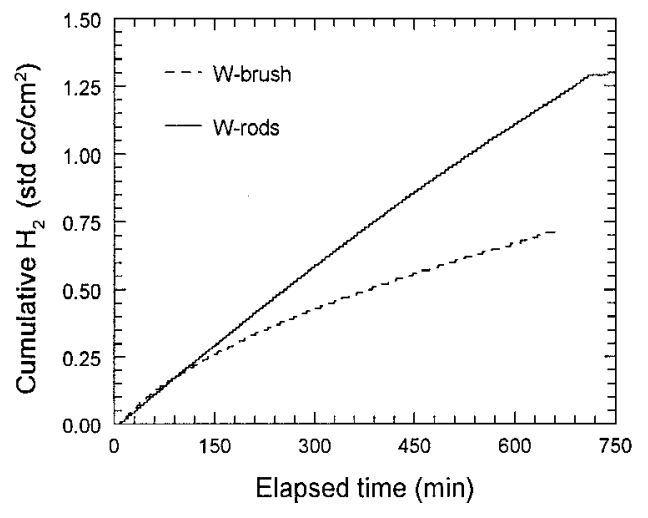

(b)

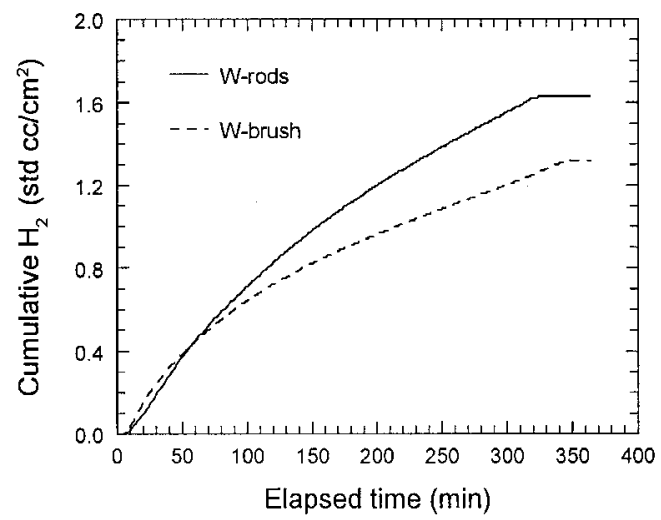

(d)

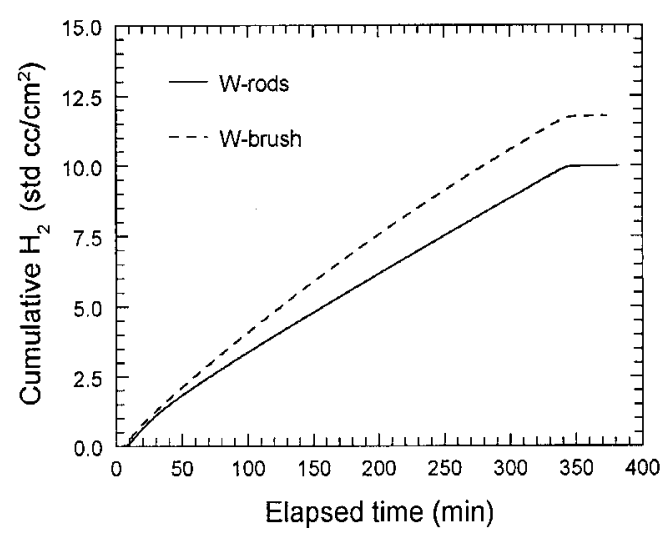

(c)
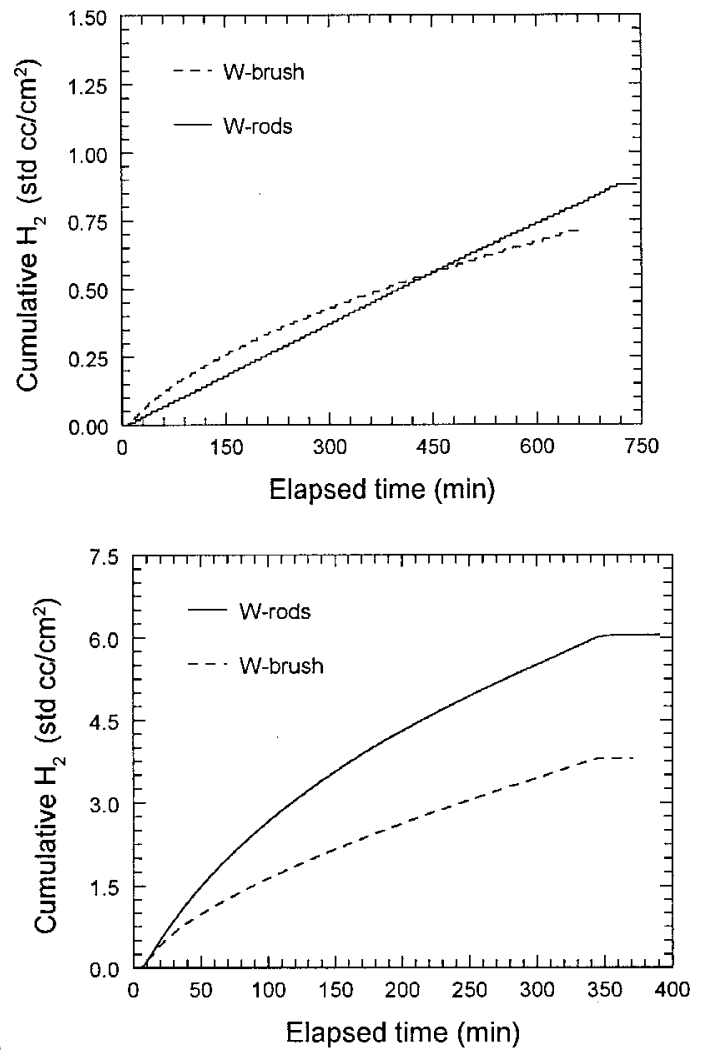

(e)

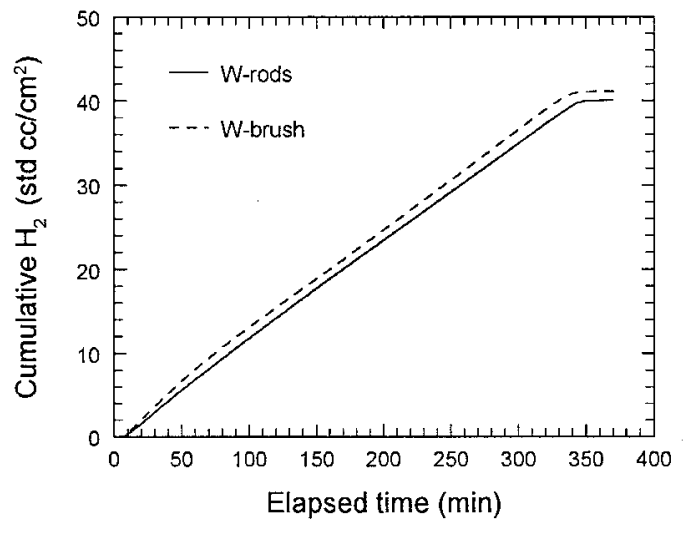

Figure 8. Comparisons of hydrogen generation from tungsten brush and tungsten rods at various temperatures. (a) $500^{\circ} \mathrm{C}$, (b) $600^{\circ} \mathrm{C}$, (c) $600^{\circ} \mathrm{C}$ with rods annealed at $1200^{\circ} \mathrm{C}$, (d) $700^{\circ} \mathrm{C}$, (e) $800^{\circ} \mathrm{C}$, (f) $900^{\circ} \mathrm{C}$ and (g) $1000^{\circ} \mathrm{C}$. 


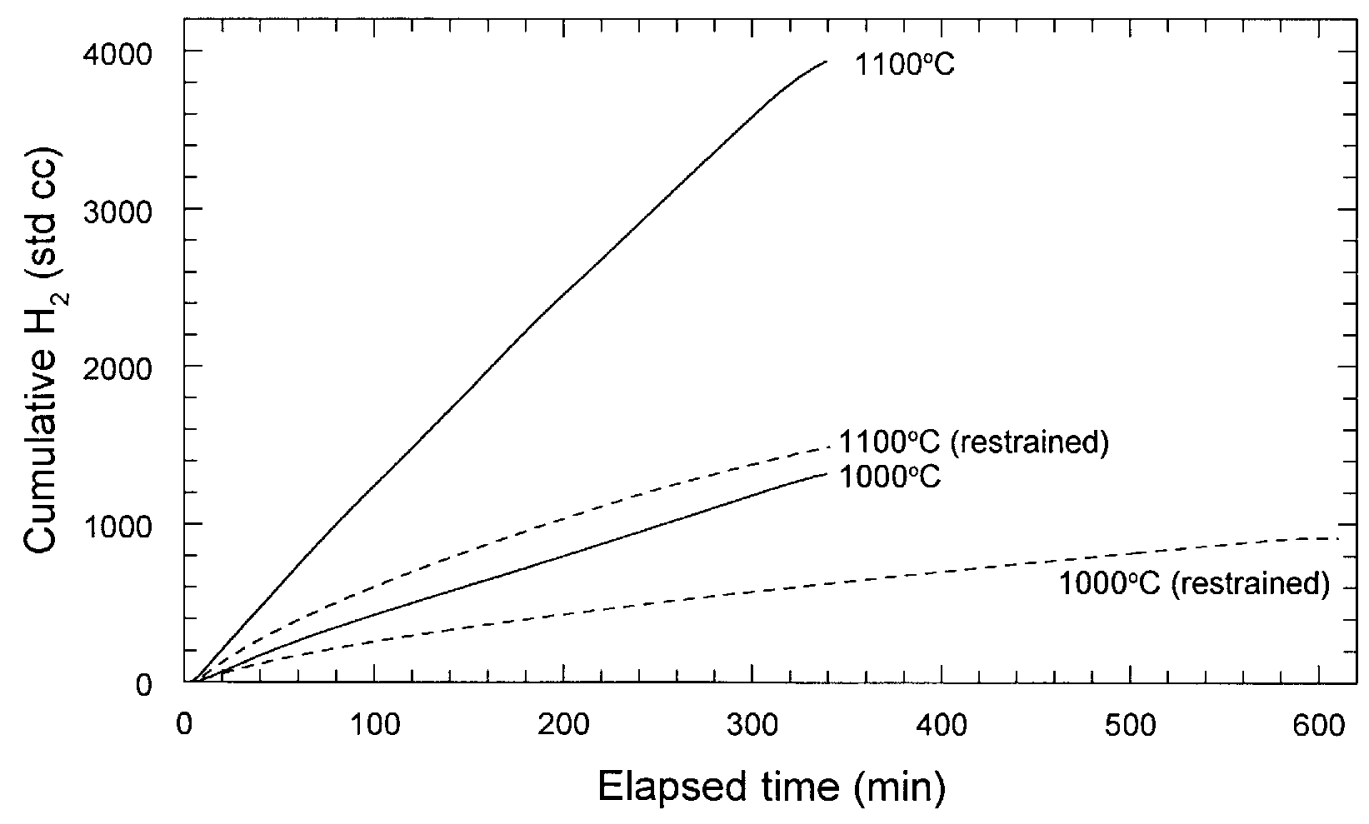

Figure 9. Comparisons of hydrogen generation from brush specimens with and without restraint when exposed to steam at 1000 and $1100^{\circ} \mathrm{C}$.

\subsubsection{Specimen Appearances and Oxide Formation}

We present in this section photographs of the tungsten brush and rod specimens showing various oxidation behavior at different temperatures and configurations.

We have previously mentioned that no visible oxide was formed on the vacuum annealed rods. Other researchers used an oxide color interference method to study the thickness of tungsten oxide films formed in air at temperatures ranging from 200 to $550^{\circ} \mathrm{C}$.[10] The films imparted various colors depending upon the time and temperature of exposure. The minimum film thickness indicated, as provided by a straw or brown color, was about $800 \AA$. When we use our detection limit of 0.0001 gram for oxygen pick-up, the surface area of the rods, and assume the formation of $\mathrm{WO}_{3}$ with a density of $7.16 \mathrm{~g} / \mathrm{cm}^{3}$, we calculate $580 \AA$ as the maximum thickness of oxide that could form during heat treatment. Similar calculations assuming an oxide with a higher oxidation state, such as $\mathrm{WO}_{2}$ with a density of $11.05 \mathrm{~g} / \mathrm{cm}^{3}$, indicate a thickness of $520 \AA$. A thin non-apparent oxide could therefore have possibly formed during annealing without being visually apparent.

The oxidation behavior of refractory metals has been fairly extensively studied particularly in environments with lower oxygen pressures. Oxidation kinetics are related to adsorption processes at these low oxygen activities. Tungsten as a VIIA Series metal reportedly has very low oxygen solubility. Several investigators have reported parabolic oxidation kinetics below $1000^{\circ} \mathrm{C}$ in environments of various oxygen potentials as summarized by Kofstad.[11]. The exact composition and structure of a very thin oxide layer attributed to providing this protection has never been confirmed. $\mathrm{WO}_{2}, \mathrm{~W}_{18} \mathrm{O}_{49}$, and $\mathrm{WO}_{3}$ have been suggested as possible phases. The structural perfection and orientation of an oxide layer rather than composition have even been suggested as critical conditions for providing protection. A porous, nonprotective, layer of $\mathrm{WO}_{3}$ is widely reported to form above this thin layer. We observed similar features in our 1996 study in steam.[5] There was a very porous outer layer that could easily be removed. Beneath this oxide was an adherent bluish-black oxide layer. We obtained indications from x-ray diffraction 
suggesting that the layer could contain $\mathrm{WO}_{2.9}$ or $\mathrm{WO}_{3}$. The effects of stoichiometry upon the color of various tungsten oxides and phases have been reported.[12] Pure $\mathrm{WO}_{3}$ is yellow. Small oxygen deficiencies, e.g., $\mathrm{WO}_{2.98}$ will cause the oxide to appear blue with no noticeable difference in crystal structure. Oxides with lower oxygen contents, e.g., $\mathrm{WO}_{2.4}$ to $\mathrm{WO}_{2.7}$, can even appear to be reddish, violet, or brown in color.

Photographs of rods tested at 500,600 and $700^{\circ} \mathrm{C}$ are shown in Figure 10. All of these rods have a bluishblack character. The rods exposed at $500^{\circ} \mathrm{C}$ have the most distinctive underlying blue oxide. There is some black, loosely adherent, powdery oxide on top. Rods tested at $600^{\circ} \mathrm{C}$ with and without the annealing treatments appeared quite similar. They displayed more of the black, loosely adherent, outer oxide but still show some hint of an underlying blue phase. The rods tested at $700^{\circ} \mathrm{C}$ show even more of the outer black oxide. There are regions where the oxide appears whitish or gray more typical of that expected from an oxide that starts to spall by exfoliation. Some regions near one end of the rods do not have much oxide. Perhaps these regions were located near the edge of the crucible and where shielded from the steam flow.
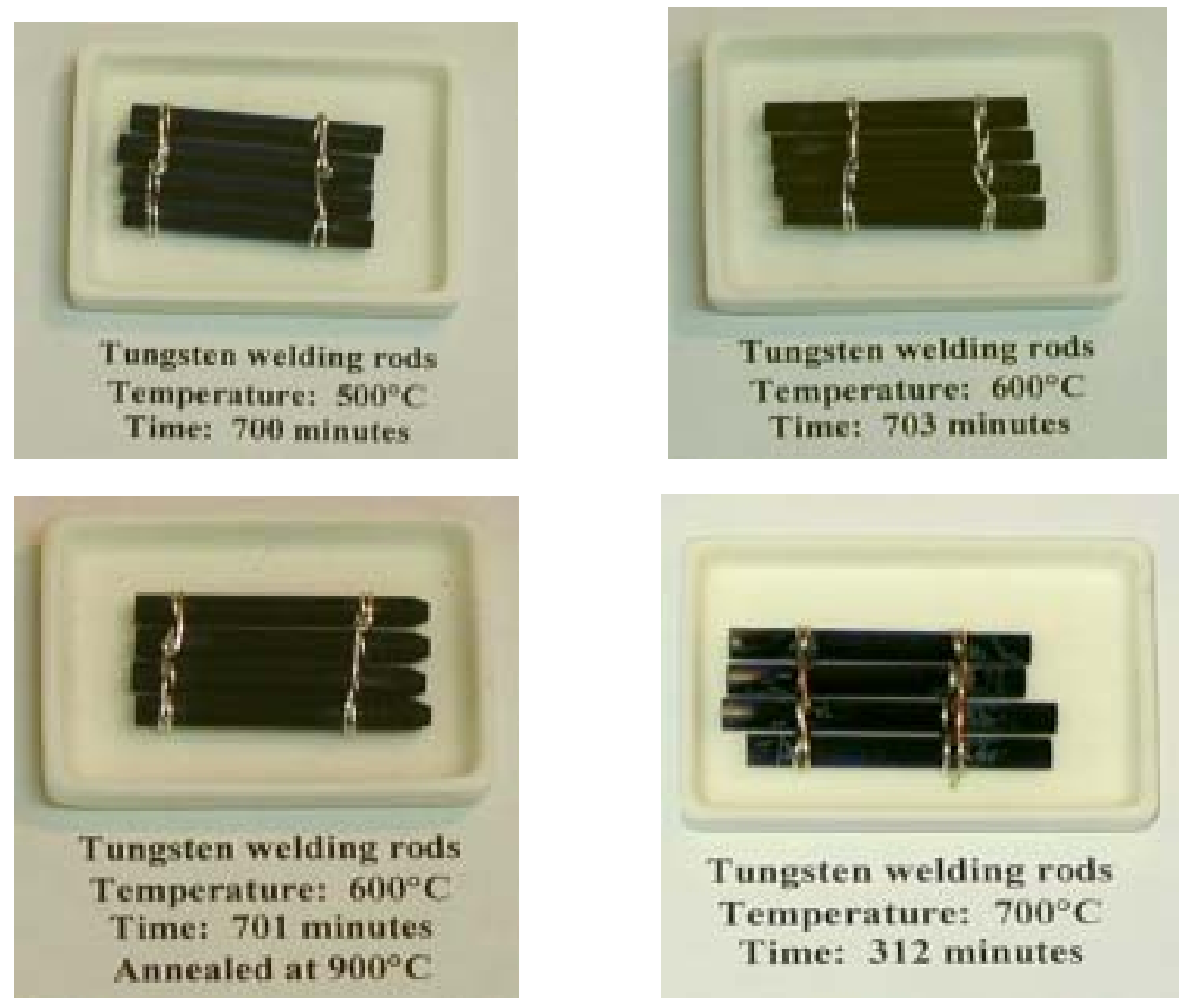

Figure 10. Photographs of tungsten rods tested in steam at 500.600 and $700^{\circ} \mathrm{C}$.

Tungsten rods tested at higher temperatures are shown in Figure 11 . The rods tested at $800^{\circ} \mathrm{C}$ showed a greater amount of whitish oxide compared to the rods tested at $700^{\circ} \mathrm{C}$. The rods exposed at $900^{\circ} \mathrm{C}$ are essentially covered with a white or a grayish-white oxide. The rod tested at $1000^{\circ} \mathrm{C}$ showed more of a black underlying oxide. Oxide particles have spalled from the specimen; however, much of the particulate shown distributed in the crucible could have been dislodged during handling. 

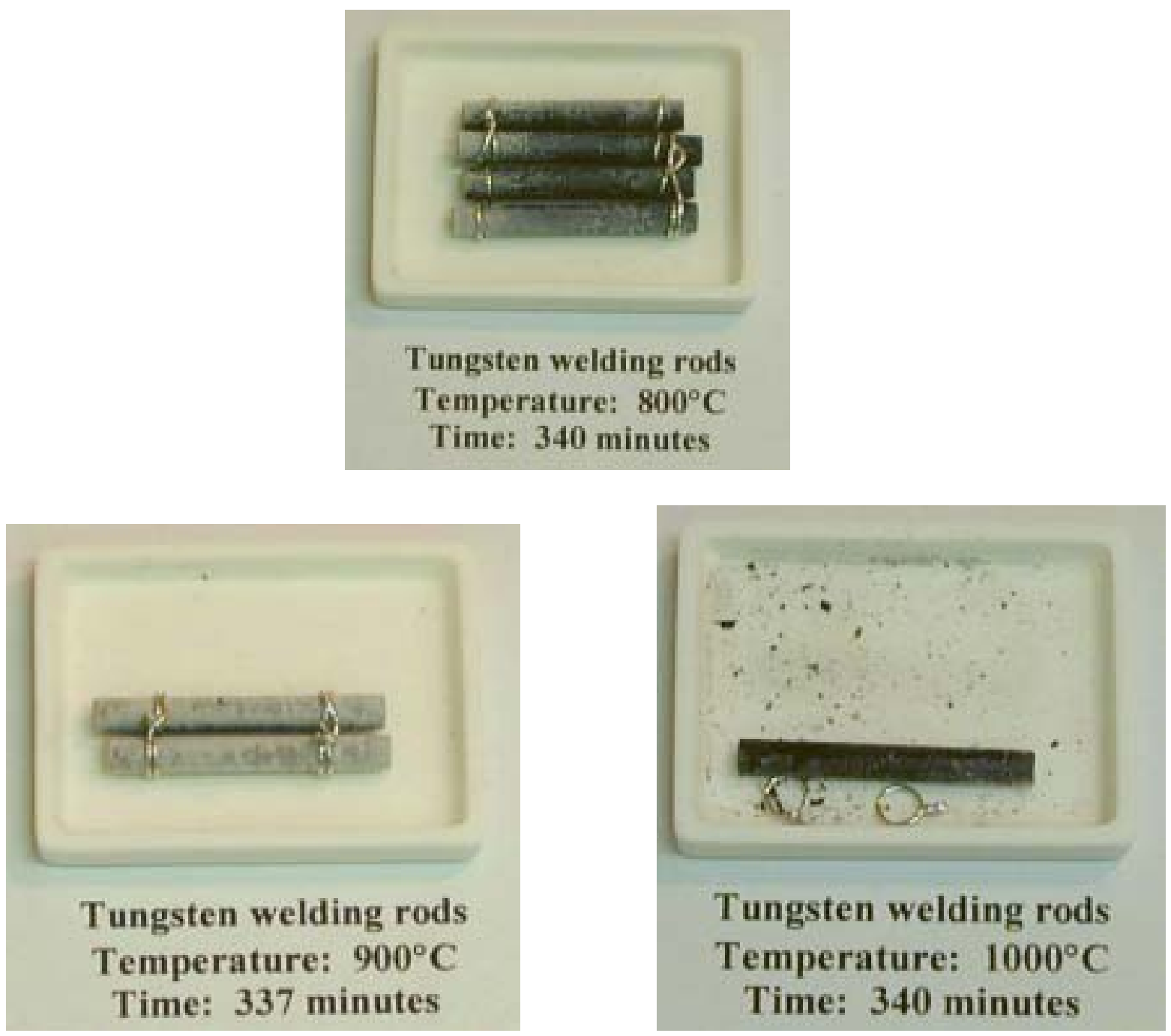

Figure 11. Photographs of tungsten rods tested in steam at 800.900 and $1000^{\circ} \mathrm{C}$.

The tungsten brush specimens tested without the restraining collar formed oxides very similar to those of the tungsten rods. Figure 12 shows brush specimens for some selected temperatures. Brush specimens tested at 500,600 , and $700^{\circ} \mathrm{C}$ all had a bluish-black oxide. The specimen tested for 640 minutes at $600^{\circ} \mathrm{C}$ is shown in Figure 12 . The specimen tested at $800^{\circ} \mathrm{C}$ contained mostly a bluish-black oxide but had some regions containing a whitish oxide. The specimen tested at $900^{\circ} \mathrm{C}$ shown in Figure 12 had a black oxide and substantial areas that had converted to a white or whitish-gray oxide. The specimen tested at $1000^{\circ} \mathrm{C}$ had a black or grayish-black oxide that also contained some lighter phase. Some of the ends of the tungsten rods appeared copper colored. This color indicates that it could be one of the tungsten oxides with lower oxygen content. The high temperature and volatilization rates appear to have removed enough outer oxide revealing the underlying copper colored oxide. The brush specimen tested at $1100^{\circ} \mathrm{C}$ exceeded the melting point of copper of $1083^{\circ} \mathrm{C}$. Molten copper is apparent in the crucible. Some of it was lost over the edge of the crucible. The crucible is also covered with other re-condensed oxidation products. The tungsten rods are generally dark grayish-black with some regions appearing to have a thinner oxide. 

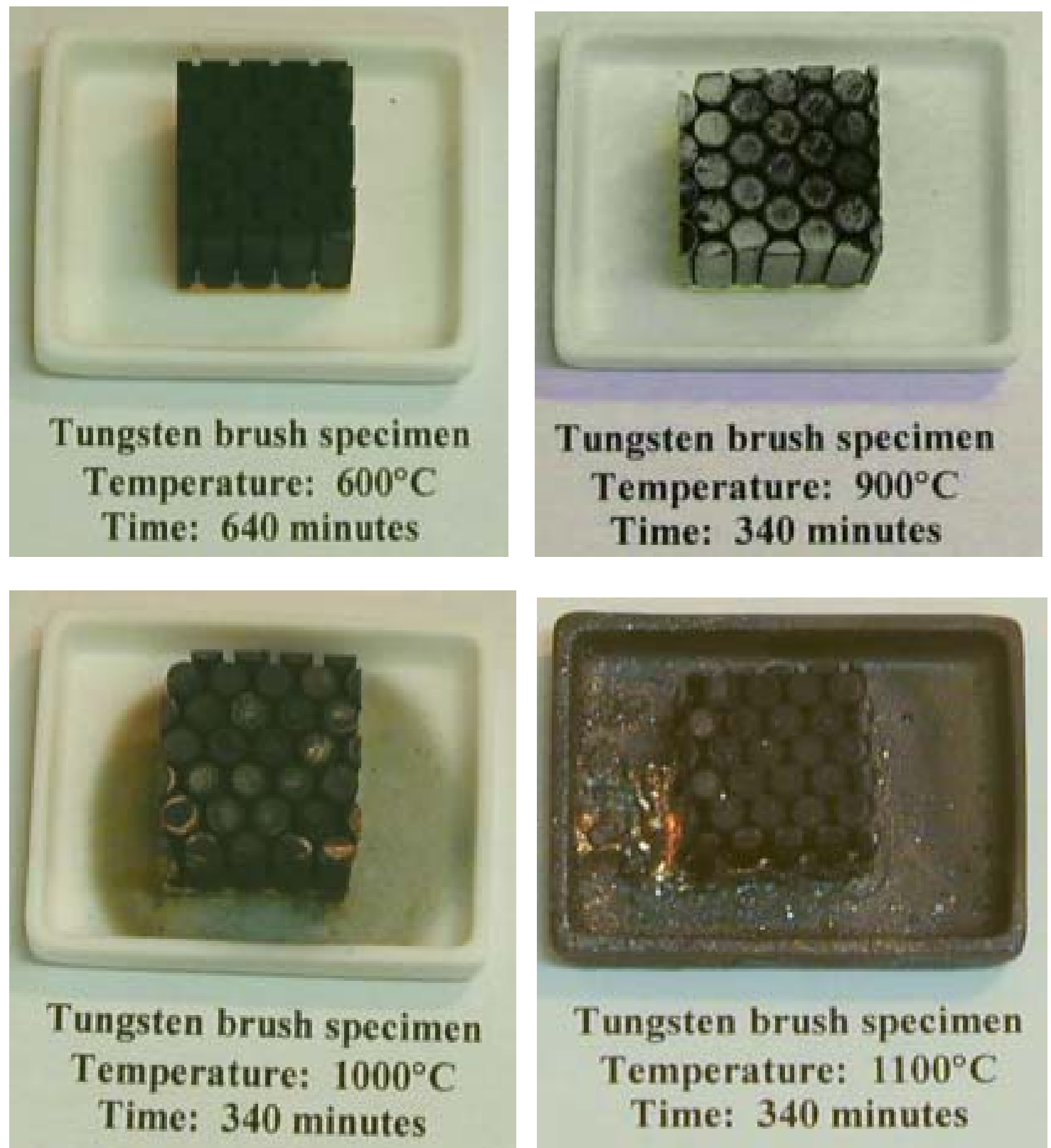

Figure 12. Photographs of the tungsten brush specimens without restraint tested in steam at various temperatures.

Photographs of the restrained tungsten brush specimens tested at 1000 and $1100^{\circ} \mathrm{C}$ are shown in Figure 13. Two views of each specimen are given. A three-dimensional perspective is provided by one view. Top views of the specimens provide a better view into the spaces between the rods and images of oxidation patterns as influenced by flow. The latter two images do not show the true color. The oxides appear too blue. Oxides on the specimens are actually more black, or grayish-black. The copper color on the rods in the upper left photograph is correct since the labels were printed in black rather than blue. Although not really apparent in the photographs, the specimens tested at 1000 and $1100^{\circ} \mathrm{C}$ showed some Inconel honeycomb and oxide by direct viewing. The brush specimen tested at $1100^{\circ} \mathrm{C}$ appeared to have more oxide at the inner locations. This agrees with our calculations in Table 2. 

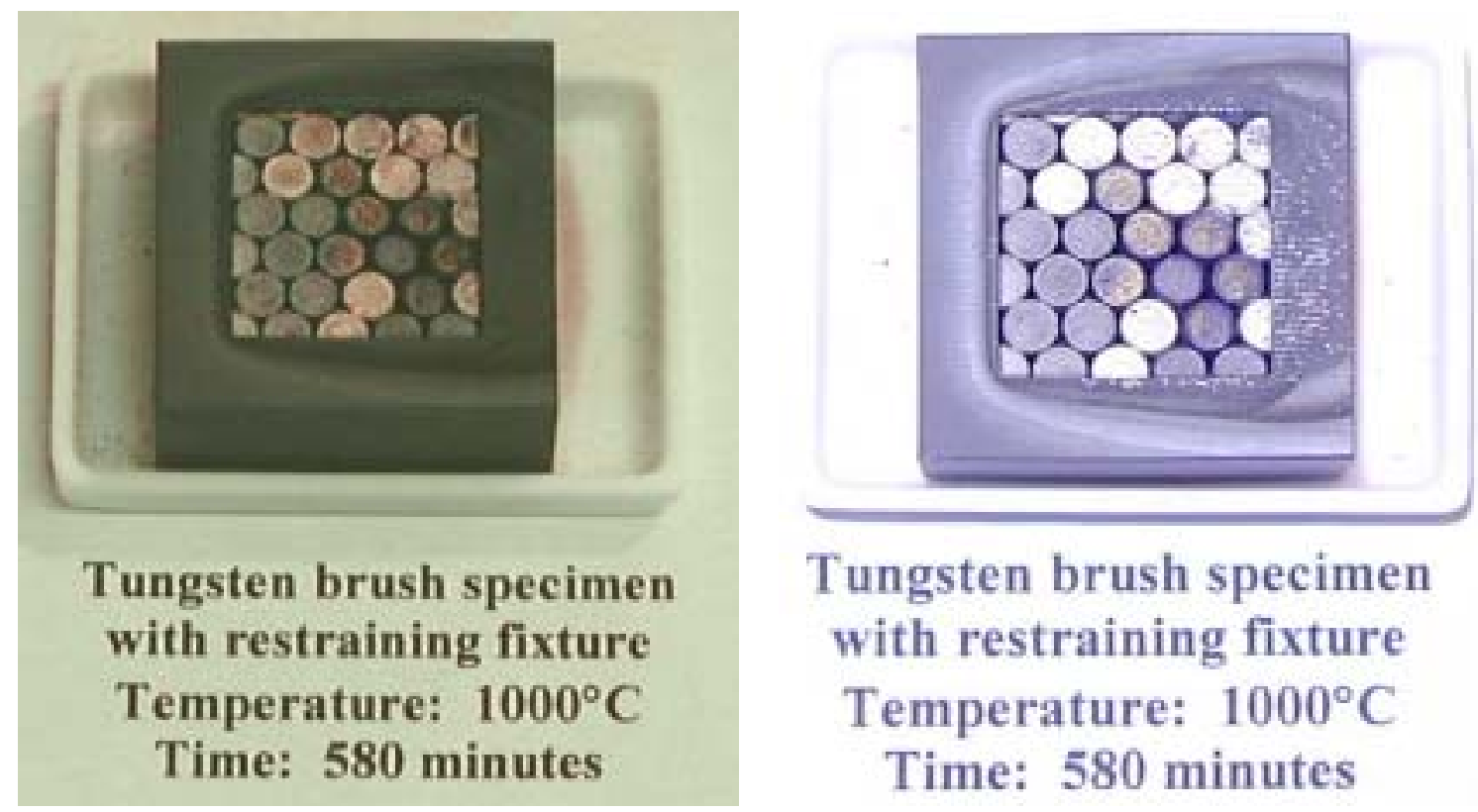

Tungsten brush specimen with restraining fixture Temperature: $1000^{\circ} \mathrm{C}$ Time: $\mathbf{5 8 0}$ minutes
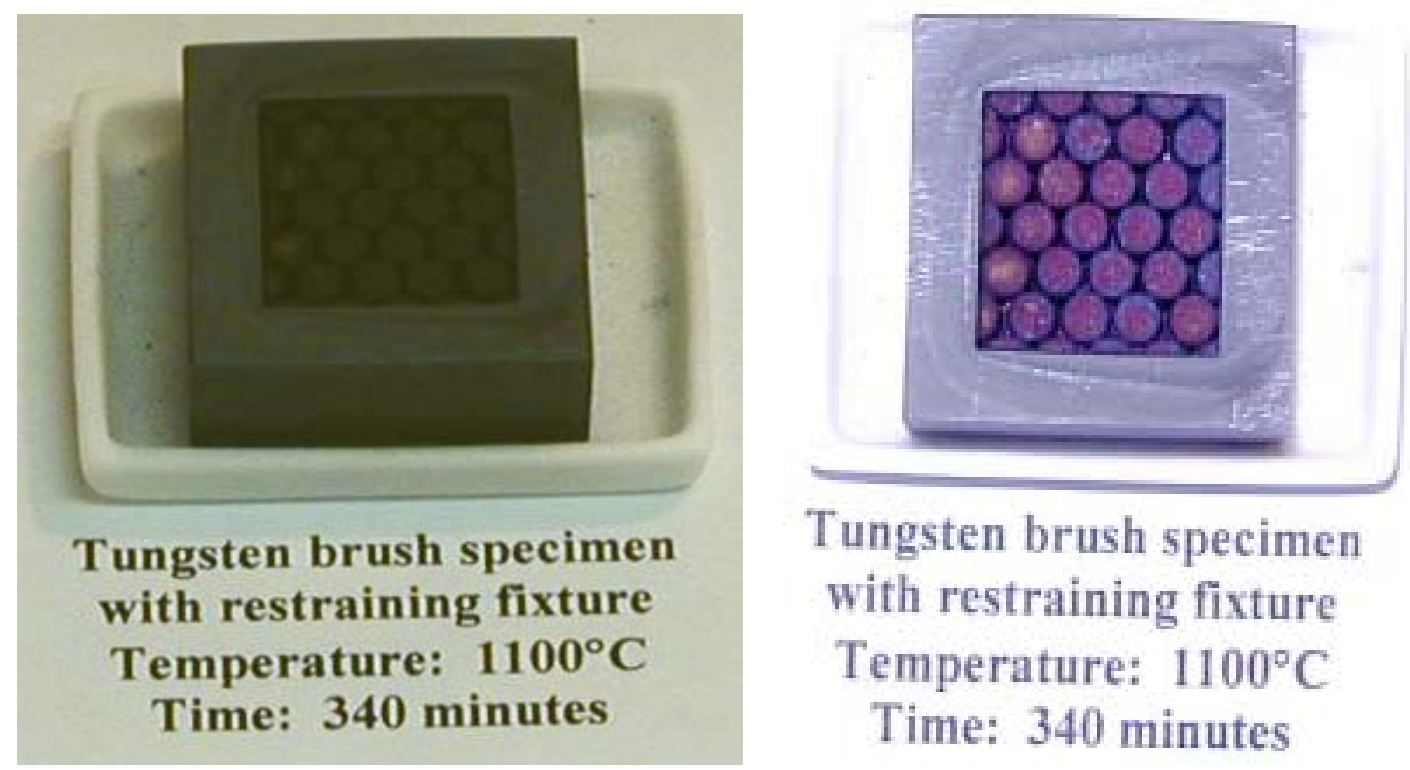

Figure 13. Tungsten brush specimens with restraining fixture tested at 1000 and $1100^{\circ} \mathrm{C}$. 


\section{DISCUSSION}

\subsection{Oxidation Kinetics of Tungsten Brush Specimens}

Cumulative hydrogen generation plots are compared at various temperatures in Figure 14. The parabolic nature is apparent particularly between 600 to $800^{\circ} \mathrm{C}$ in the upper plot. The parabolic behavior for temperatures below $1000^{\circ} \mathrm{C}$ agrees with that reported in the literature and with our previous studies.[5] The more condensed view on the bottom shows that reaction rates can be fairly well represented by linear approximations. This shows that it is reasonable to represent the rates by the linear average reaction method.
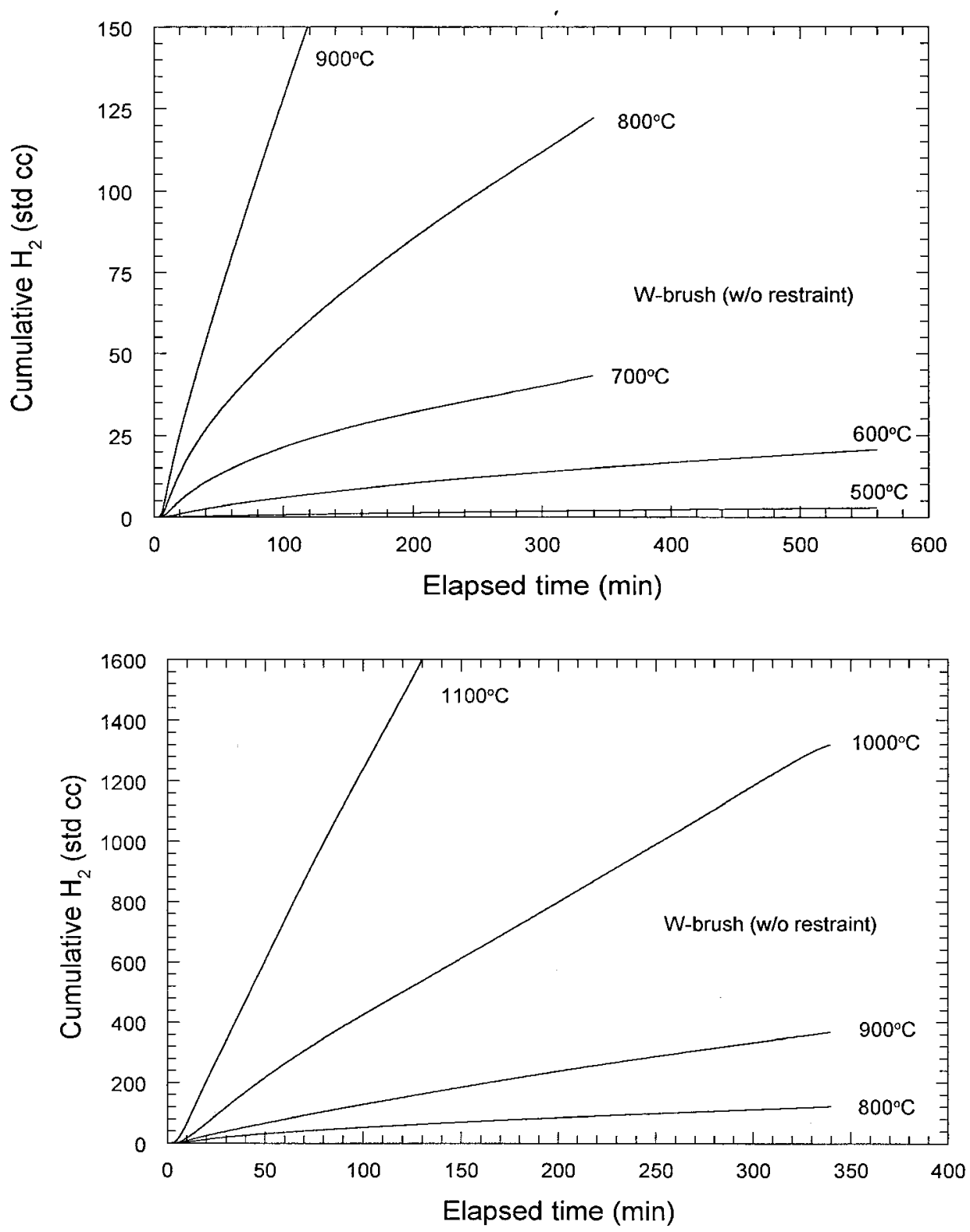

Figure 14. Cumulative hydrogen generation plots from tungsten brush compared at various temperatures. 


\subsection{Comparison of Oxidation Rates with PM Product}

We compare in Figure 15 reaction rates determined for the tungsten brush and tungsten rods from Table 2 with a pressed and sintered powder metallurgy product from our 1996 studies.[5,8] These comparisons are based upon the total area of tungsten exposed to steam. The rods and brush show reaction rates about 5 times higher than the sintered tungsten PM alloy at 500 and $600^{\circ} \mathrm{C}$. This may be due to differences in the pre-existing microstructures. The pressed and sintered pellets contain $95 \mathrm{wt} \%$ tungsten and nickel and iron as other minor alloying elements. The sintering process forms tungsten grains surrounded by an alloy with up to $50 \mathrm{wt} \%$ nickel. This product would not contain any deformation. The microstructure in the welding rods on the other hand is not likely completely recrystallized. Recovery processes have been observed in heavily cold-worked tungsten sheet at lower temperature.[13] Some recovery in electrical resistivity associated with vacancy annealing occurs below $400^{\circ} \mathrm{C}$. Other recovery processes involving dislocation restructuring at cell and grain boundaries were observed by transmission electron microscopy. Cellular networks were eliminated and discrete grain boundaries reported with exposures at $1400^{\circ} \mathrm{C}$. Schmunk and Korth [14] reported that $1480^{\circ} \mathrm{C}$ was needed to recrystallize and reduce the hardness in hotrolled tungsten plate. Tungsten is generally hot worked between 1350 and $1650^{\circ} \mathrm{C}$. The Metals Handbook provides some additional background on the processing of tungsten wire and rods.[15] High purity tungsten powders are often doped with other components such as silicates, or oxides $\left(\mathrm{Al}_{2} \mathrm{O}_{3}, \mathrm{ThO}_{2}\right.$, or $\mathrm{La}_{2} \mathrm{O}_{3}$ ). Dopants generally increase recrystallization temperature whereas surface contaminants such as nickel from tooling or machining can reduce it. An example is given of initial stages of recrystallization developing at $1400^{\circ} \mathrm{C}$ due to surface contaminants. This reference also shows examples of recrystallization beginning at $1900^{\circ} \mathrm{C}$ and complete recrystallization of pure tungsten resulting from exposure at $2700^{\circ} \mathrm{C}$. The data from the Metals Handbook show the temperatures likely used in processing the rods and that they likely contain residual effects from deformation. Since these temperatures are higher than those experienced during fabrication or the rod anneals, the bulk microstructure was not likely changed during the latter activities. Machining could have introduced some surface deformation and roughness. This may have contributed to the higher oxidation rates of the as-received rods and brush at low temperatures. Since the nickel in the sintered product is concentrated in a minor phase occupying only about ten percent of the microstructure it probable did not influence the oxidation process.

Above $700^{\circ} \mathrm{C}$, data for the tungsten rods and the brush without the restraint agree very well with those of the PM sintered product. Surface effects are readily nullified by the higher reaction rates. The good correlation also shows that diffusion of reactant and product gases are not significantly hindered in the small brush specimens without the fixture. The similarity in reactivity of the various tungsten products provides a good crosscheck of the various experimental methods. It suggests that hydrogen generation may be fairly well predicted when gaseous diffusion barriers are not a factor. The reaction rates of tungsten brush with the restraining fixture, however, are two to three times lower at the higher temperatures. 


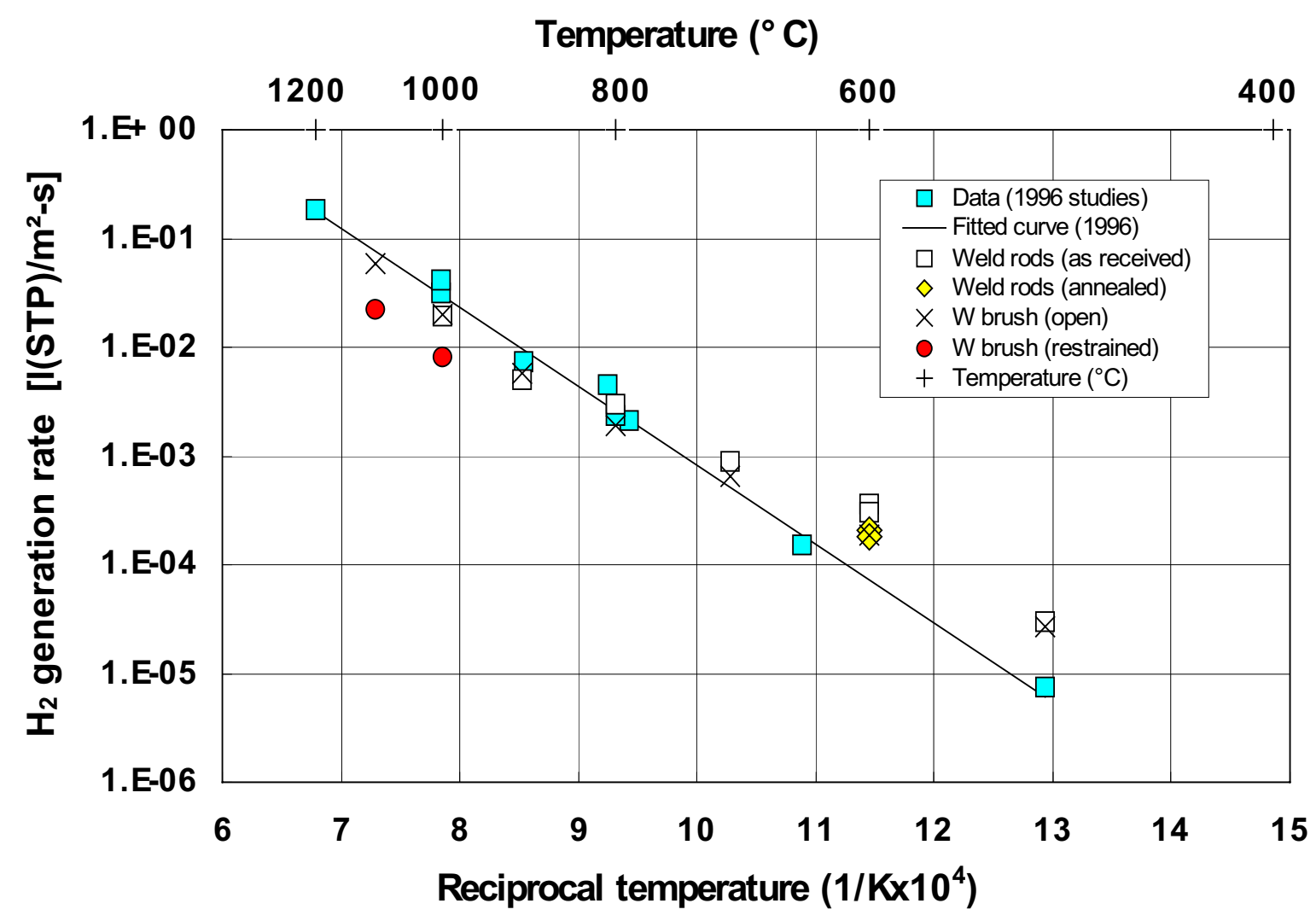

Figure 15. Hydrogen generation from various product forms of tungsten tested in steam.

\subsection{Hydrogen Generation Rates for Engineering Applications}

A comparison of the hydrogen generation rates calculated by the two different methods is shown in Figure 16. The rates based upon total exposed surface area (TSA) of tungsten are basically of scientific interest. They allow comparison with other tungsten products when steam access is not obstructed. The rates for the restrained specimens based upon normal surface area (NSA) are more applicable to engineering applications such as the prediction of hydrogen from larger scaled-up components. Accumulations of oxidation products reduce rates by a factor of 2 to 3 relative to the small coupons without restraint. The magnitude of this reduction would depend upon the geometry of the brush. Brush with higher packing density should provide an additional lowering of the reaction rates relative to those shown for the open brush. The current specimens with the tungsten rods supported in Inconel honeycomb had an 85 percent packing density. Packing densities can reportedly be increased to 91 to 94 percent by using bimodal rod distributions or hot pressing.[1] A higher packing density should provide further reductions in reaction rates compared to those based upon TSA at the higher temperatures. 


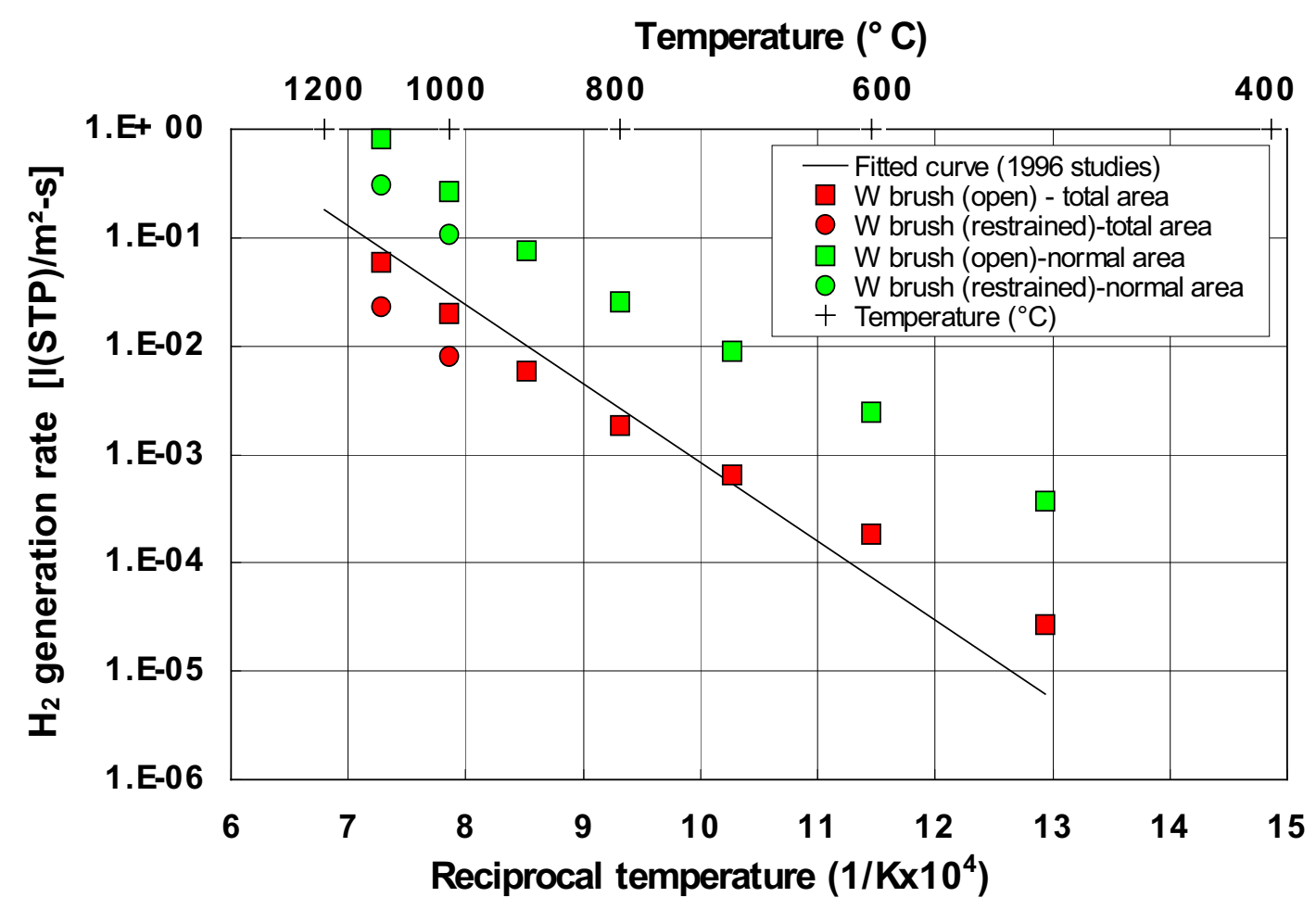

Figure 16. Hydrogen generation rates from tungsten brush in steam based upon total tungsten area and normal unit area.

\subsection{Extent of Oxidation Incurred by Specimens}

Calculations of the percent of tungsten oxidized from the rod and brush specimens were given in Table 2. Oxidation incurred by the specimens is plotted with respect to temperature in Figure 17. The individual rods and the tungsten brush without restraint show a very similar trend up to $1000^{\circ} \mathrm{C}$. Oxidation of the brush then increased by a factor of three with exposure at $1100^{\circ} \mathrm{C}$. None of the individual rods were tested at this temperature. Oxidation of the brush specimens with the restraining fixtures remained low at 1000 and $1100^{\circ} \mathrm{C}$. The value at $1100^{\circ} \mathrm{C}$ was about one-third that of the nonrestrained specimen. These trends follow those for the hydrogen generation rate data shown in Figure.15. The calculations for the amounts of tungsten oxidized as listed in Table 2 were based upon the assumption of oxidation proceeding to tungsten trioxide, $\mathrm{WO}_{3}$. The dark grayish-black, or bluish color of the oxide on the specimens indicates that the oxide could be substoichiometric, e.g., $\mathrm{WO}_{2.98}$ to $\mathrm{WO}_{2.9}$. We checked the calculations in Table 2 by assuming oxidation to $\mathrm{WO}_{2.9}$ and found that neither the quantities of tungsten oxidized or the amounts volatilized as discussed later in Section 4.5 were significantly affected. 


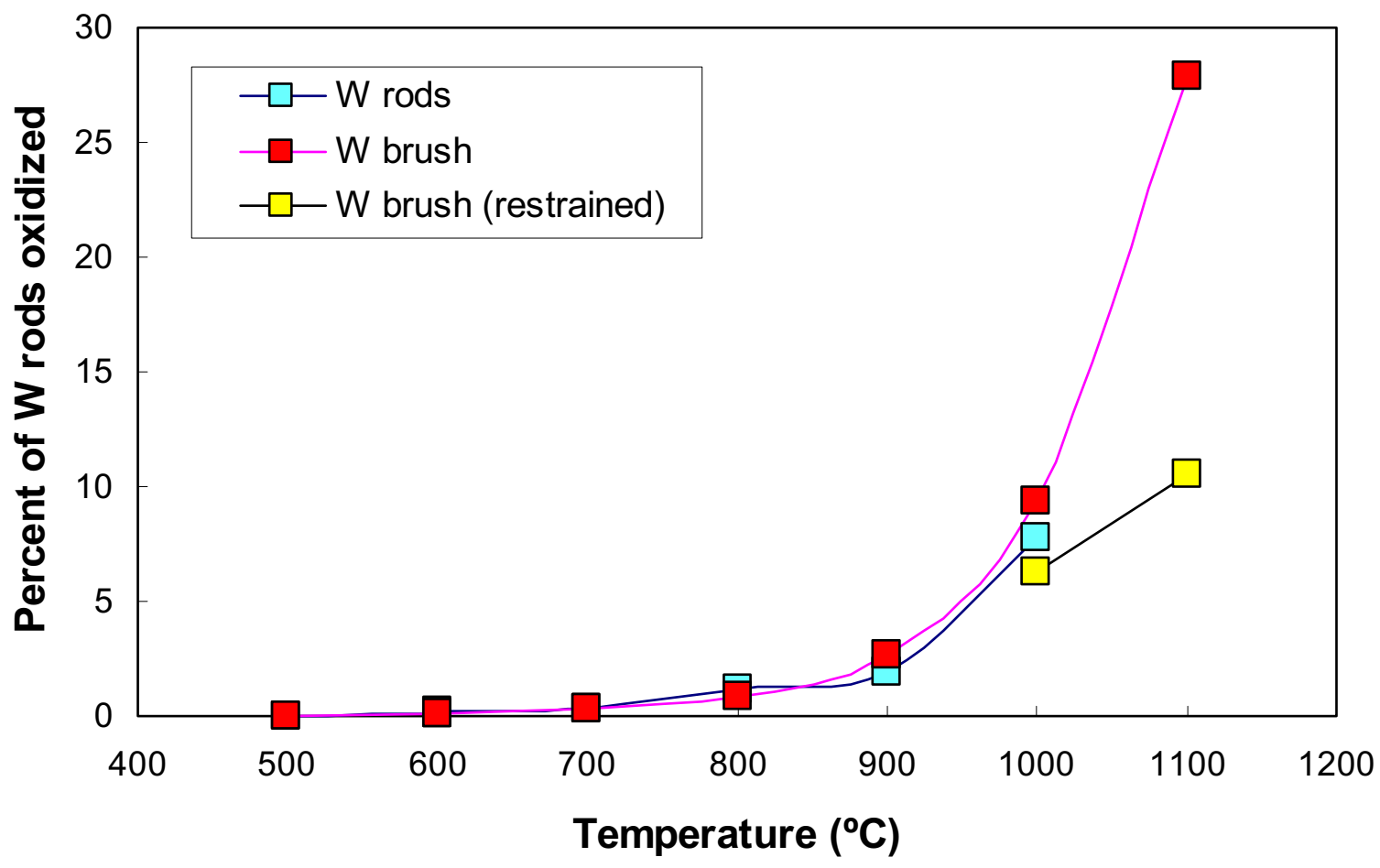

Figure 17. Percent of tungsten oxidized in tungsten rods and tungsten brush specimens.

\subsection{Volatilization from Various Products and Configurations}

Relative amounts of oxide volatilized from the various types of specimens are shown plotted with respect to temperature in Figure 18. Below $600^{\circ} \mathrm{C}$ several tests showed a meaningless condition of negative volatilization. Measurements of mass change from these tests likewise indicated higher hydrogen generation than that measured by QMS. This suggests that either some extra weight gain had occurred or that the cumulative value from the QMS was low. Either conditions would result in Equation (8) indicating too low of a volatilization loss. The ceramic crucible could possibly have adsorbed some moisture, or the background to signal ratios are such at low temperatures that the QMS results could be low. The volatilization calculations appear to become more credible at $700^{\circ} \mathrm{C}$. The fraction of oxide volatilized from the individual rods is only slightly higher than the fraction from the open brush at 700 and $800^{\circ} \mathrm{C}$. Volatilization from the individual rods then increased substantially relative to the brush specimen without restraint at 900 and $1000^{\circ} \mathrm{C}$. About 90 percent of the oxide volatilized from the rods at $1000^{\circ} \mathrm{C}$. The brush specimen without restraint lost only 35 percent of its oxide. The brush specimens with restraint lost even less of their oxide about 25 to 30 percent at 1000 and $1100^{\circ} \mathrm{C}$. We were not able to obtain a mass change for the brush specimen tested at $1100^{\circ} \mathrm{C}$ without restraint. Some of the molten copper was lost from the crucible. However, we expect that from the trends in Figure 18, the volatilization loss would be more similar to that of the restrained brush rather than the individual rods. 


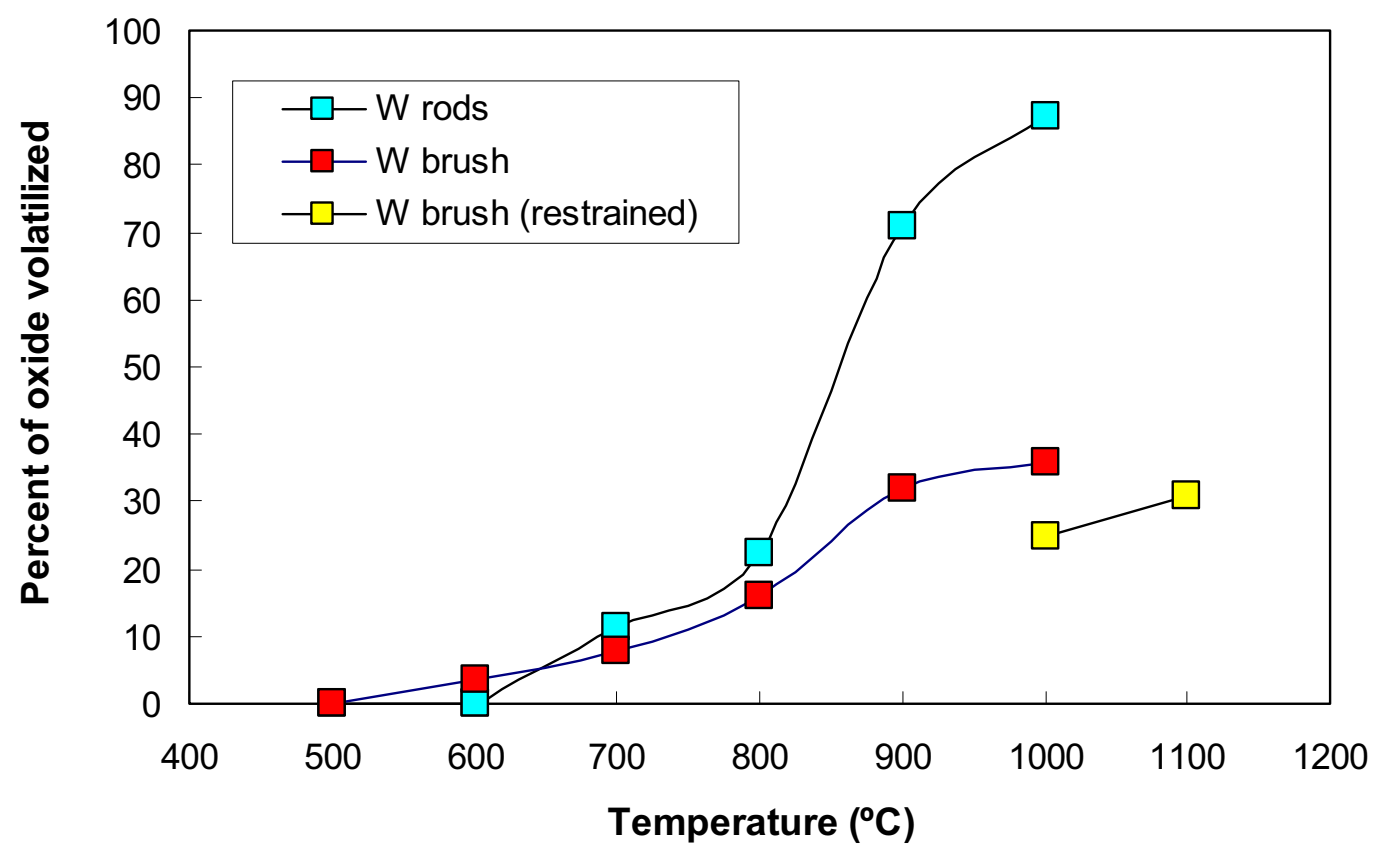

Figure 18. Relative amount of tungsten oxide volatilized from tungsten rod and brush specimens.

\subsection{Comparison of Volatilization with Previous CMFPs}

We obtained volatilization rates from the calculated amounts of tungsten volatilized shown in Table 2 . These rates are shown in Table 3. In Figure 19 we compare the mass flux of tungsten $\left(\mathrm{g} / \mathrm{m}^{2}-\mathrm{hr}\right)$ from the rod and brush specimens with a cumulative maximum flux plot (CMFP) that we have obtained from previous studies.[6,7] Mass flux values from the tungsten rods agree very well the CMFP. The mass flux values from the brush specimens based upon the total exposed surface area (TSA) of tungsten are somewhat below the CMFP. Figure 20 compares the CMFP with mass flux data from the brush specimens based upon normal surface area (NSA). The data for the brush without restraint lie above the CMFP. The data for the brush specimens with restraint are very close to that of the CMFP at 1000 and $1100^{\circ} \mathrm{C}$. In fact, with the potential that volatilization could be further reduced using brush with higher packing density, it appears possible that the mass flux from brush could approach that of a flat surface. This is an important finding since the mobilization of activation products is the primary safety issue with the use of tungsten-base components in fusion applications. 
Table 3. Mass flux calculations for tungsten from rod and brush specimens.

\begin{tabular}{|c|c|c|c|c|c|c|c|c|}
\hline $\begin{array}{l}\text { Test } \\
\text { I.D. }\end{array}$ & $\begin{array}{l}\text { Type of } \\
\text { product }\end{array}$ & $\begin{array}{c}\text { Temp. } \\
{ }^{\circ} \mathrm{C}\end{array}$ & $\begin{array}{l}\text { Time } \\
\text { (min.) }\end{array}$ & $\begin{array}{c}\text { Total } \\
\text { surface } \\
\text { area } \\
\left(\mathrm{cm}^{2}\right) \\
\end{array}$ & $\begin{array}{c}\text { Normal } \\
\text { surface } \\
\text { area } \\
\left(\mathrm{cm}^{2}\right) \\
\end{array}$ & $\begin{array}{l}\text { Calculated } \\
\text { grams of } \\
\text { tungsten } \\
\text { volatilized }\end{array}$ & $\begin{array}{l}\text { Mass flux } \\
\text { based upon } \\
\text { total area } \\
\left(\mathrm{g} / \mathrm{m}^{2}-\mathrm{hr}\right)\end{array}$ & $\begin{array}{c}\text { Mass flux } \\
\text { based upon } \\
\text { normal area } \\
\left(\mathrm{g} / \mathrm{m}^{2}-\mathrm{hr}\right)\end{array}$ \\
\hline WB-7 & brush & 500 & 640 & 32.936 & 2.391 & -0.00032 & n.d. & n.d. \\
\hline WB-4 & brush & 600 & 640 & 32.294 & 2.457 & 0.00229 & $6.64 \mathrm{E}-2$ & $8.73 \mathrm{E}-1$ \\
\hline WB-6 & brush & 700 & 340 & 33.329 & 2.450 & 0.00959 & $5.08 \mathrm{E}-1$ & $6.90 \mathrm{E}+0$ \\
\hline WB-1 & brush & 800 & 340 & 32.460 & 2.419 & 0.05434 & $2.95 \mathrm{E}+0$ & $3.96 \mathrm{E}+1$ \\
\hline WB-2 & brush & 900 & 340 & 31.559 & 2.427 & 0.32335 & $1.81 \mathrm{E}+1$ & $2.35 \mathrm{E}+2$ \\
\hline WB-3 & brush & 1000 & 340 & 32.325 & 2.426 & 1.29717 & $7.08 \mathrm{E}+1$ & $9.44 \mathrm{E}+2$ \\
\hline WB-5 & $\begin{array}{c}\text { restrained } \\
\text { brush }\end{array}$ & 1000 & 580 & 32.735 & 2.492 & 0.6159 & $1.95 \mathrm{E}+1$ & $2.56 \mathrm{E}+2$ \\
\hline WB-8 & brush & 1100 & 340 & 32.832 & 2.425 & n.d. & n.d. & n.d. \\
\hline WB-7b & $\begin{array}{c}\text { restrained } \\
\text { brush }\end{array}$ & 1100 & 340 & 32.936 & 2.391 & 1.26870 & $6.82 \mathrm{E}+1$ & $9.23 \mathrm{E}+2$ \\
\hline WR-1 & (4) rods & 500 & 700 & 10.8572 & ---- & -0.00019 & n.d. & ---- \\
\hline WR-2 & (4) rods & 600 & 340 & 11.0911 & ---- & -0.00045 & n.d. & ---- \\
\hline WR-3 & (4) rods & 600 & 703 & 10.6981 & ---- & 0.00000 & n.d. & ---- \\
\hline WR-4 & (4) rods & $600(a)$ & 701 & 11.6994 & ---- & 0.00037 & $2.74 \mathrm{E}-2$ & ---- \\
\hline WR-5 & (3) rods & $600(b)$ & 575 & 8.0533 & ---- & -0.00011 & n.d. & ---- \\
\hline WR-6 & (4) rods & 700 & 312 & 10.9759 & ---- & 0.00554 & $9.71 \mathrm{E}-1$ & ---- \\
\hline WR-7 & (4) rods & 800 & 340 & 10.3106 & ---- & 0.03820 & $6.54 \mathrm{E}+0$ & ---- \\
\hline WR-8 & (2) rods & 900 & 337 & 5.3455 & ---- & 0.10386 & $3.46 \mathrm{E}+1$ & ---- \\
\hline WR-9 & (1) rods & 1000 & 340 & 2.6734 & ---- & 0.25624 & $1.69 \mathrm{E}+2$ & ---- \\
\hline \multicolumn{9}{|c|}{ Cumulative maximum flux values from previous investigations } \\
\hline & & & & & & & & \\
\hline & & 500 & & & & & $4.58 \mathrm{E}-3$ & ---- \\
\hline & & 600 & & & & & $9.45 \mathrm{E}-2$ & ---- \\
\hline & & 800 & & & & & $1.31 \mathrm{E}+1$ & ---- \\
\hline & & 900 & & & & & $3.00 \mathrm{E}+1$ & ---- \\
\hline & & 1000 & & & & & $1.75 \mathrm{E}+2$ & ---- \\
\hline & & 1100 & & & & & $6.55 \mathrm{E}+2$ & ---- \\
\hline & & 1140 & & & & & $1.48 \mathrm{E}+3$ & ---- \\
\hline & & 1200 & & & & & $3.23 \mathrm{E}+3$ & ---- \\
\hline
\end{tabular}

(a) annealed at $900^{\circ} \mathrm{C}$ for one hour prior to testing. (b) annealed at $1200^{\circ} \mathrm{C}$ for one hour prior to testing. 


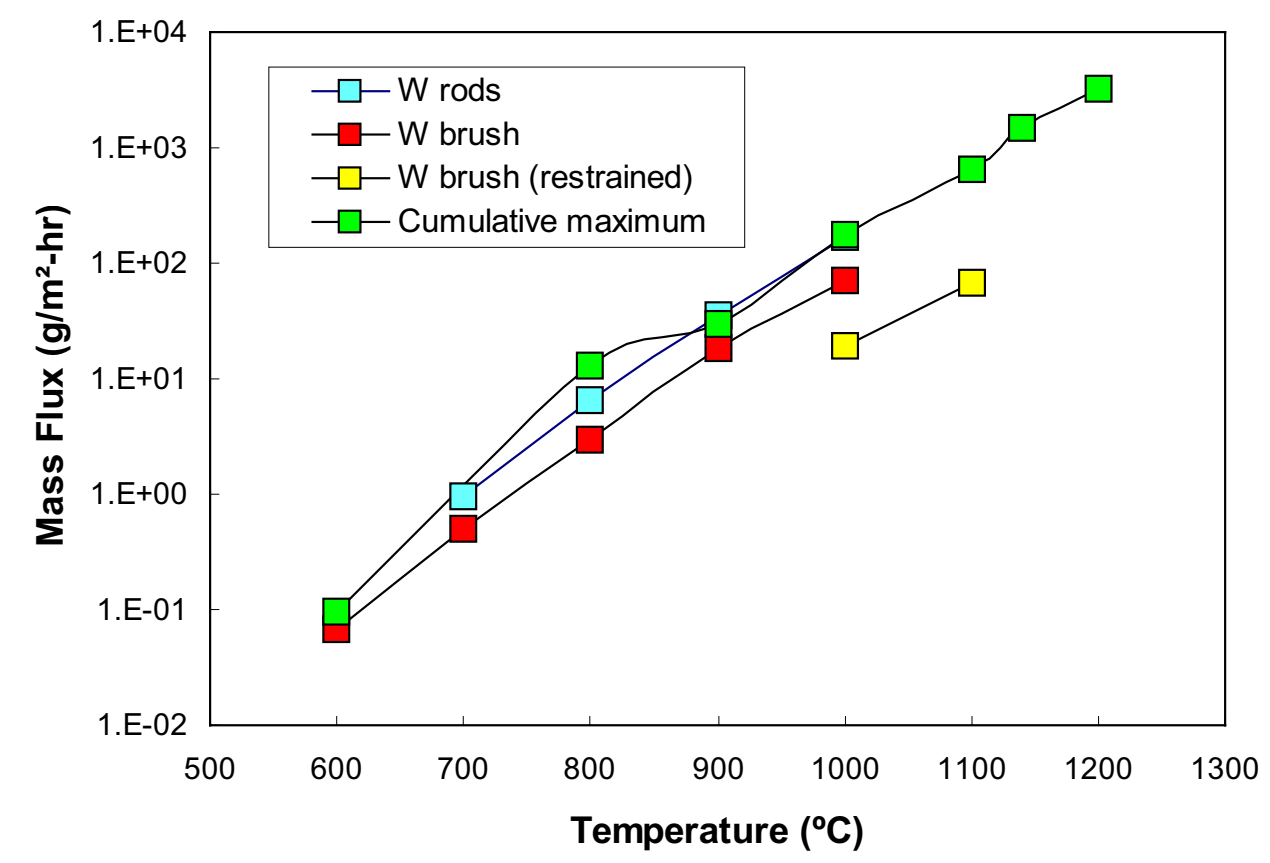

Figure 19. Mass flux of tungsten from various products based upon the total exposed surface area (TSA) of tungsten compared with the cumulative maximum flux plot.

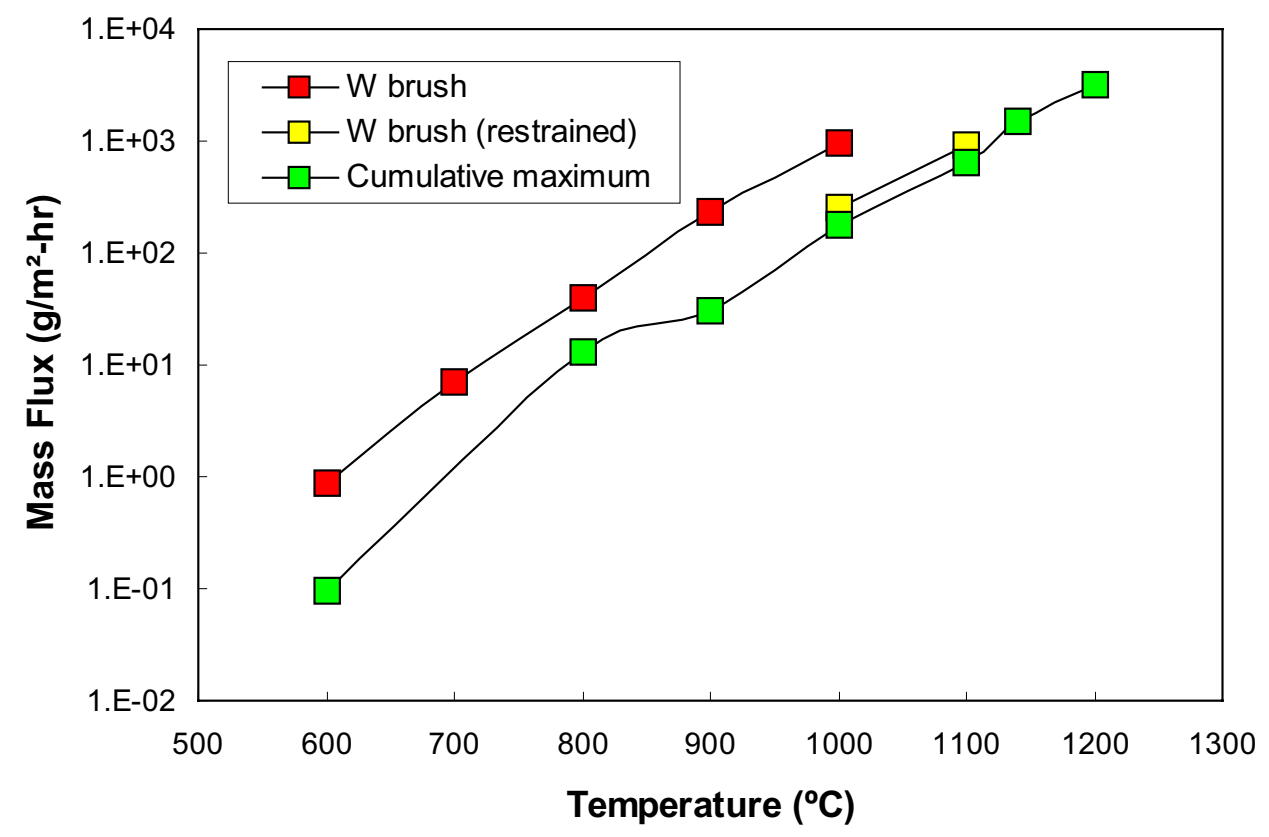

Figure 20. Mass flux of tungsten from brush specimens based upon normal surface area (NSA) compared with the cumulative maximum flux plot from previous investigations. 


\section{CONCLUSIONS}

The steam oxidation rates of the tungsten welding rods and tungsten brush, based upon the total exposed surface area (TSA) of tungsten, show good agreement with those from our previously investigation of a pressed and sintered product. Minor differences at the lowest temperatures of 500 and $600^{\circ} \mathrm{C}$ may be due to preexisting microstructures, e.g., full recrystallization versus residual or machining induced surface deformation, small alloy elements such as nickel, or differences in surface roughness. The data merge quite well at $700^{\circ} \mathrm{C}$. The oxidation rates of the individual welding rods and the brush specimens without restraint are nearly identical at all temperatures. This shows that the diffusion of steam into the void spaces of the finite size brush specimens were not significantly different than that for the rods. Surrounding the brush specimens with a fixture to more closely represent a unit cell within larger matrix of a heat flux component reduced the TSA oxidation rates at the high temperatures of 1000 and $1100^{\circ} \mathrm{C}$ by about a factor of three. This shows that the ingress of steam was likely influenced by the accumulation of hydrogen and oxidation products within the void spaces. Hydrogen generation rates based on normal surface area (NSA) remain higher than those obtained using total surface area (TSA). Potentially, the differences between these two types of rates could be further reduced by brush having higher packing density or a lower total surface area to normal surface area ratio.

More importantly from an activation product standpoint, the volatilization of tungsten oxide species are significantly reduced by the brush configuration relative to that predicted from previously determined mass flux values and total surface area (TSA). The volatilization process is apparently lower due to the stagnant conditions existing within the void spaces of the brush. The mass flux rates from the brush based upon total surface area lie below our historic cumulative maximum flux plot (CMFP) for tungsten. When based upon normal surface area (NSA) the rates from the brush specimens without restraint are about 5 times higher than the CMFP. Volatilization from restrained brush specimens at 1000 and $1100^{\circ} \mathrm{C}$, however, are only about 50 percent higher than the CMFP. Volatilization rates from brush with higher packing density could potentially be further reduced such that it would approach those from a flat surface. 


\section{REFERENCES}

1 Watson, R. D., et al., 1998, "Development of High-Z Plasma Facing Components for ITER," Fusion Technology, Vol. 34, pp.443-453.

2. Nygren, R. E., D. L. Youchison, D., R. D. Watson, and S. O’Dell, September 19-24, 1999, "High Heat Flux Tests on Heat Sinks Armored with Tungsten Rods," $5^{\text {th }}$ Symposium on Fusion Nuclear Technology. Rome, Italy.

3 O’Dell, J. S. and T. N. McKechnie, September 15-17, 1999, "Beryllium and Tungsten Brush Armor for High Heat Flux Applications," Fourth International Workshop on Beryllium Technology for Fusion, Karlsruhe, Germany.

4. Smolik, G. R., March 1992, Tungsten Alloy Oxidation Behavior in Air and Steam, EGG-FSP-10166.

5. Smolik, G. R., K. A. McCarthy, D. A. Petti, and K. Coates, 1998, "Hydrogen Generation from Steam Reaction with Tungsten," J. Nuclear Materials, Vol. 258-263, pp. 1979-1984.

6. Smolik, G. R, and K. Coates, November 1996, Mobilization from Oxidation of a Tungsten Alloy in Steam, EDF Report No: ITER/US/96/TE/SA-21.

7 Petti, D. A., G. R. Smolik and K. A. McCarthy, September 9-11, 1999, "Tungsten Mobilization During Steam Exposure Between 400 and $1200^{\circ} \mathrm{C}$," $20^{\text {th }}$ Symposium on Fusion Technology, Marseille, France.

8. Anderl, R. A., October 17, 1996, Performance and Scoping Test Results for Steam-Metal Chemical Reactivity System, EDF Report No.: ITER/US/96/TE/SA-17.

9. Anderl, R. A., et al., 1996, "System for Steam-Reactivity Measurements on Fusion-Relevant Materials," Fusion Technology, Vol. 30, pp.1435-1441.

10 Barth, V. D., and G. W. P. Rengstorff, July 1961, Oxidation of Tungsten, DMIC Report 155, Defense Metals Information Center-Battelle Memorial Institute, pp. 32-35.

11 Kofstad, P., 1966, High Temperature Oxidation of Metals, John Wiley \& Sons, Inc., New York, NY, pp. 251-263.

12 Barth and Rengstorff, ibid., pp. 14-18.

13 Trybus, C. L., C. H. Sellars, and R. A. Anderl, February 1991,"Substructure and Electrical Resistivity Analyses of Pure Tungsten Sheet," Proceedings of the TMS Symposium: Tungsten and Tungsten Alloys Recent Advances, Editors I. Ahamed, et al., TMS Publications

14. Schmunk, R. E, and G. E. Korth, 1981, "Tensil and Low-Cycle Fatigue Measurements on CrossRolled Tungsten," J. Nuclear Mat., Vol. 103-104, pp. 943-948.

15 American Society for Metals, 1972, Metals Handbook: Volume 7-Atlas of Microstructures of Industrial Alloys, (8 ${ }^{\text {th }}$ Edition), pp.197-198. 


\section{APPENDIX A}

\section{Plots of Hydrogen Generation Rates and}

$$
\text { Cumulative Hydrogen Determined from }
$$

Quadrupole Mass Spectrometer Measurements 

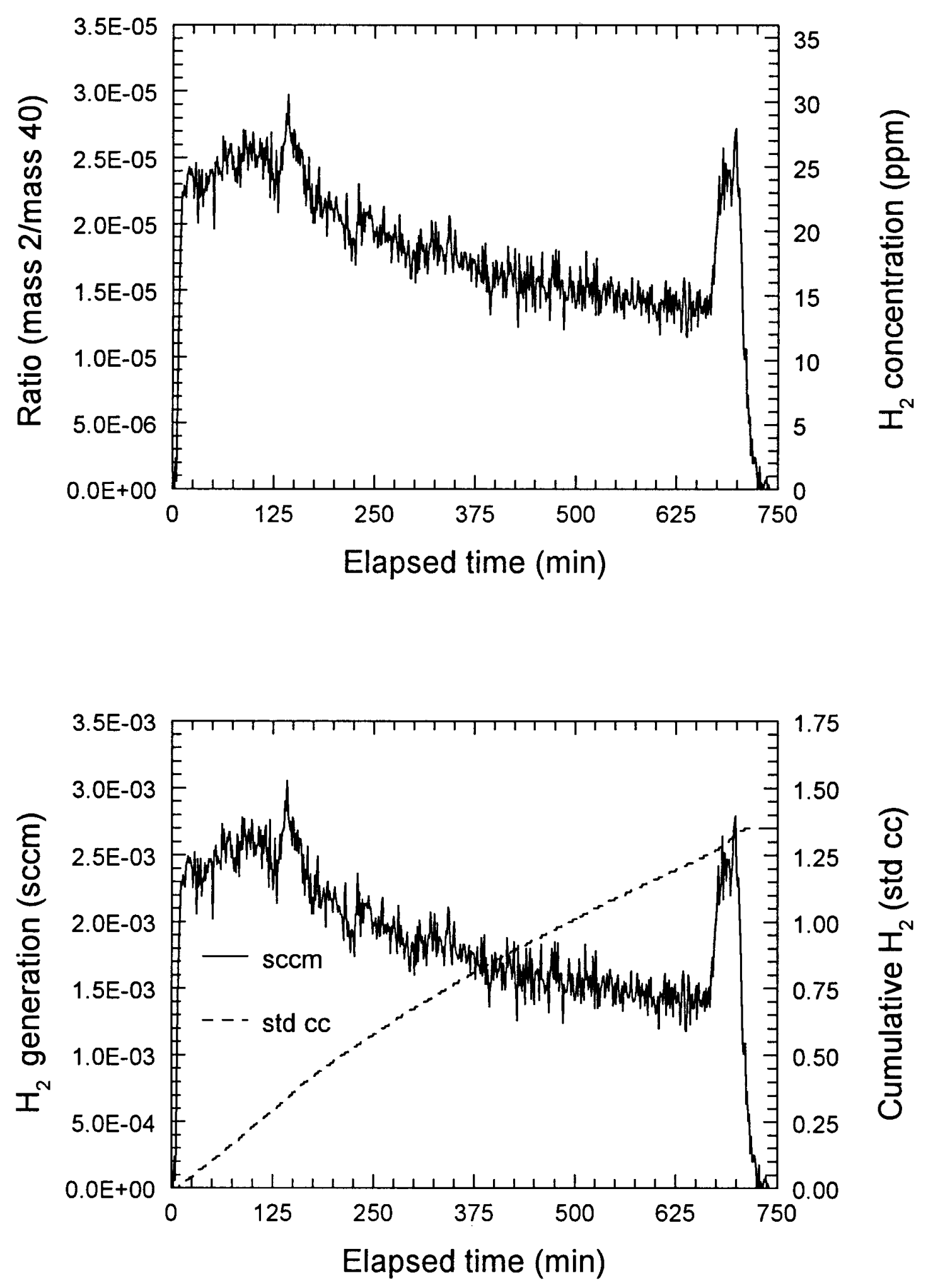

Figure A1. Results of mass-spectrometer analyses for hydrogen generation for tungsten welding rods (Test WR-1) exposed 700 minutes in $500^{\circ} \mathrm{C}$ steam. Top --mass $2 /$ mass 40 ratio (left axis) and $\mathrm{H}_{2}$ concentration (ppm, right axis). Bottom plots $-\mathrm{H}_{2}$ generation rate ( $\mathrm{sccm}$, left axis) and cumulative $\mathrm{H}_{2}$ (std cc, right axis). 

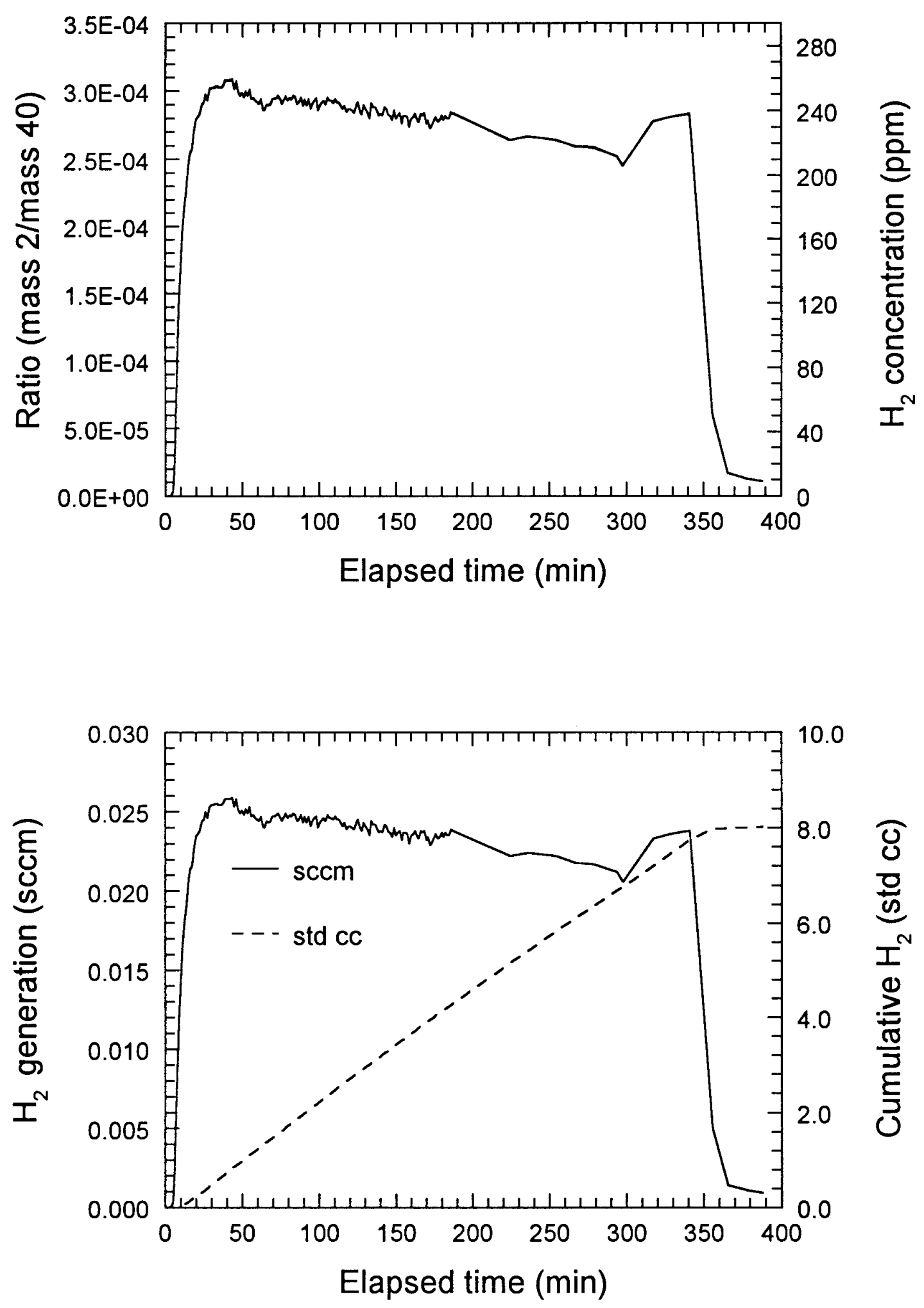

Figure A2. Results of mass-spectrometer analyses for hydrogen generation for tungsten welding rods (Test WR-2) exposed 340 minutes in $600^{\circ} \mathrm{C}$ steam. Top --mass $2 /$ mass 40 ratio (left axis) and $\mathrm{H}_{2}$ concentration (ppm, right axis). Bottom plots $-\mathrm{H}_{2}$ generation rate ( $\mathrm{sccm}$, left axis) and cumulative $\mathrm{H}_{2}$ (std cc, right axis). 

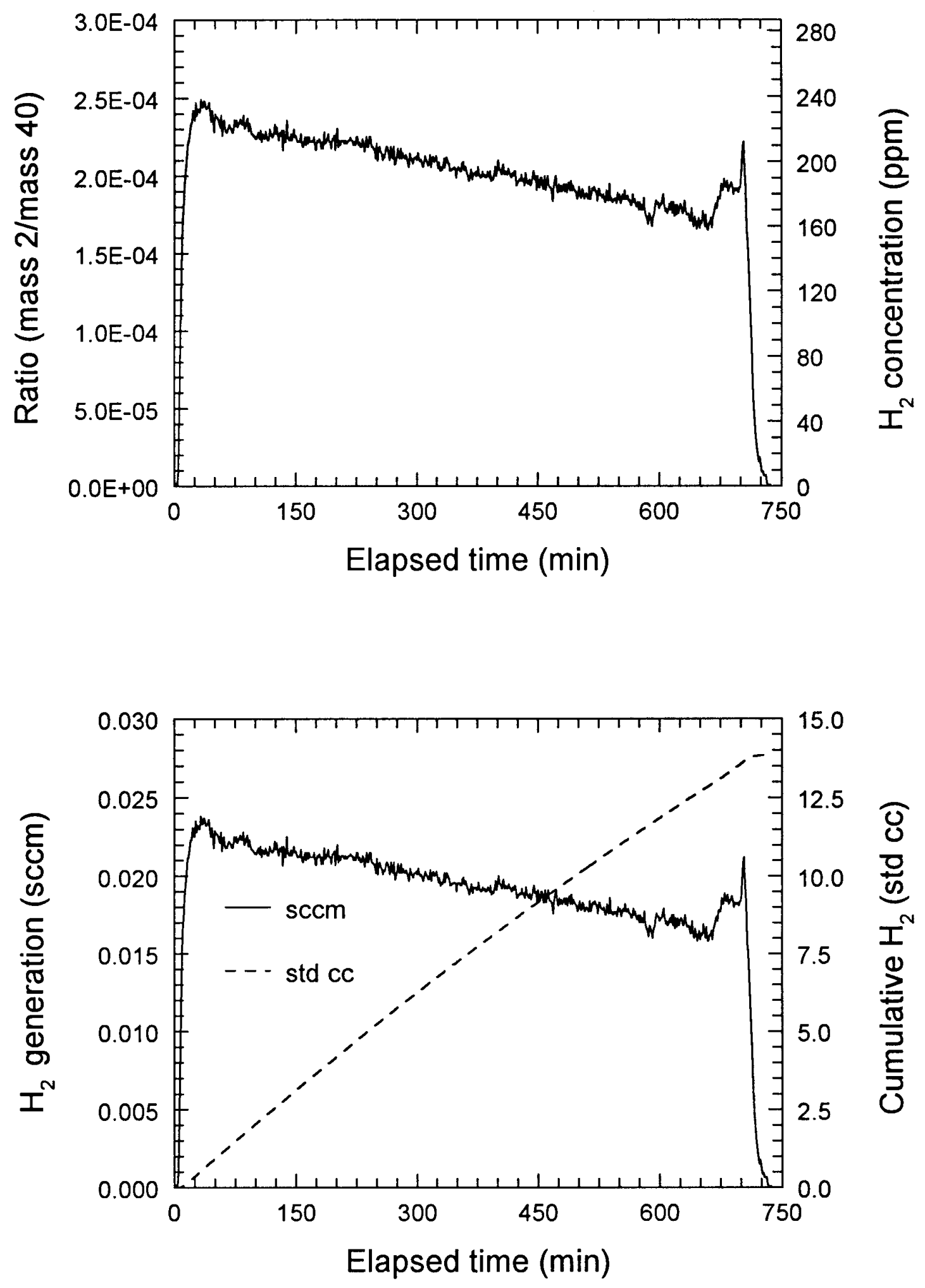

Figure A3. Results of mass-spectrometer analyses for hydrogen generation for tungsten welding rods (Test WR-3) exposed 703 minutes in $600^{\circ} \mathrm{C}$ steam. Top --mass $2 /$ mass 40 ratio (left axis) and $\mathrm{H}_{2}$ concentration (ppm, right axis). Bottom plots $-\mathrm{H}_{2}$ generation rate ( $\mathrm{sccm}$, left axis) and cumulative $\mathrm{H}_{2}$ (std cc, right axis). 

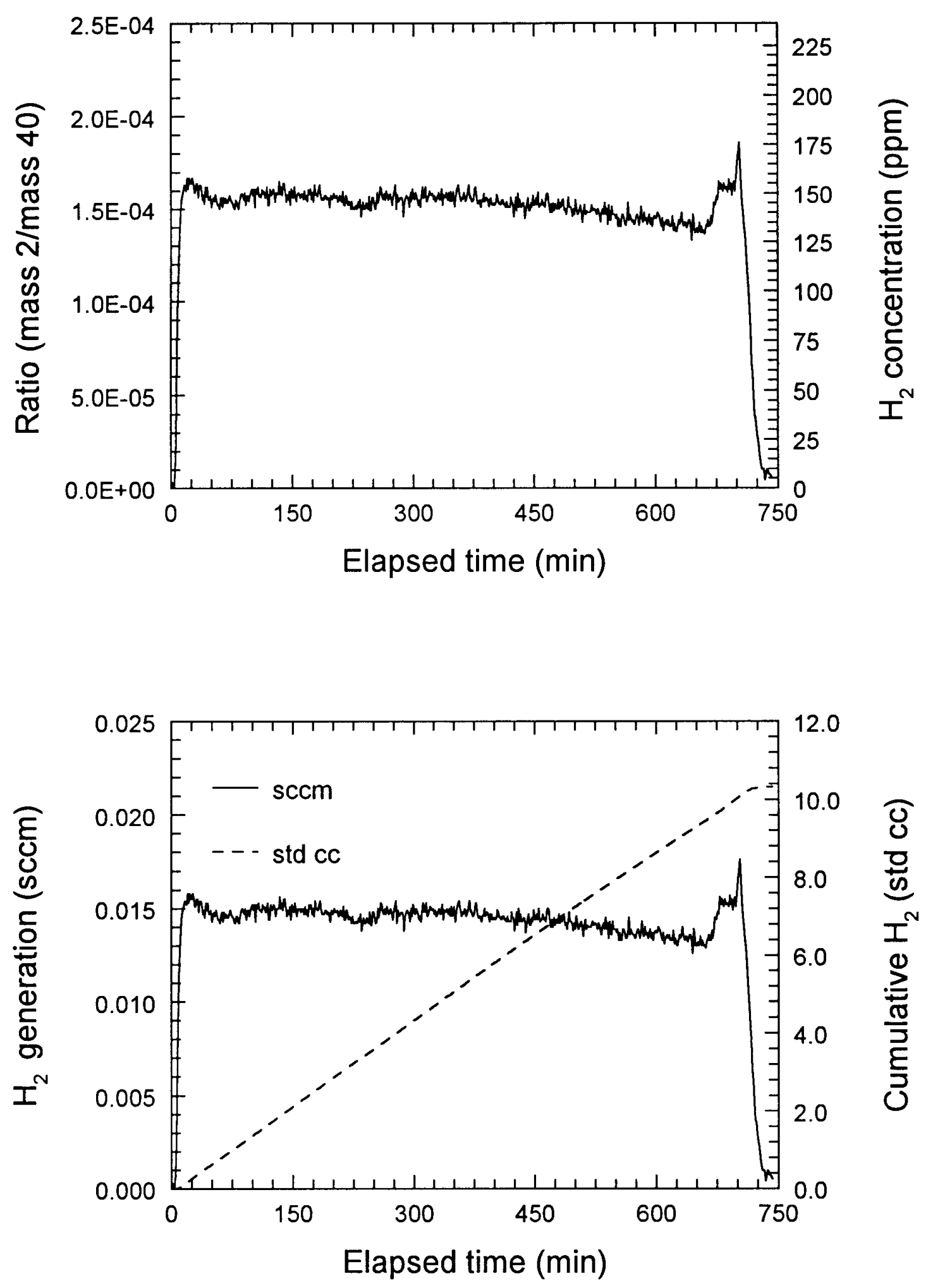

Figure A4. Results of mass-spectrometer analyses of hydrogen generation for tungsten welding rods annealed one hour at $900^{\circ} \mathrm{C}$ then exposed 701 minutes in $600^{\circ} \mathrm{C}$ steam (WR-4). Top --mass $2 /$ mass 40 ratio (left axis) and $\mathrm{H}_{2}$ concentration (ppm, right axis). Bottom plots $-\mathrm{H}_{2}$ generation rate (sccm, left axis) and cumulative $\mathrm{H}_{2}$ (std cc, right axis). 

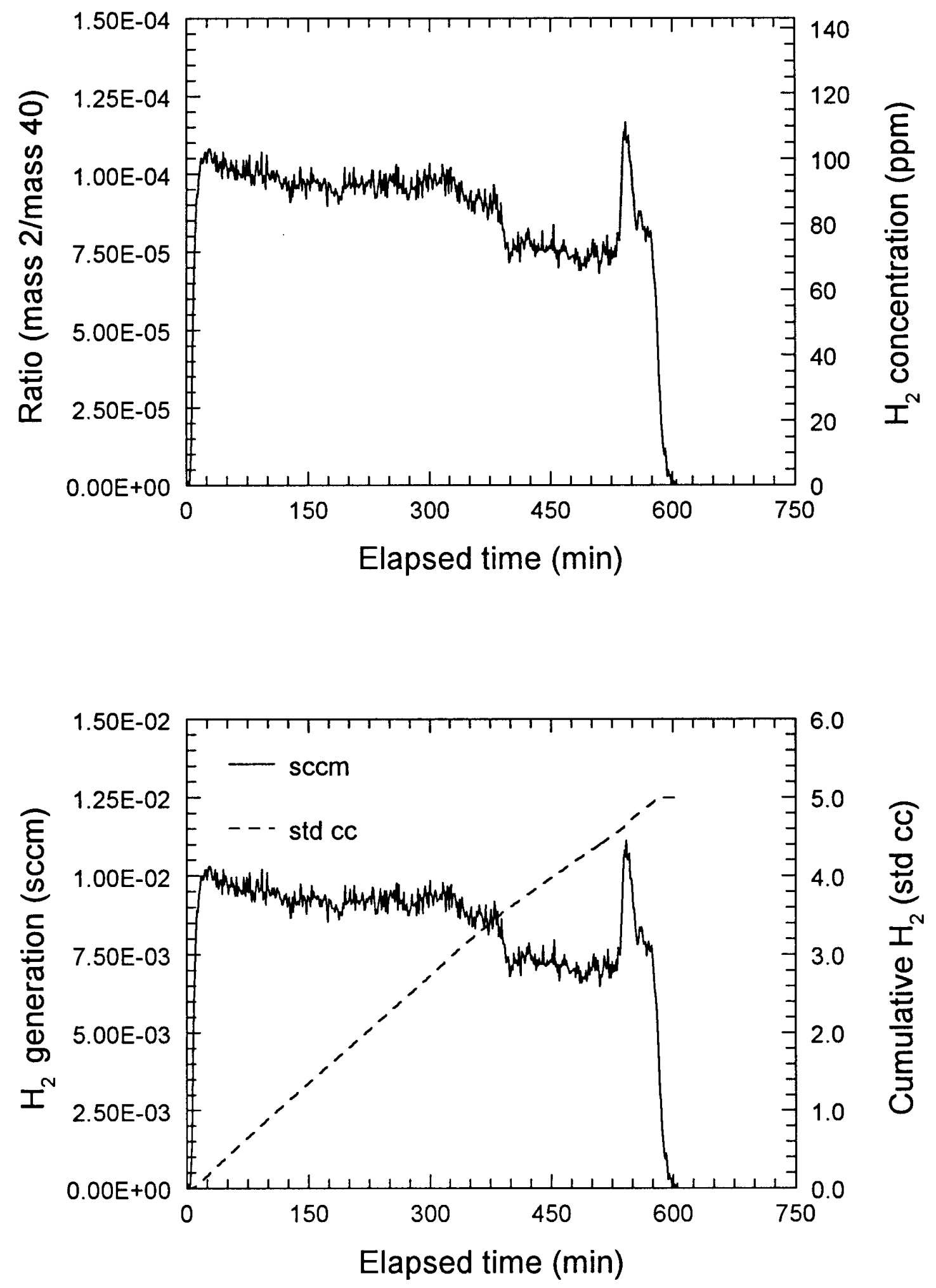

Figure A5. Results of mass-spectrometer analyses of hydrogen generation for tungsten welding rods annealed one hour at $1200^{\circ} \mathrm{C}$ then exposed 575 minutes in $600^{\circ} \mathrm{C}$ steam (WR-5). Top -mass 2 /mass 40 ratio (left axis) and $\mathrm{H}_{2}$ concentration (ppm, right axis). Bottom plots $-\mathrm{H}_{2}$ generation rate (sccm, left axis) and cumulative $\mathrm{H}_{2}$ (std cc, right axis). 

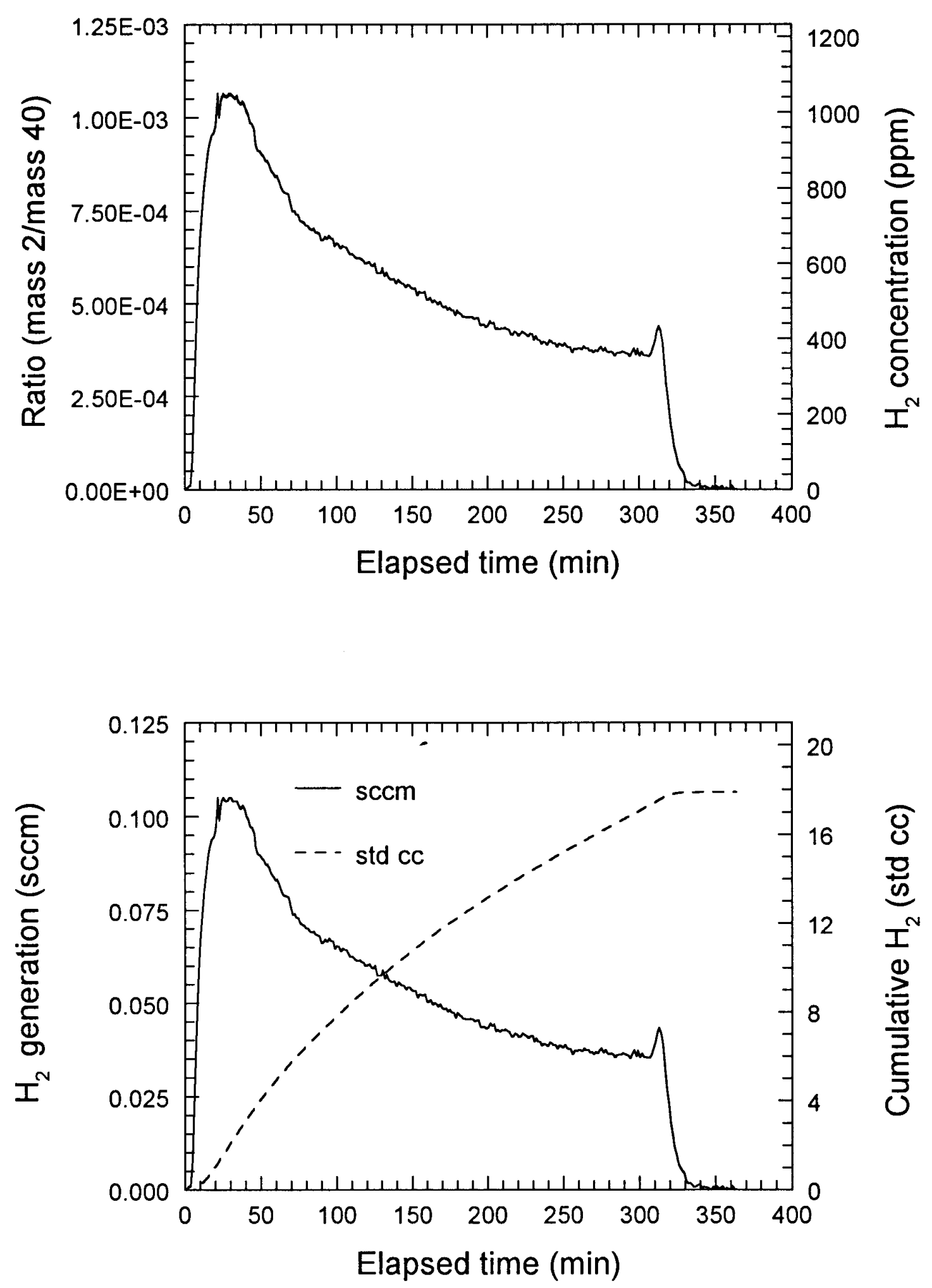

Figure A6. Results of mass-spectrometer analyses for hydrogen generation for tungsten welding rods (Test WR-6) exposed 312 minutes in $700^{\circ} \mathrm{C}$ steam. Top --mass $2 /$ mass 40 ratio (left axis) and $\mathrm{H}_{2}$ concentration (ppm, right axis). Bottom plots $-\mathrm{H}_{2}$ generation rate ( $\mathrm{sccm}$, left axis) and cumulative $\mathrm{H}_{2}$ (std cc, right axis). 

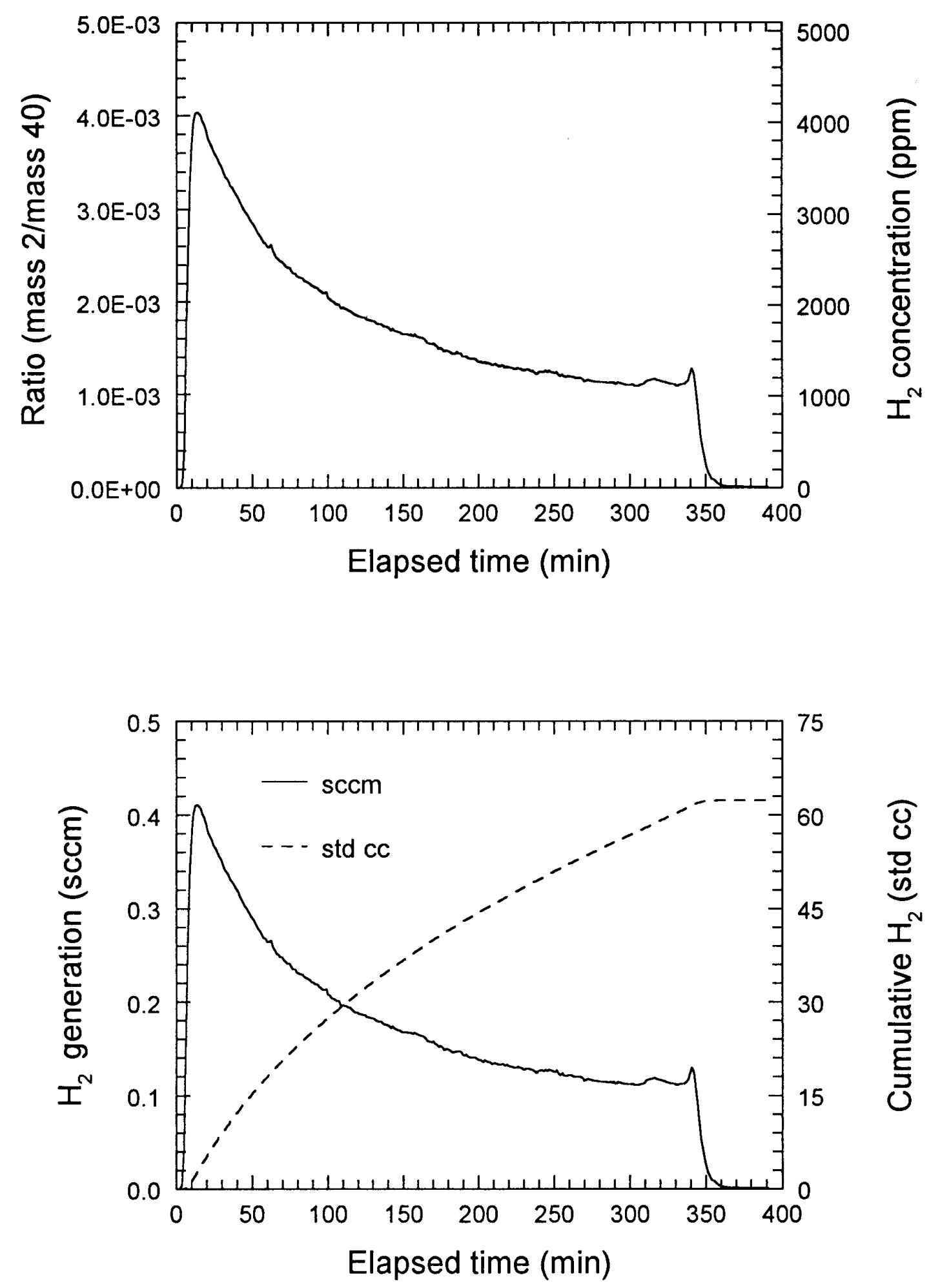

Figure A7. Results of mass-spectrometer analyses for hydrogen generation for tungsten welding rods (Test WR-7) exposed 340 minutes in $800^{\circ} \mathrm{C}$ steam. Top --mass $2 /$ mass 40 ratio (left axis) and $\mathrm{H}_{2}$ concentration (ppm, right axis). Bottom plots $-\mathrm{H}_{2}$ generation rate ( $\mathrm{sccm}$, left axis) and cumulative $\mathrm{H}_{2}$ (std cc, right axis). 

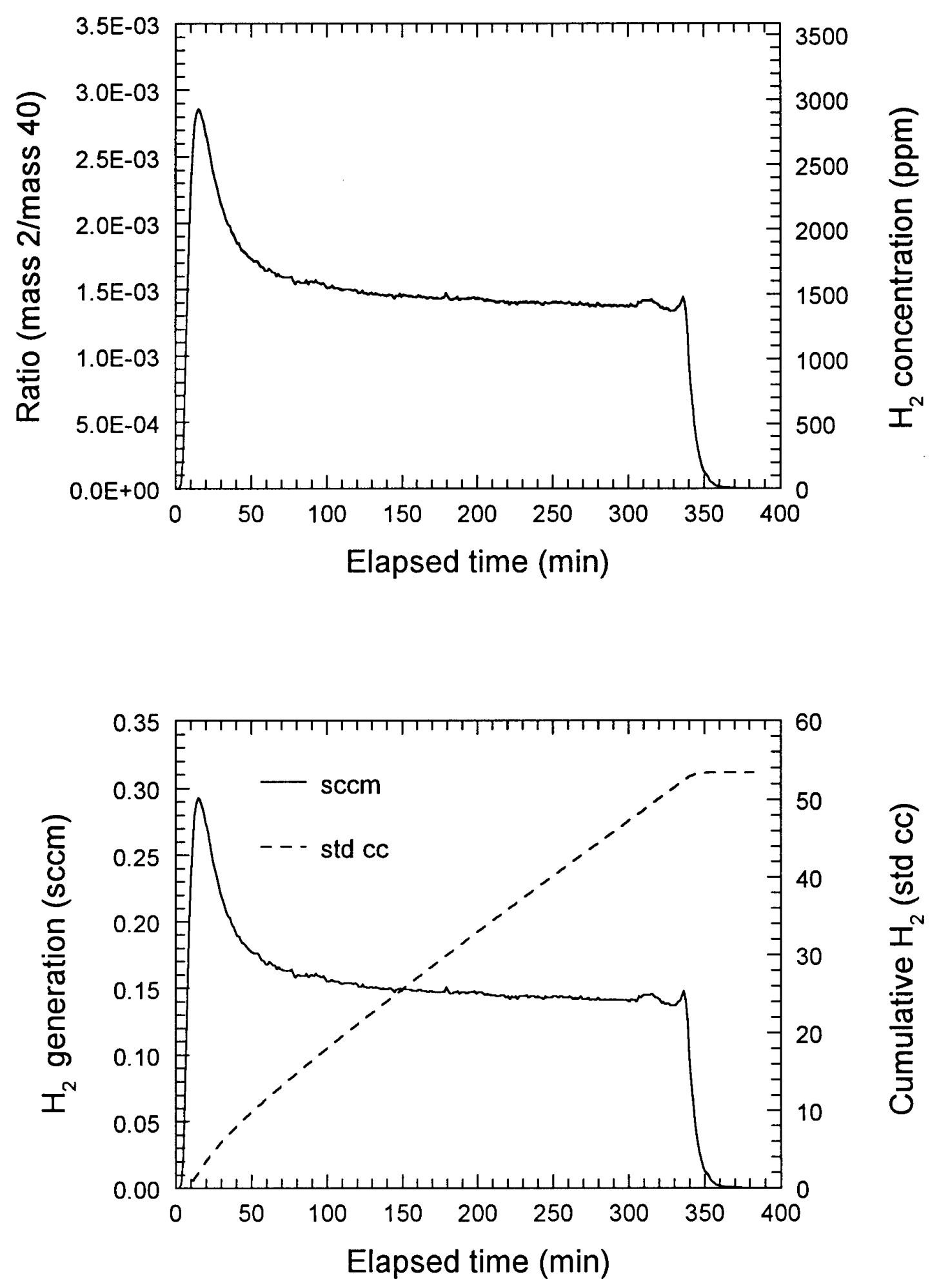

Figure A8. Results of mass-spectrometer analyses for hydrogen generation for tungsten welding rods (Test WR-9) exposed 337 minutes in $900^{\circ} \mathrm{C}$ steam. Top --mass $2 /$ mass 40 ratio (left axis) and $\mathrm{H}_{2}$ concentration (ppm, right axis). Bottom plots $-\mathrm{H}_{2}$ generation rate ( $\mathrm{sccm}$, left axis) and cumulative $\mathrm{H}_{2}$ (std cc, right axis). 

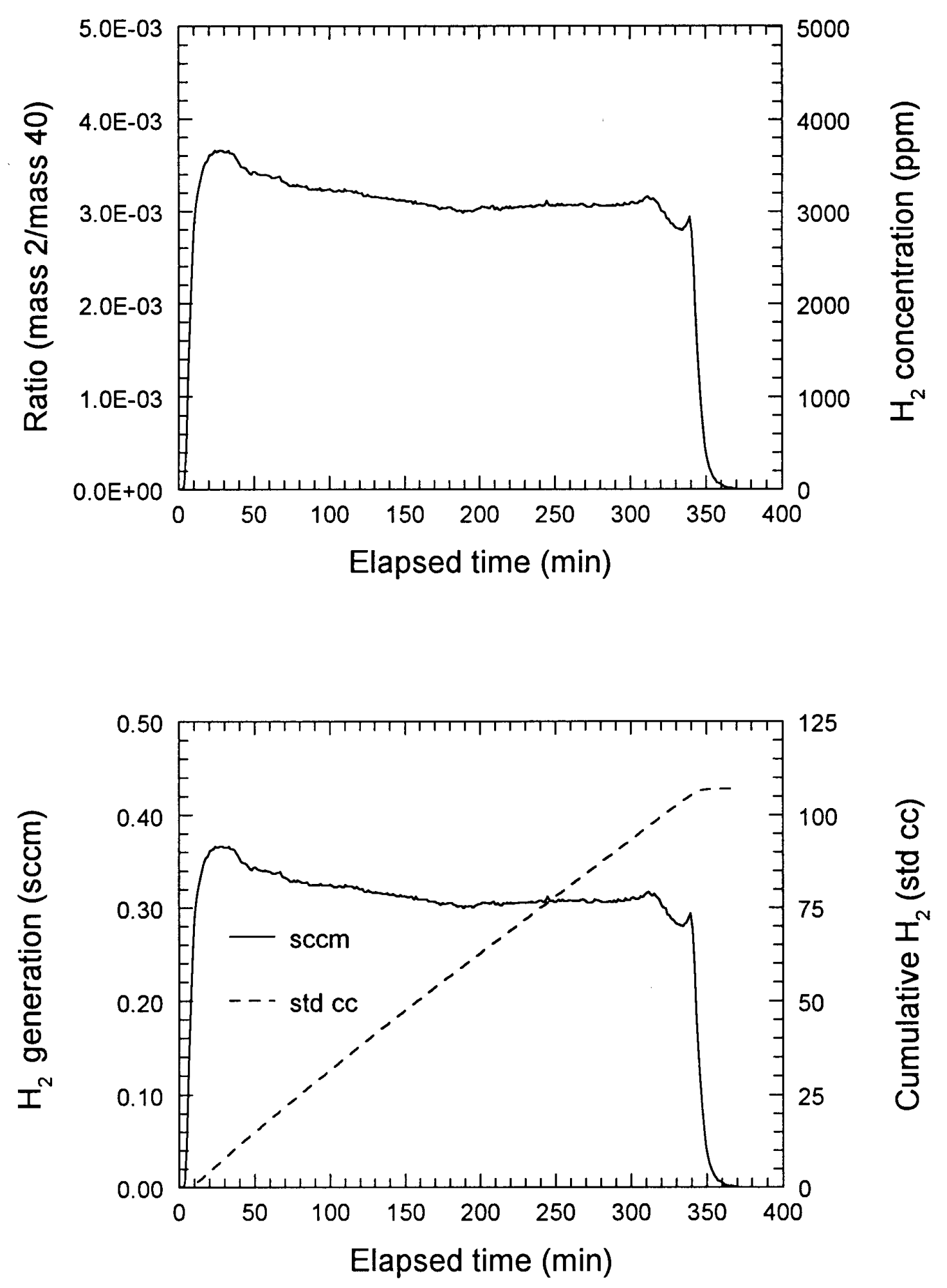

Figure A9. Results of mass-spectrometer analyses for hydrogen generation from tungsten rod (Test WR-9) exposed 340 minutes in $1000^{\circ} \mathrm{C}$ steam. Top --mass $2 /$ mass 40 ratio (left axis) and $\mathrm{H}_{2}$ concentration (ppm, right axis). Bottom plots $-\mathrm{H}_{2}$ generation rate (sccm, left axis) and cumulative $\mathrm{H}_{2}$ (std cc, right axis). 

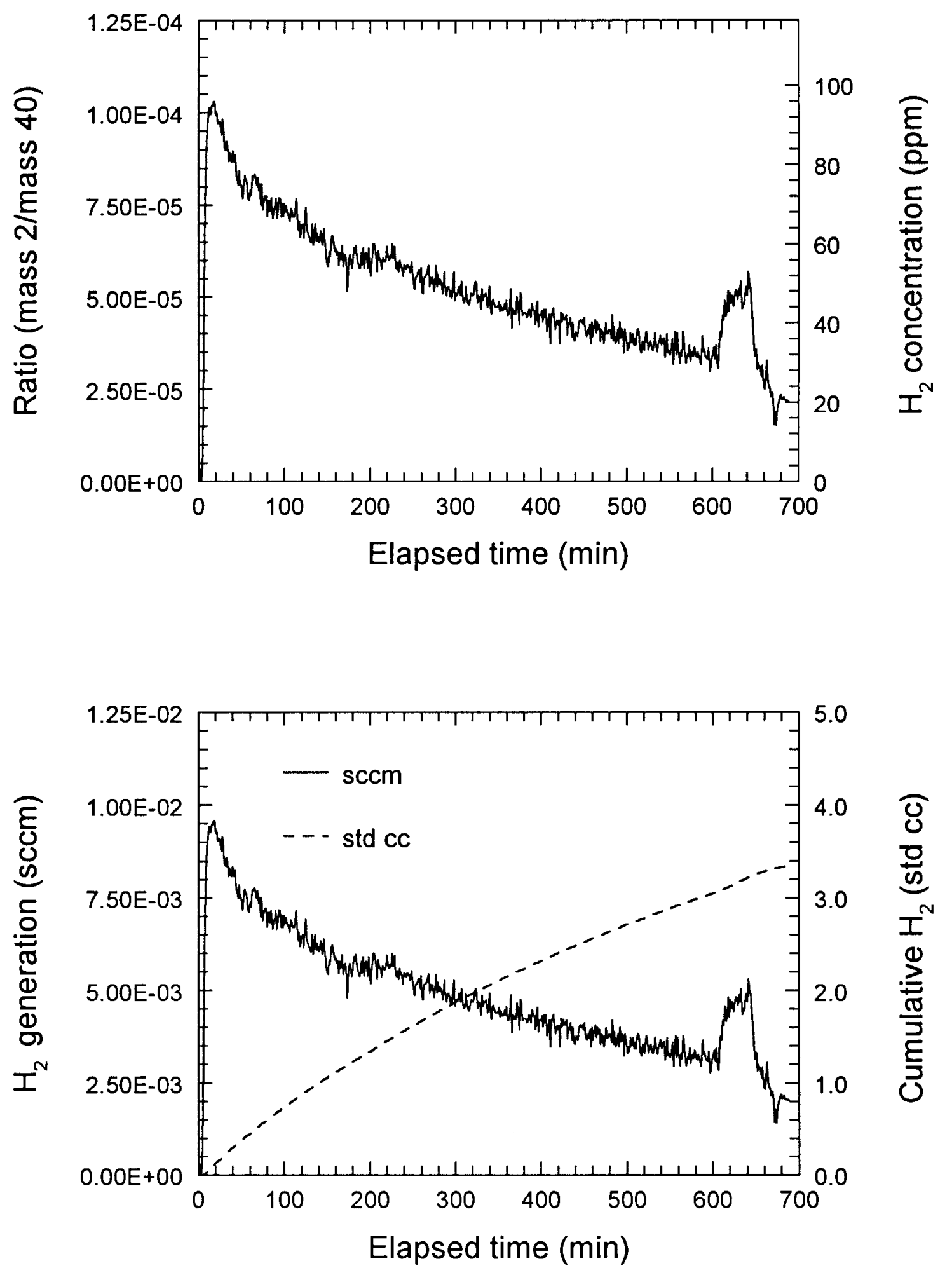

Figure A10. Results of mass-spectrometer analyses for hydrogen generation for tungsten brush specimen (WB-7) exposed 640 minutes in $500^{\circ} \mathrm{C}$ steam. Top --mass $2 /$ mass 40 ratio (left axis) and $\mathrm{H}_{2}$ concentration (ppm, right axis). Bottom plots $-\mathrm{H}_{2}$ generation rate ( $\mathrm{sccm}$, left axis) and cumulative $\mathrm{H}_{2}$ (std cc, right axis). 

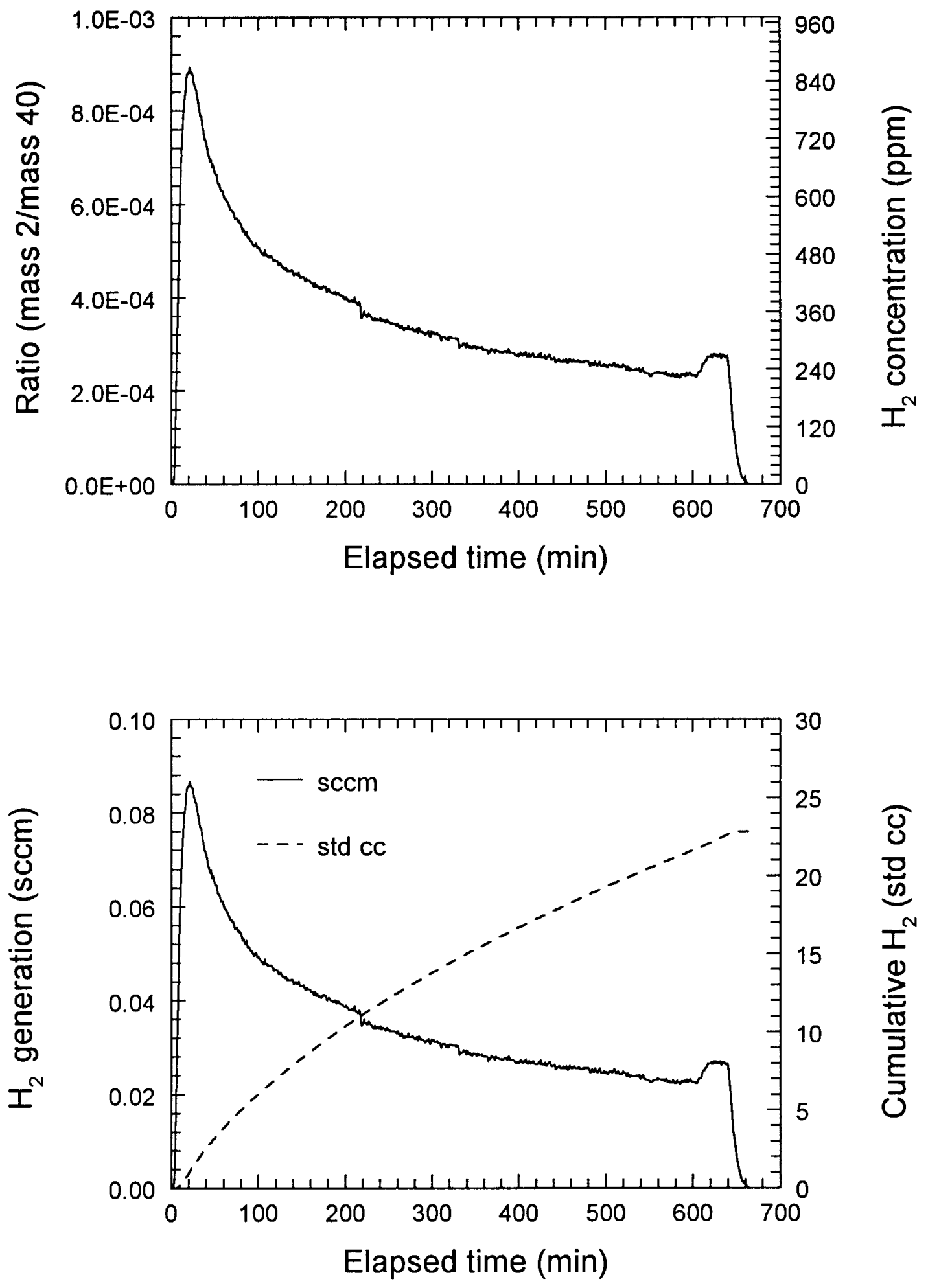

Figure A11. Results of mass-spectrometer analyses of hydrogen generation from tungsten brush specimen (WB-4) exposed 640 minutes in $600^{\circ} \mathrm{C}$ steam. Top plots --mass $2 /$ mass 40 ratio (left axis) and $\mathrm{H}_{2}$ concentration (ppm, right axis). Bottom plots $-\mathrm{H}_{2}$ generation rate (sccm, left axis) and cumulative $\mathrm{H}_{2}$ (std cc, right axis). 

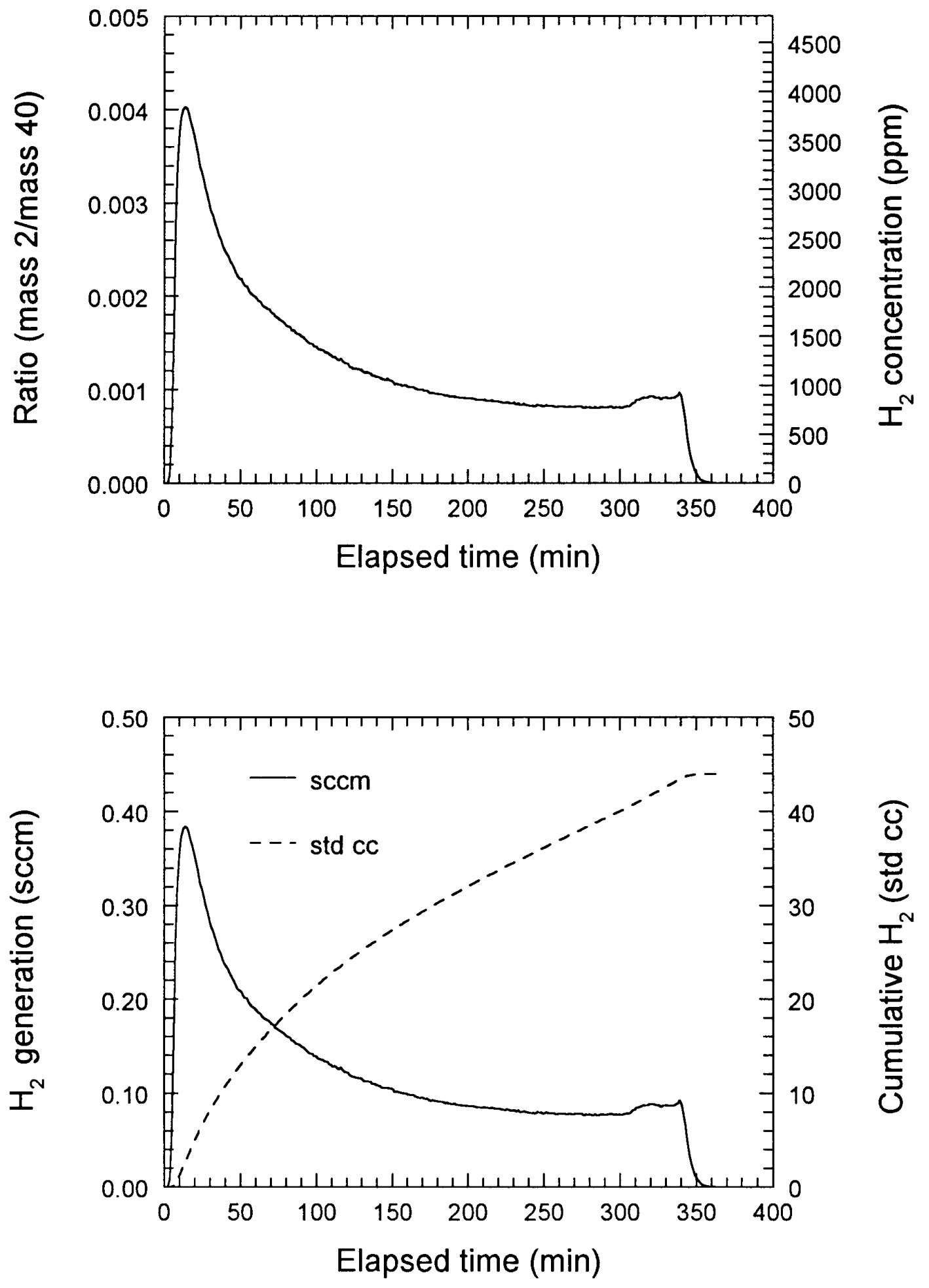

Figure A12. Results of mass-spectrometer analyses of hydrogen generation from tungsten brush specimen (WB-6) exposed 340 minutes in $700^{\circ} \mathrm{C}$ steam. Top plots --mass $2 /$ mass 40 ratio (left axis) and $\mathrm{H}_{2}$ concentration (ppm, right axis). Bottom plots $-\mathrm{H}_{2}$ generation rate (sccm, left axis) and cumulative $\mathrm{H}_{2}$ (std cc, right axis). 

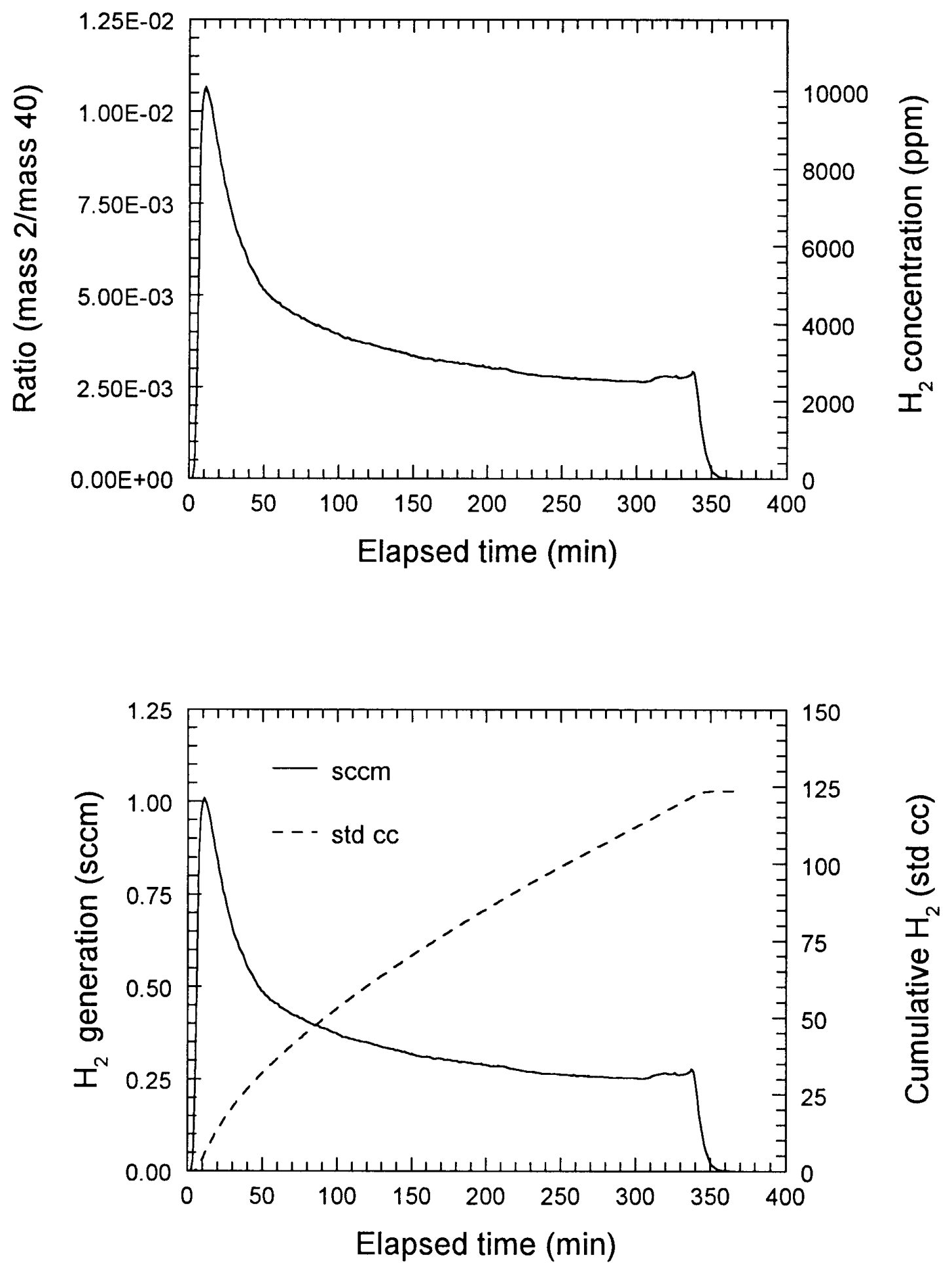

Figure A13. Results of mass-spectrometer analyses of hydrogen generation from tungsten brush specimen (WB-1) exposed 340 minutes in $800^{\circ} \mathrm{C}$ steam. Top plots --mass $2 /$ mass 40 ratio (left axis) and $\mathrm{H}_{2}$ concentration (ppm, right axis). Bottom plots $-\mathrm{H}_{2}$ generation rate (sccm, left axis) and cumulative $\mathrm{H}_{2}$ (std cc, right axis). 

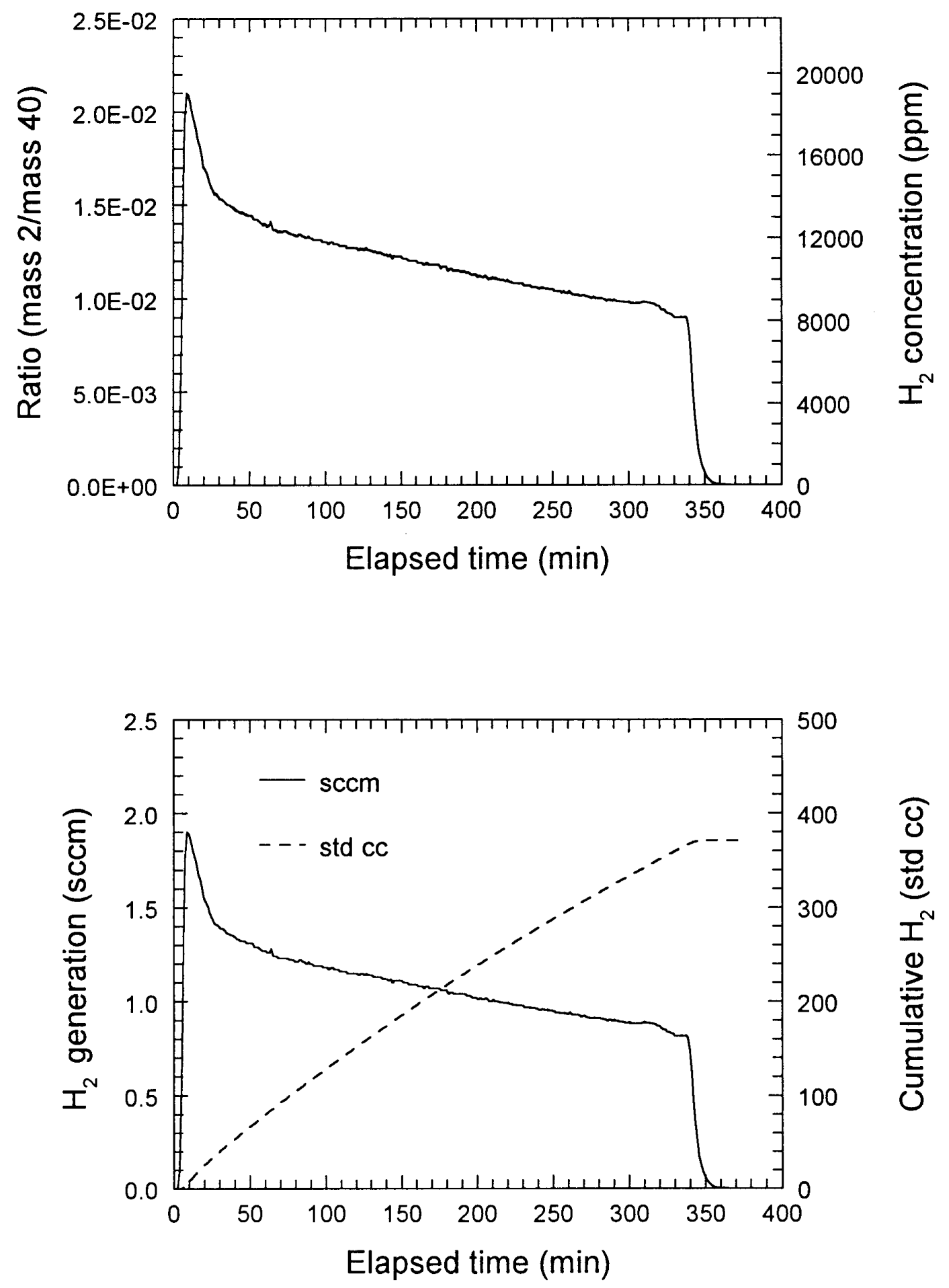

Figure A14. Results of mass-spectrometer analyses of hydrogen generation from tungsten brush specimen (WB-2) exposed 340 minutes in $900^{\circ} \mathrm{C}$ steam. Top plots --mass $2 /$ mass 40 ratio (left axis) and $\mathrm{H}_{2}$ concentration (ppm, right axis). Bottom plots $-\mathrm{H}_{2}$ generation rate (sccm, left axis) and cumulative $\mathrm{H}_{2}$ (std cc, right axis). 

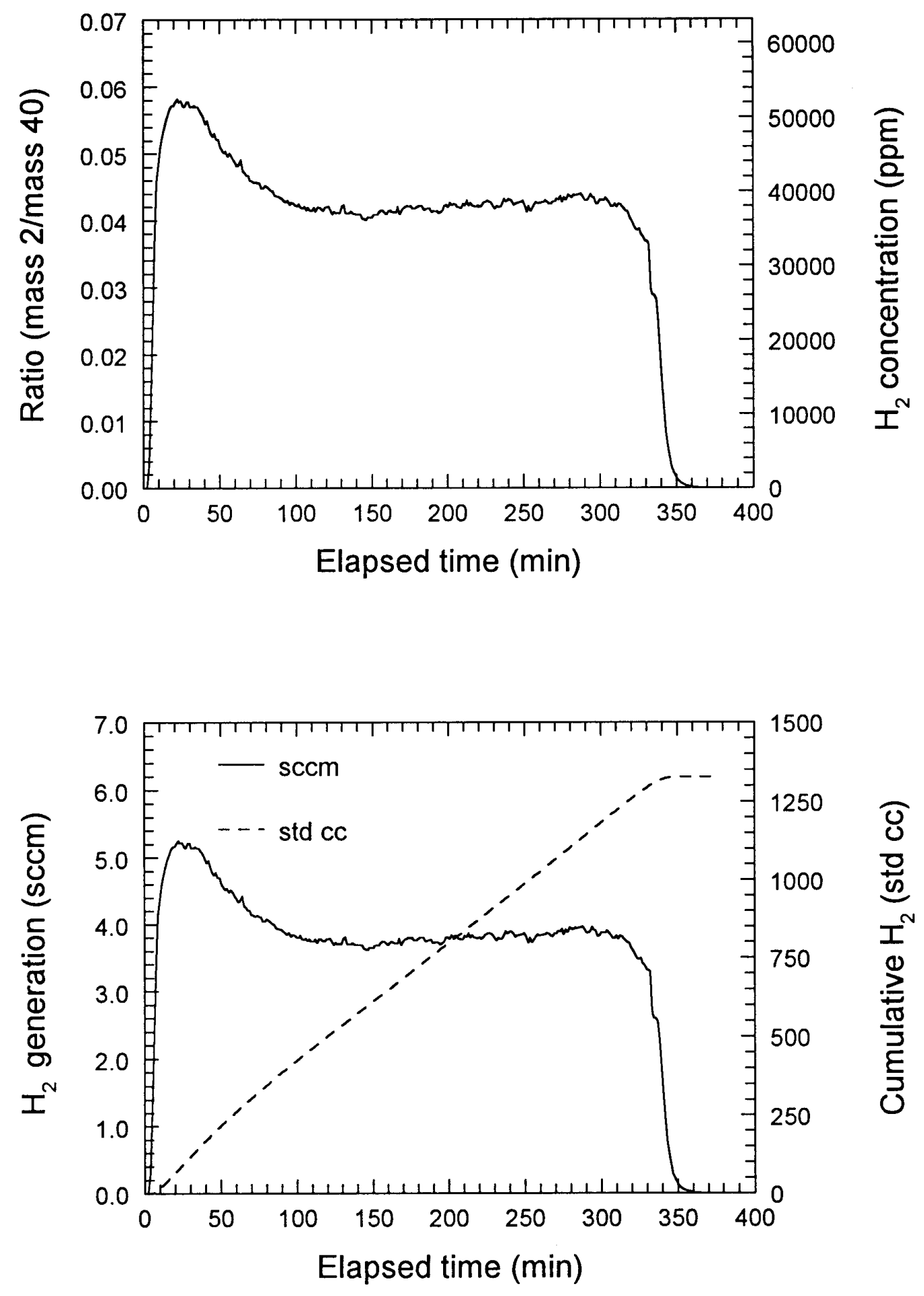

Figure A15. Results of mass-spectrometer analyses of hydrogen generation from tungsten brush specimen (WB-3) exposed 340 minutes in $1000^{\circ} \mathrm{C}$ steam. Top plots --mass $2 /$ mass 40 ratio (left axis) and $\mathrm{H}_{2}$ concentration (ppm, right axis). Bottom plots $-\mathrm{H}_{2}$ generation rate (sccm, left axis) and cumulative $\mathrm{H}_{2}$ (std cc, right axis). 

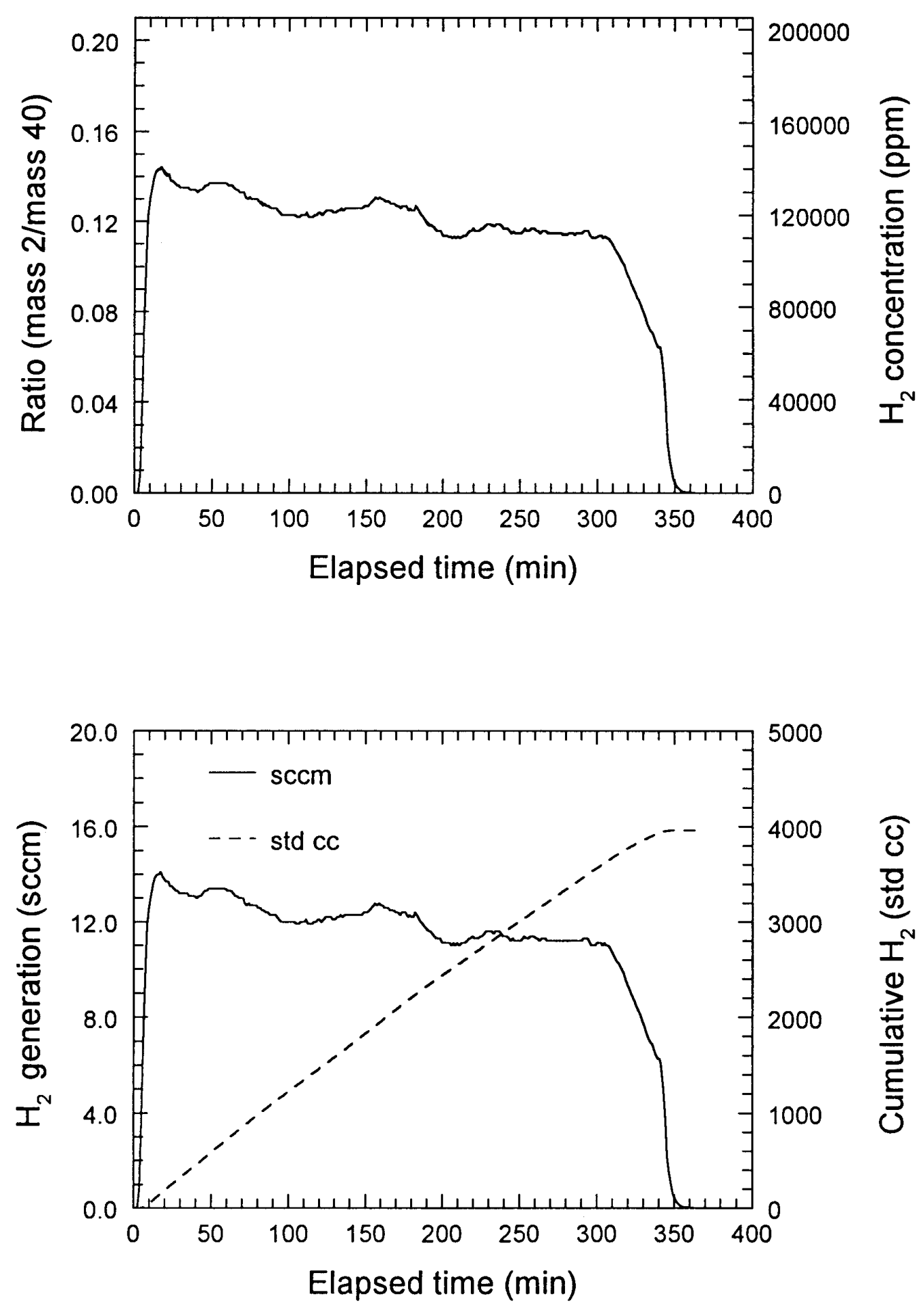

Figure A16. Results of mass-spectrometer analyses of hydrogen generation from tungsten brush specimen (WB-7b) exposed 340 minutes in $1100^{\circ} \mathrm{C}$ steam. Top plots --mass $2 /$ mass 40 ratio (left axis) and $\mathrm{H}_{2}$ concentration (ppm, right axis). Bottom plots $-\mathrm{H}_{2}$ generation rate ( $\mathrm{sccm}$, left axis) and cumulative $\mathrm{H}_{2}$ (std cc, right axis). 

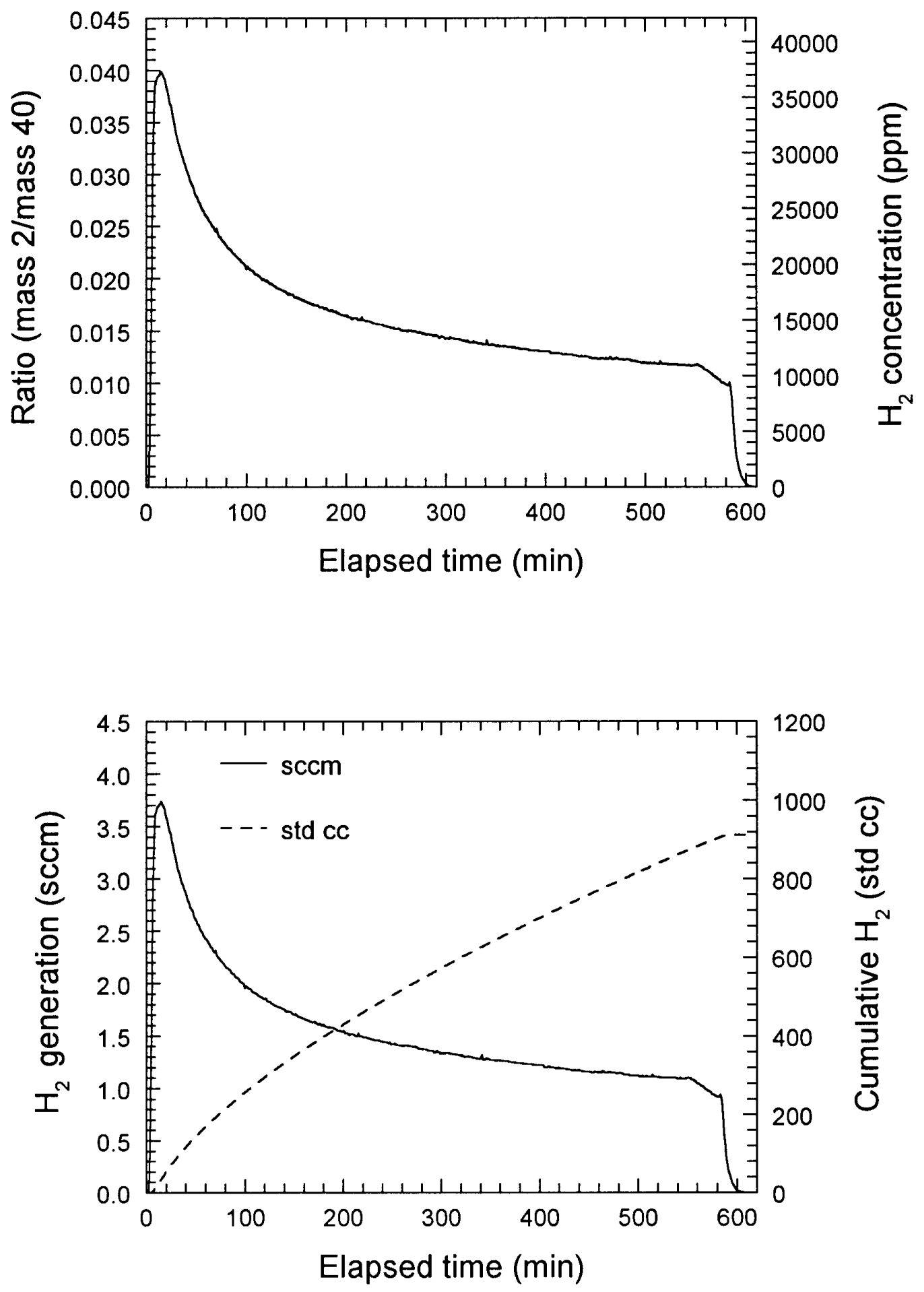

Figure A17. Results of mass-spectrometer analyses of hydrogen generation from the restrained tungsten brush specimen (WB-5) exposed 580 minutes in $1000^{\circ} \mathrm{C}$ steam. Top-mass $2 /$ mass 40 ratio (left axis) and $\mathrm{H}_{2}$ concentration (ppm, right axis). Bottom plots $-\mathrm{H}_{2}$ generation rate (sccm, left axis) and cumulative $\mathrm{H}_{2}$ (std cc, right axis). 

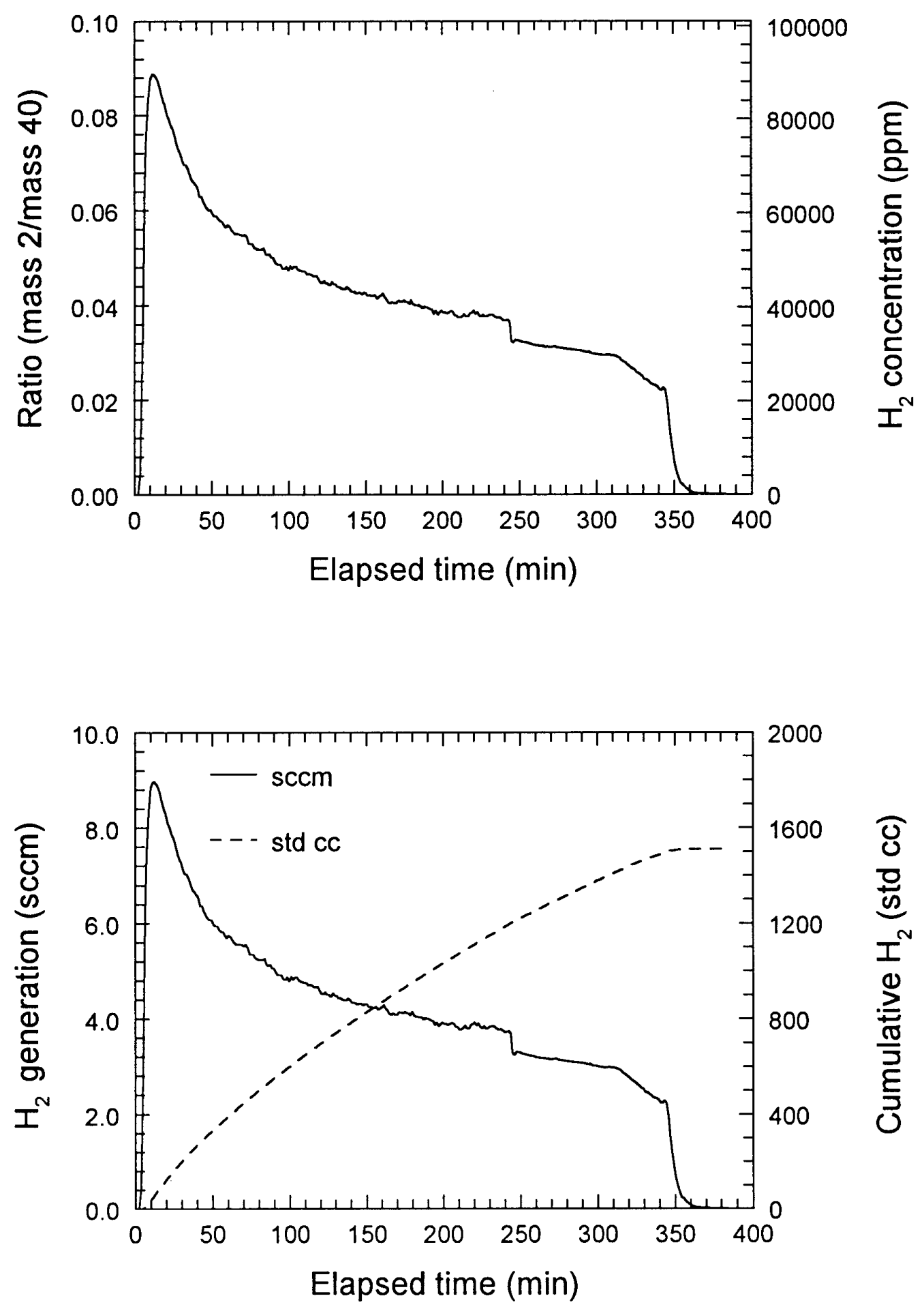

Figure A18. Results of mass-spectrometer analyses of hydrogen generation from tungsten brush specimen (WB-8) exposed 340 minutes in $1100^{\circ} \mathrm{C}$ steam. Top plots -mass $2 /$ mass 40 ratio (left axis) and $\mathrm{H}_{2}$ concentration (ppm, right axis). Bottom plots $-\mathrm{H}_{2}$ generation rate (sccm, left axis) and cumulative $\mathrm{H}_{2}$ (std cc, right axis). 